University of Louisville

ThinkIR: The University of Louisville's Institutional Repository

Electronic Theses and Dissertations

$5-2021$

\title{
Computational frameworks for microRNA functional analysis of inter-kingdom and indirect targeting.
}

\author{
Mohammed Sayed \\ University of Louisville
}

Follow this and additional works at: https://ir.library.louisville.edu/etd

Part of the Computer Engineering Commons

\section{Recommended Citation}

Sayed, Mohammed, "Computational frameworks for microRNA functional analysis of inter-kingdom and indirect targeting." (2021). Electronic Theses and Dissertations. Paper 3612.

https://doi.org/10.18297/etd/3612

This Doctoral Dissertation is brought to you for free and open access by ThinkIR: The University of Louisville's Institutional Repository. It has been accepted for inclusion in Electronic Theses and Dissertations by an authorized administrator of ThinkIR: The University of Louisville's Institutional Repository. This title appears here courtesy of the author, who has retained all other copyrights. For more information, please contact thinkir@louisville.edu. 


\title{
COMPUTATIONAL FRAMEWORKS FOR MicroRNA FUNCTIONAL ANALYSIS OF INTER-KINGDOM AND INDIRECT TARGETING
}

\author{
By \\ Mohammed Sayed \\ B.Sc. Minia University, Egypt, 2009 \\ M.Sc. Alexandria University, Egypt, 2015 \\ A Dissertation \\ Submitted to the Faculty of the \\ J.B. Speed School of Engineering of the University of Louisville \\ in Partial Fulfillment of the Requirements \\ for the Degree of \\ Doctor of Philosophy \\ in Computer Science and Engineering \\ Department of Computer Science and Engineering \\ University of Louisville \\ Louisville, Kentucky
}

May 2021 
C Copyright 2021 by Mohammed Sayed

All rights reserved 

COMPUTATIONAL FRAMEWORKS FOR MicroRNA FUNCTIONAL ANALYSIS OF INTER-KINGDOM AND INDIRECT TARGETING

\author{
By \\ Mohammed Sayed \\ B.Sc. Minia University, Egypt, 2009 \\ M.Sc. Alexandria University, Egypt, 2015
}

A Dissertation Approved on

April 19th, 2021

by the following Committee

Dr. Juw Won Park, Dissertation Chair

Dr. Eric Rouchka

Dr. Olfa Nasraoui

Dr. Nihat Altiparmak

Dr. Huang-Ge Zhang 


\section{DEDICATION}

This dissertation is dedicated to my parents 


\section{ACKNOWLEDGEMENTS}

I would like first to thank my advisor Dr. Park for his guidance, patience, and continuous support throughout my Ph.D. I'd also like to thank him for giving me the opportunity to work on interesting projects and encouraging me to pursue my ideas.

I would also like to thank Dr. Rouchka for his valuable feedback about my work. I learned a lot about the concepts of bioinformatics during his classes. I'd also to thank Dr. Nasraoui, Dr. Zhang, and Dr. Altiparmak for being part of my dissertation committee and taking the time to give me suggestions to make it better.

I would like to thank Dr. Julia Chariker for her continuous support and constructive feedback. I'd like to extend my thanks to current and former lab members Sen Yao, Andrey Smelter, Ernur Saka, Kalpani De Silva, Mohamed Chaabane, Aanchal Malhotra, Aryan Neupane, Dr. Jae Hwang, Jonah Daneshmand, and Tae Lim Kook. 


\title{
ABSTRACT \\ COMPUTATIONAL FRAMEWORKS FOR MicroRNA FUNCTIONAL ANALYSIS OF INTER-KINGDOM AND INDIRECT TARGETING
}

\author{
Mohammed Sayed
}

April 19, 2021

Genes are DNA sequences that encode the information needed to synthesize molecules necessary for the function of the cell. Some genes are called protein-coding genes because they have the code required to manufacture proteins. The expression of a certain gene means its product (protein) is produced. Although some genes are not protein-coding, they regulate the gene expression of other protein-coding genes. Of these, microRNAs (miRNAs) are small RNA molecules that inhibit the expression of other genes by binding to their mRNA transcripts. miRNAs have been shown to be linked to several biological processes like development and diseases like cancer.

Recently, researchers have hypothesized that miRNAs are involved in the regulation of the expression of genes from other species. Although tools to predict miRNA target genes are available in the case when miRNAs and target genes belong to the same species, to our knowledge there are no available tools to predict inter-kingdom miRNA target genes (miRNA and target genes belong to two different kingdoms). To address this limitation, we developed an efficient tool to predict potential gut bacterial 
genes targeted by miRNAs from edible plants. We successfully predicted ginger miRNAs that target two genes from a gut bacterial strain called Lactobacillus rhamnosus $G G$. To maintain the efficiency of our tool while using a larger number of miRNAs and bacterial strains, we used a hash-table to index the sequences of bacterial genes.

To predict the function of a miRNA, we start by compiling the list of direct target genes (ones with binding sites) and then we search for biological process in which these genes are enriched. This approach does not include other genes affected by the miRNA but do not necessarily have a physical binding site (indirect targets). An example of an indirect target is the gene that doesn't have a binding site and is regulated through other direct targets like transcription factors. To overcome this limitation, we developed miRin $G O$ an interactive web application to include these indirect targets in the functional analysis. Our approach showed better performance compared to the existing approach in predicting biological processes known to be targeted by certain miRNAs. 


\section{TABLE OF CONTENTS}

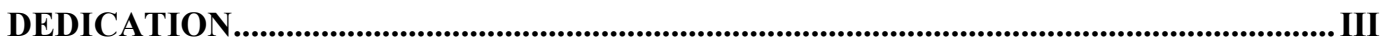

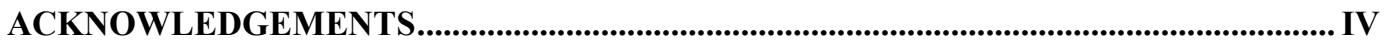

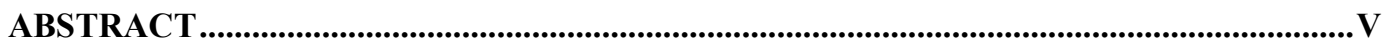

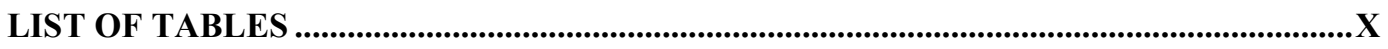

LIST OF FIGURES ............................................................................................................................ XI

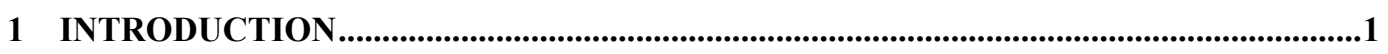

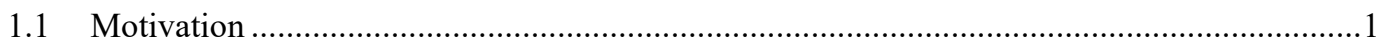

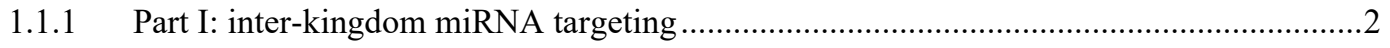

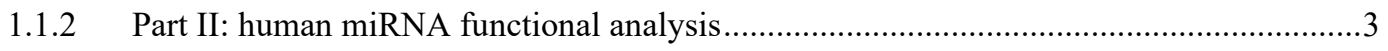

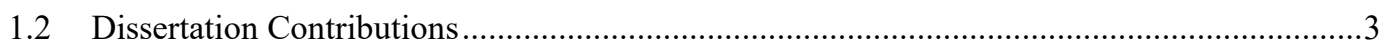

1.2.1 A framework for inter-kingdom miRNA targeting .............................................................

1.2.2 A web application for human miRNA functional analysis ............................................

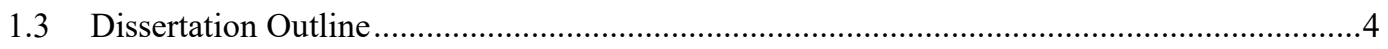

2 BACKGROUND AND LITERATURE REVIEW .............................................................5

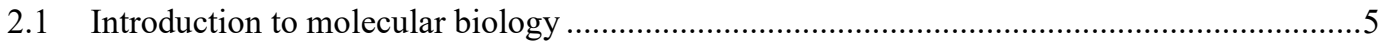

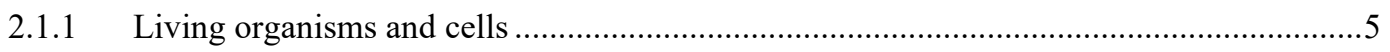

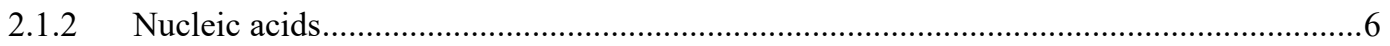

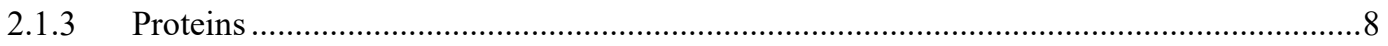

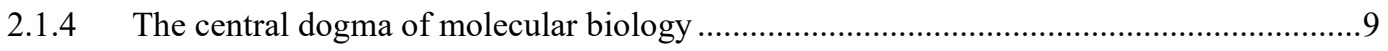

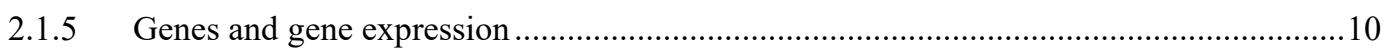

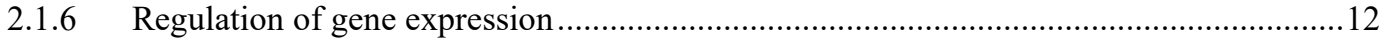




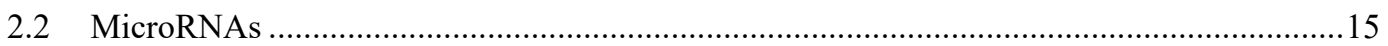

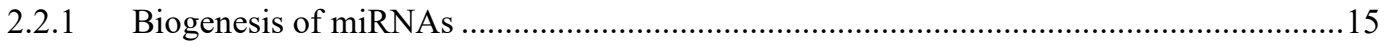

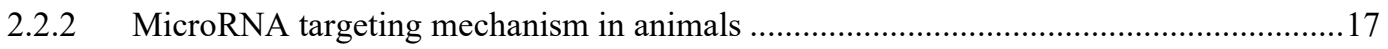

2.2.3 Computational prediction of miRNA targets in animals............................................20

\section{PREDICTION OF POTENTIAL BACTERIAL GENES TARGETED BY PLANT}

\section{MIRNAS 25}

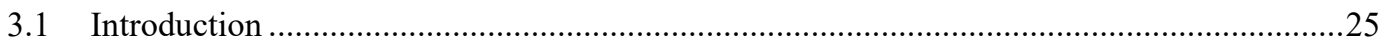

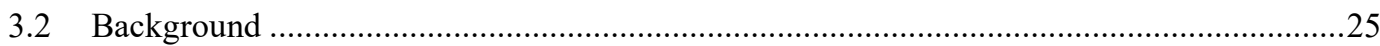

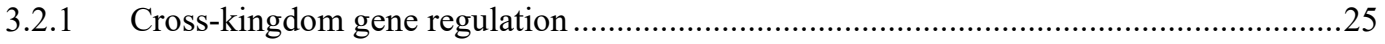

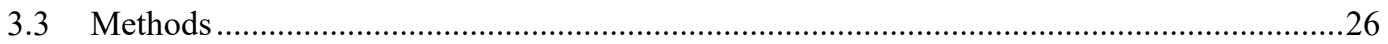

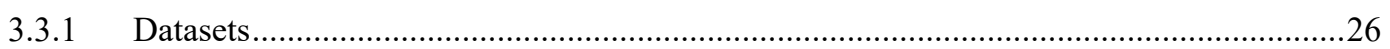

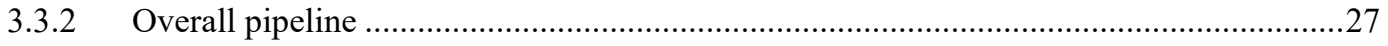

3.3.3 Hash table-based miRNA seed binding site detection ........................................28

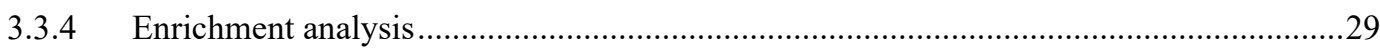

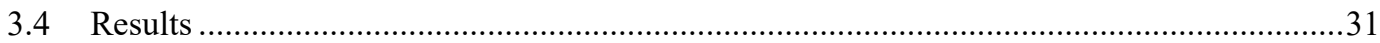

3.4.1 Identification of potential gut bacterial genes targeted by ginger miRNAs ...................31

3.4.2 Case study 1: Ginger miRNA ath-miR167a-5p targets LGG SpaC gene .......................32

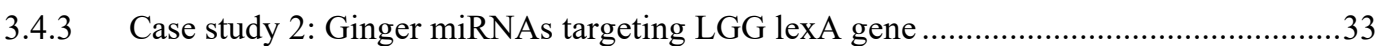

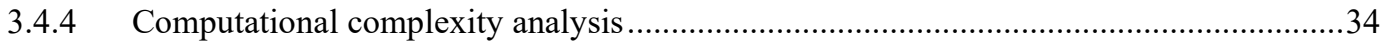

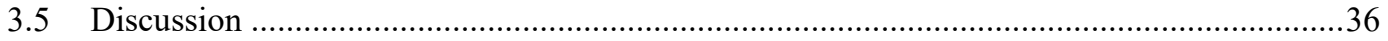

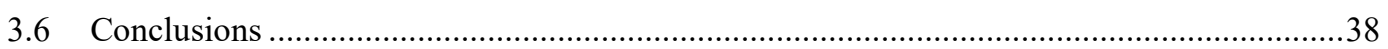

4 PATHWAY ANALYSIS OF MICRORNA TARGETS IN ANIMALS..........................39

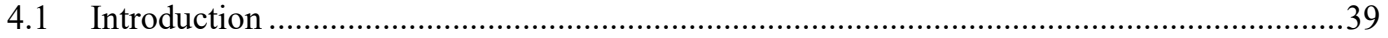

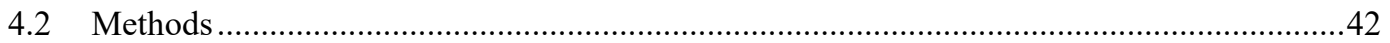

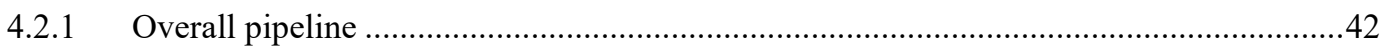

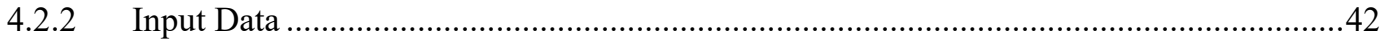

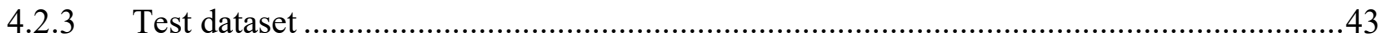

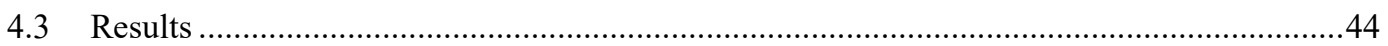

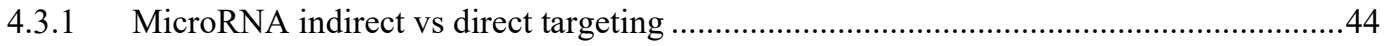




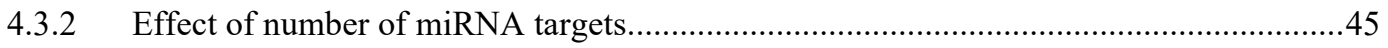

4.3.3 Indirect targeting reveals the role of miRNAs in developmental processes ......................46

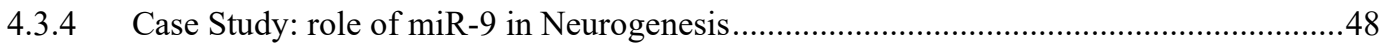

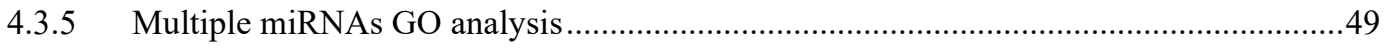

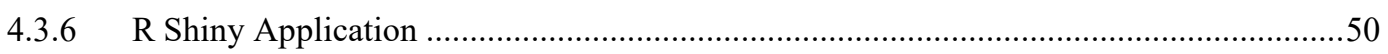

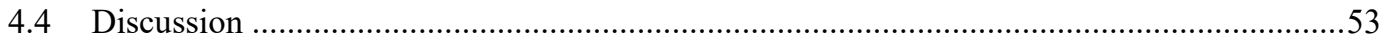

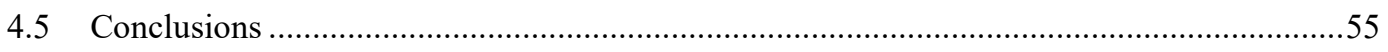

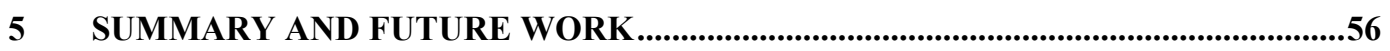

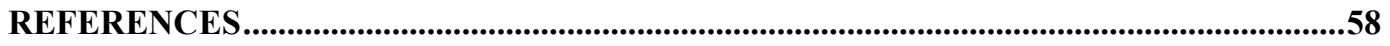

APPENDIX I ................................................................................................................................64

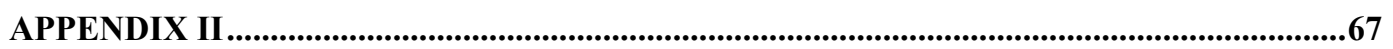

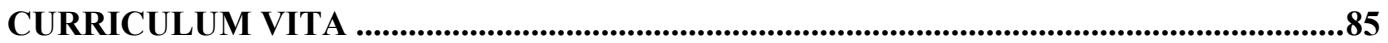




\section{LIST OF TABLES}

Table 3-1: Common gut bacteria and their RefSeq accession numbers ..................................................26

Table 3-2: Target bacterial gene sequences represented as a hash table .....................................................28

Table 3-3: Number of potential genes targeted by ginger miRNAs .......................................................... 31

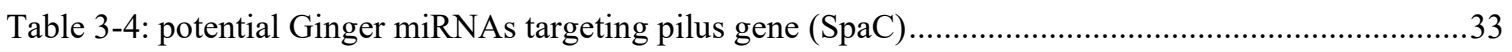

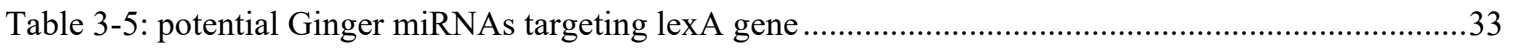

Table 4-1: A comparison of current tools of miRNAs pathway analysis .......................................................41

Table 4-2: Top 5 GO terms with the highest TF density ...................................................................... 46

Table 4-3: Comparison of highest-ranking GO terms related to neurogenesis from different miRNA GO

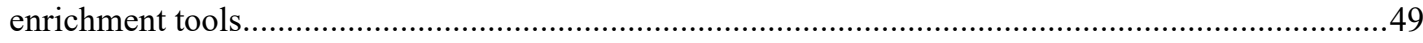

Table 4-4: Effect of using multiple miRNAs in capturing EMT-related GO terms ....................................50

Table 4-5: A description of different parameters of the Shiny application ................................................51 


\section{LIST OF FIGURES}

Figure 2-1: Eukaryotic and prokaryotic cells [11] .............................................................................

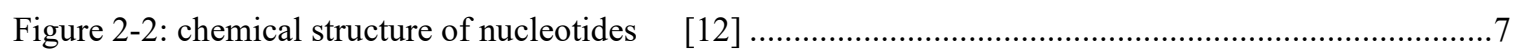

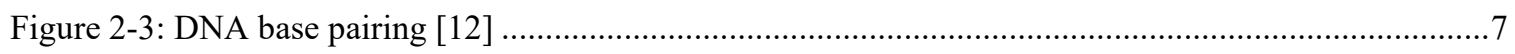

Figure 2-4: Example functions of membrane proteins [10]...............................................................

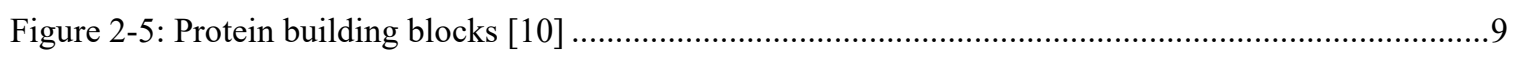

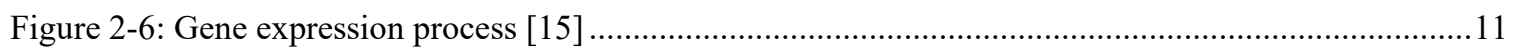

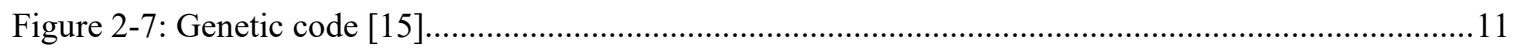

Figure 2-8: Epigenetic mechanisms for gene regulation [18]...........................................................13

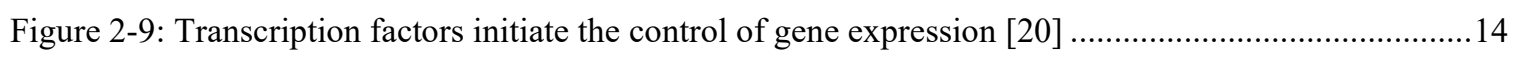

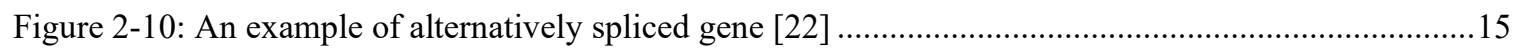

Figure 2-11: Different pathways of animal miRNA biogenesis [27] .......................................................17

Figure 3-1: Overall pipeline to detect potential bacterial genes targeted by plant miRNAs ........................27

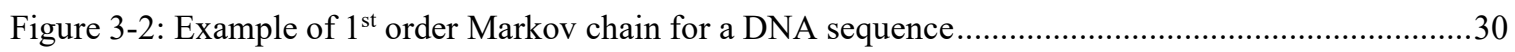

Figure 3-3: Average running time with different number of bacterial genomes and Markov chain model

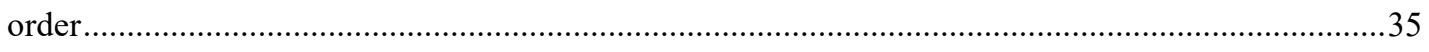

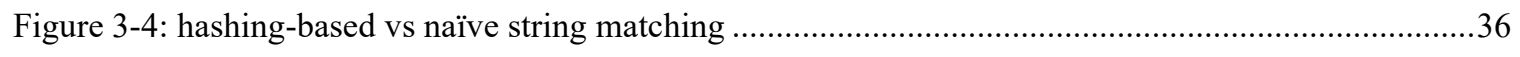

Figure 4-1: miRNAs can indirectly target biological pathways through transcriptions factors.....................40

Figure 4-2: Pipeline of our miRNA GO enrichment analysis tool .........................................................42

Figure 4-3: Comparison of indirect targeting with direct targeting $\left({ }^{* *}\right.$ represents $p$-value $\left.<0.01\right) \ldots \ldots \ldots \ldots \ldots . .45$

Figure 4-4: Effect of number of miRNA targets on miRNA GO enrichment analysis. Error bars represent

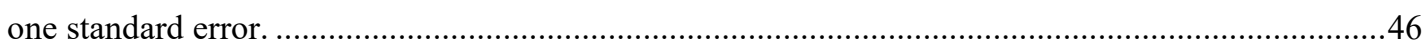

Figure 4-5: Comparison of TF density in development-related GO terms vs. all other terms......................48

Figure 4-6: A screenshot of the R Shiny application (miRinGO) ……........................................................50

Figure 4-7: Bar plot of top 15 GO terms indirectly targeted by miR-9-5p in brain.....................................52 
Figure 4-8: WordCloud of top 30 enriched GO terms predicted to be indirectly targeted by miR-16 in the

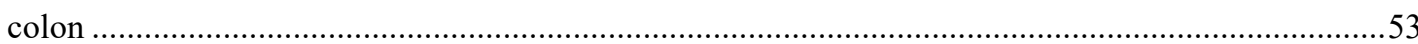




\section{INTRODUCTION}

MicroRNAs (miRNAs) are small non-coding RNA sequences (21-24 nucleotides long) that have a prominent role in gene regulation. MiRNAs mainly act posttranscriptionally by binding to mRNA transcripts and either inhibit translation (protein synthesis) or initiate the degradation of the target transcript. Computational tools have been introduced to predict potential target genes and biological processes affected by a specific miRNA or a set of miRNAs. Despite extensive work in miRNA research, the full spectrum of the role of miRNAs in gene regulation is still to be revealed.

\subsection{Motivation}

Typically, to predict the function of a miRNA, computational tools follow a twostep process. The first step is to identify the list of potential target genes and then they identify biological processes that are enriched in these target genes. Although many tools are developed to do each of the two steps, they have some limitations. For instance, miRNA target prediction tools are species-specific (i.e. they are used to predict target genes when miRNAs and targets belong to the same species e.g. human). Also, current tools include only target genes with physical binding sites (direct targets) in the enrichment step. 
In this dissertation, we discuss the need for computational tools to address interkingdom miRNA targeting (part I). We also discuss the motivation to develop new tools for miRNA functional analysis (Part II).

\subsubsection{Part I: inter-kingdom miRNA targeting}

The overall goal of this project is to determine how edible plants (e.g. ginger and broccoli) affect our gut bacteria and ultimately our health. Gut bacteria play an important role in human health. For example, help digest hard-to-digest dietary fibers, defend the host against harmful microorganisms, and synthesize essential vitamins and amino acids. The imbalance of gut bacteria can lead to multiple diseases including inflammatory bowel diseases (IBD), obesity, liver disease, and cancer.

Studies have shown that food including edible plants can affect the balance of gut bacteria. Edible plant cells use secreted nanoparticles called exosomes to communicate with other cells and tissues [1]. The cargo of exosomes includes different types of molecules: proteins, DNAs, mRNAs, and miRNAs. Researchers hypothesize that exosomes from edible plants may interact with gut bacteria.

MiRNAs play a role in the regulation of target gene expression even across kingdoms [2]. In our case, we are dealing with two different kingdoms (plants and bacteria), and each has its miRNA targeting mechanism. In animals, a limited number of base-pairings ( $\sim 7 \mathrm{bp})$ is sufficient for miRNA targeting. On the other hand, in plants perfect (or near-perfect) base pairing between miRNA and mRNA sequences is required. Although miRNAs have been shown to target gut bacteria [3], the actual mechanism is still unknown. For the above reasons, new computational tools are needed to identify cross-kingdom miRNA targets. 


\subsubsection{Part II: human miRNA functional analysis}

To computationally predict miRNA-targeted biological processes, typically potential target genes are compiled using one or more miRNA target prediction tools and a standard gene enrichment analysis [4] is used to find potential biological processes enriched in these genes. Although current tools are widely used, they have some limitations. Of these, existing tools consider only direct targets (ones with physical binding sites) of miRNAs but do not consider other targets that do not necessarily have miRNA binding sites [5].

\subsection{Dissertation Contributions}

To address the aforementioned limitations, we developed the following computational frameworks.

\subsubsection{A framework for inter-kingdom miRNA targeting}

Given the importance of the miRNA seed region in targeting mechanisms in different kingdoms, animals, plants, and viruses, we developed a seed-based miRNA targeting framework to find potential gut bacterial genes targeted by edible plant miRNAs. In this framework, first gut bacterial genes were searched for potential plant miRNA binding sites. Then, we employed a technique proposed by Murphy et al. [6], initially to predict targets of viral miRNAs, to identify target genes with enriched binding sites. We showed that using our tool we can identify ginger miRNAs that target genes from Lactobacillus rhamnosus GG(LGG) bacteria. To validate our results, two miRNAs have been experimentally validated to downregulate and bind to two LGG genes. 


\subsubsection{A web application for human miRNA functional analysis}

We developed, $\operatorname{miRin} G O$, an interactive R Shiny application [7] to predict potential biological processes both directly and indirectly targeted by human miRNAs. In addition to a list of top-ranked biological processes, the web application gives the user a visual summary of the results. It is freely available from GitHub at https://github.com/Fadeel/miRinGO

\subsection{Dissertation Outline}

The remainder of this dissertation is organized as follows. Chapter 2 provides an introduction to molecular biology and miRNA targeting techniques. Chapter 3 introduces a proposed method to predict potential gut bacterial genes targeted by edible plant miRNAs. Chapter 4 introduces the proposed framework to find biological processes indirectly targeted by miRNAs in humans. Chapter 5 provides conclusions and potential future work. 


\section{BACKGROUND AND LITERATURE REVIEW}

\subsection{Introduction to molecular biology}

\subsubsection{Living organisms and cells}

It is estimated that there are more than 10 million different living species on Earth [8]. The building block of these organisms is the cell. Although the cell size can vary from $1 \mu \mathrm{m}$ (bacteria) to $100 \mu \mathrm{m}$ (plants), all cells share mainly two characteristics [9]. First, the ability to take up nutrients from the environment and converting them to other molecules and energy. Second, the ability to make many copies of themselves and passing genetic material to their offspring.

Some organisms are composed of single cells like bacteria but other species like humans can have up to $10^{13}$ cells. Cells can be categorized into two types: prokaryotic and eukaryotic. Prokaryotic cells do not have a nucleus and on the other hand, eukaryotic cells have a nucleus where it contains the cell's DNA. Prokaryotes include bacteria and archaea. Animals, plants, and fungi are examples of eukaryotes.

Cells are surrounded by fat-based molecules (phospholipids) forming what is called the cell membrane (or plasma membrane) [10]. Inside the cell membrane, cellular machinery and other structural units exist within a water-based environment called cytoplasm. Cells contain a variety of molecules including nucleic acid, proteins, carbohydrates, and lipids. Nucleic acids and proteins will be discussed in more detail below. 


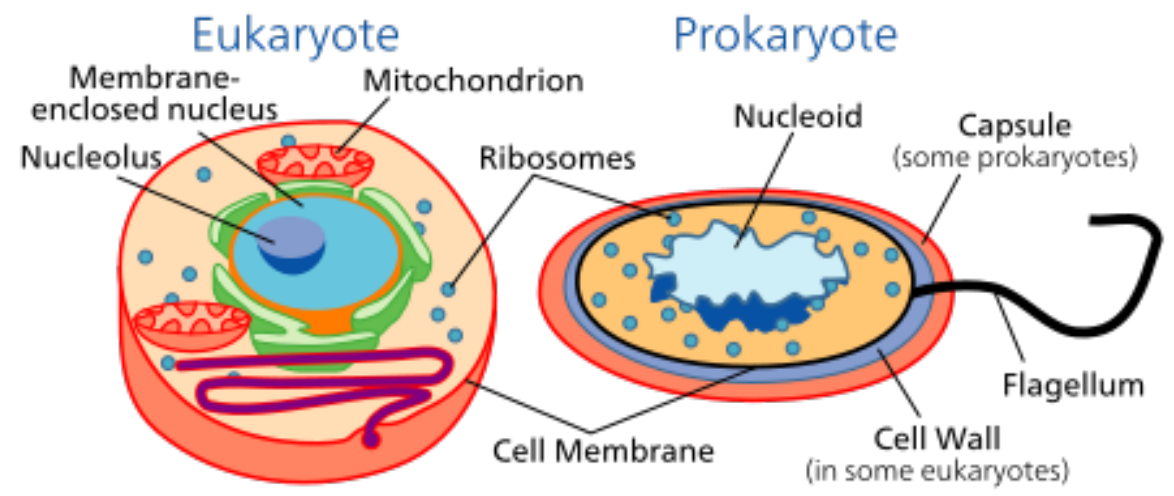

Figure 2-1: Eukaryotic and prokaryotic cells [11]

\subsubsection{Nucleic acids}

Nucleic acids are the molecules that contain genetic information. There are two types of nucleic acids: deoxyribonucleic acid (DNA) and ribonucleic acid (RNA).

\subsubsection{DNA}

DNA consists of a sequence of smaller molecules called nucleotides [10]. Each nucleotide contains three molecules: a nitrogenous base, a sugar molecule, and a phosphate group. There are four different DNA nucleotides based on the nitrogenous base: adenine (A), thymine (T), cytosine (C), and guanine (G) as shown in Figure 2-2.

Although DNA can be found as single-strand polynucleotides, it is more stable when two strands come together and bases from one strand are bound (paired) to the complementary bases for the other strand via hydrogen bonds as shown in Figure 2-3. Each "A" from one strand always pairs with a " $T$ " from the other strand and each " $G$ " from one strand pairs with a "C" from the other strand. 


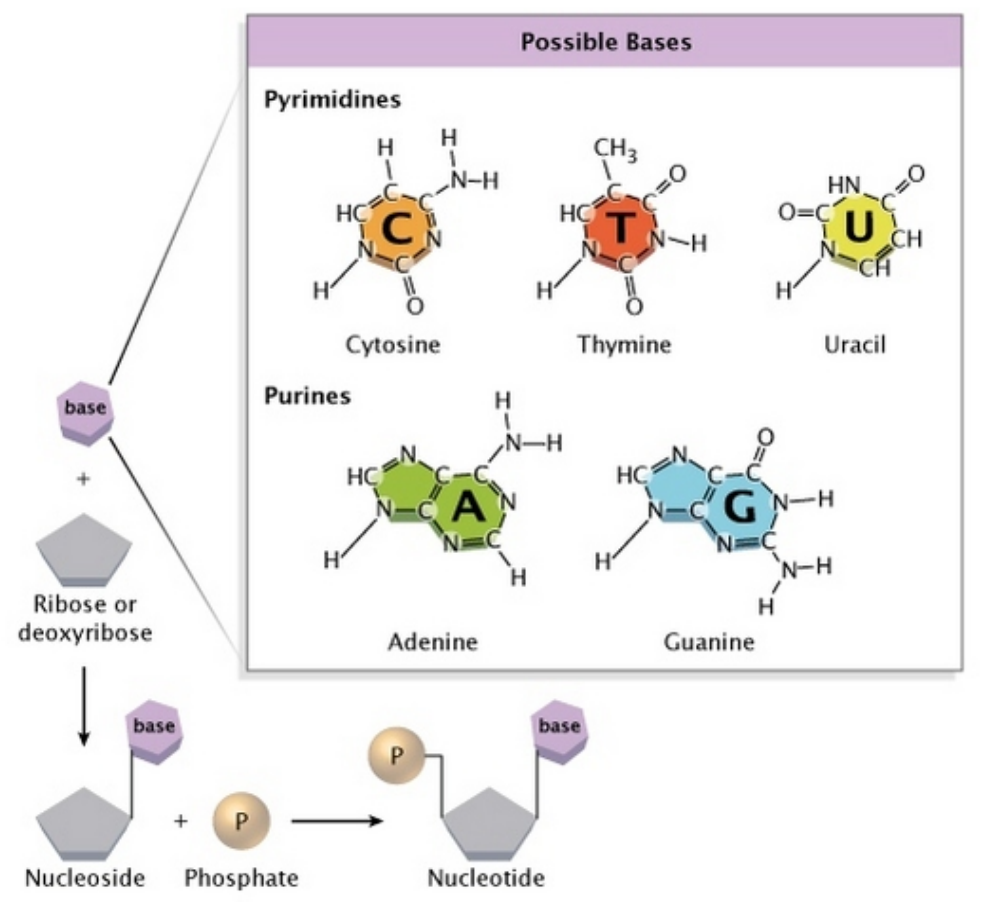

Figure 2-2: chemical structure of nucleotides [12]

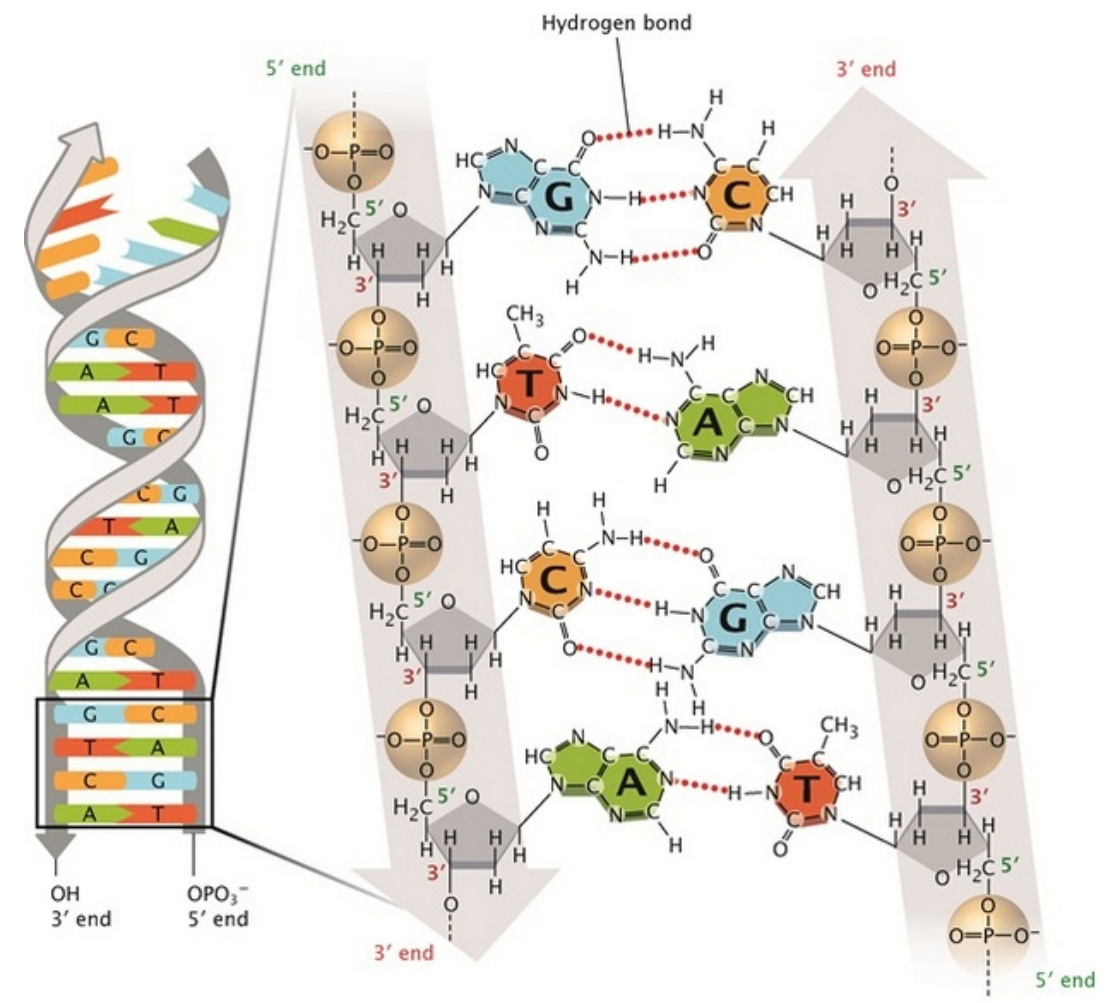

Figure 2-3: DNA base pairing [12] 


\subsubsection{Proteins}

Proteins are large molecules that contribute to a cell's function and structure. For example, structural proteins maintain cell shape and are part of structural elements of connective tissues like cartilage and bone [13]. Other proteins called enzymes work as catalysts for biochemical reactions within the cell. Another category of proteins are attached to the cell membrane and have diverse functionality e.g. transporting molecules from/to the cell, activating an intracellular process upon receiving an extracellular signal or attach the cell to a specific location.

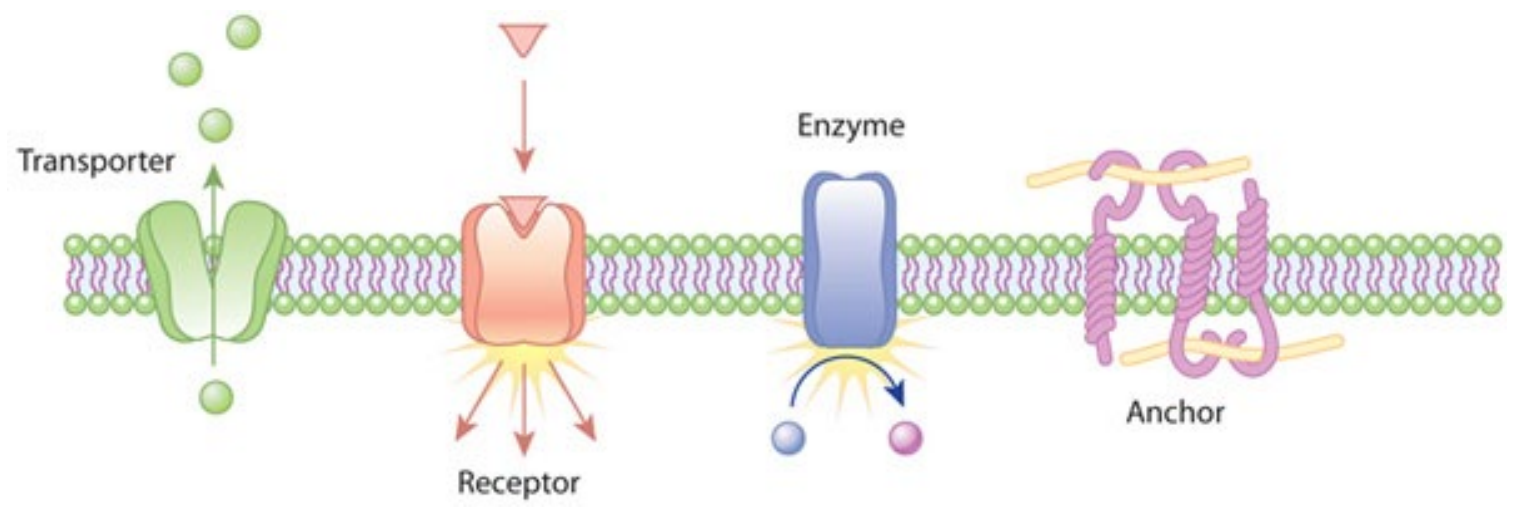

Figure 2-4: Example functions of membrane proteins [10]

Each protein consists of a series of building blocks called amino acids. Each amino acid consists of a central carbon atom, an amino group, a carboxyl group, a hydrogen atom, and a side chain. Multiple amino acids are bound together by peptide bonds to form a long chain of polypeptides or a protein as shown in Figure 2-5. The linear sequence of amino acids is considered the primary structure. Protein's primary structure determines its conformation and ultimately the three-dimensional shape. 

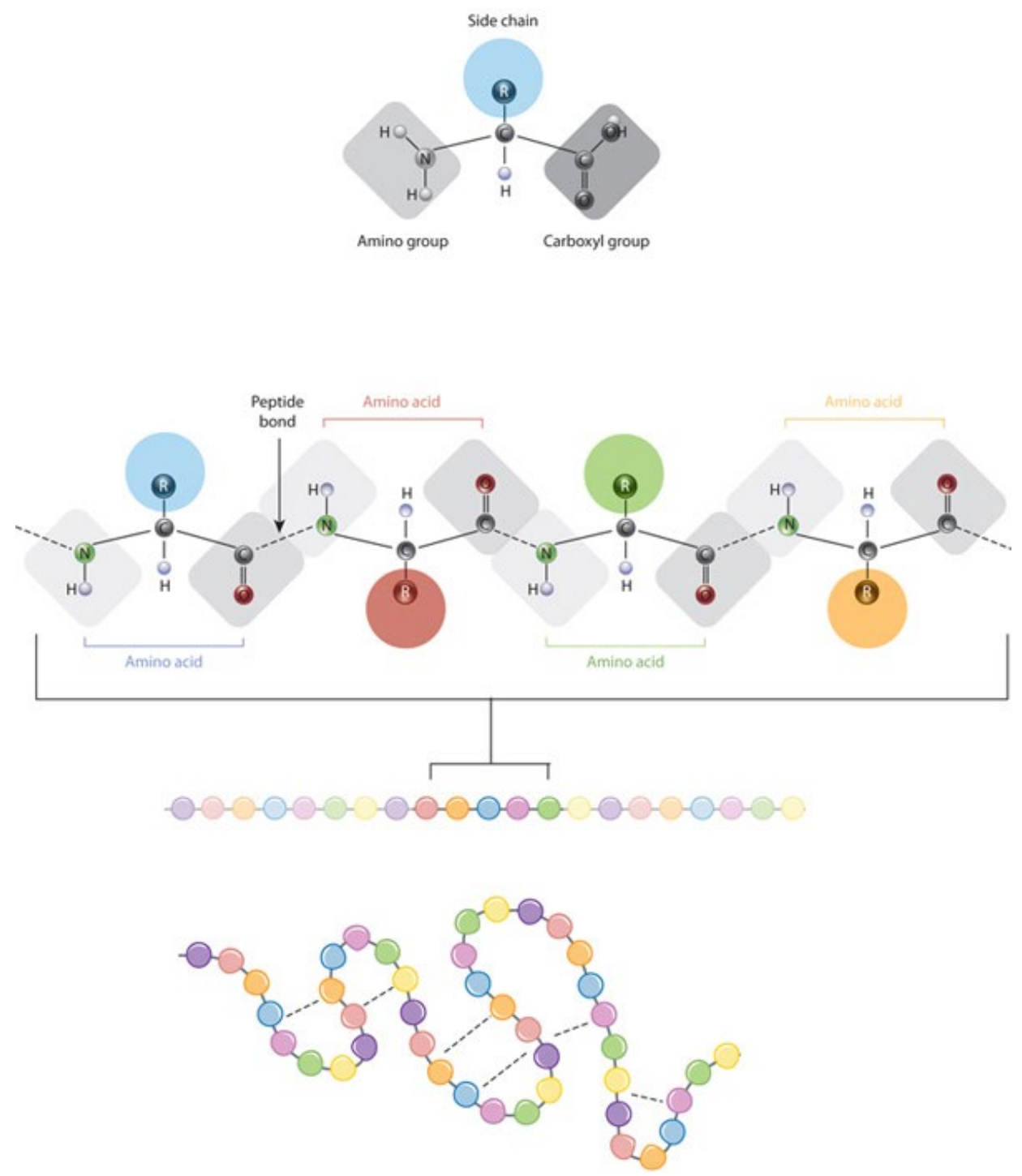

Figure 2-5: Protein building blocks [10]

\subsubsection{The central dogma of molecular biology}

The term "central dogma" was coined by Francis Crick in 1956 to describe the flow of information (genetic code needed to form a protein) from DNA to protein. It states that

“once information has got into a protein it can't get out again" [14]. 
The information flow was classified into three categories. General transfers occur in most cells and include DNA $\rightarrow$ DNA, DNA $\rightarrow$ RNA, and RNA $\rightarrow$ protein. Special transfers occur under specific conditions and include the following transfers RNA $\rightarrow$ RNA, RNA $\rightarrow$ DNA, and DNA $\rightarrow$ protein. The last category includes transfers unlikely to occur (protein $\rightarrow$ protein, protein $\rightarrow$ RNA, and protein $\rightarrow$ DNA).

\subsubsection{Genes and gene expression}

Genes are DNA sequences that encode the information needed to synthesis a protein. In humans, a child inherits a copy of the same gene from each parent. Genes are expressed when their corresponding proteins are manufactured [15]. Gene expression process goes through two main steps: DNA transcription and translation as shown in Figure 2-6.

DNA transcription is the process in which information required for protein synthesis is transferred to an intermediate molecule called messenger RNA (mRNA). The transcription process is initiated by an enzyme called RNA polymerase where one strand of DNA is used as a template [16].

During translation process, the genetic code in the mRNA molecule is read sequentially to produce a linear chain of amino acids (protein). With help of translation machinery called the ribosome, every three nucleotides in mRNA correspond to one amino acid according to a specific code as shown in Figure 2-7. 

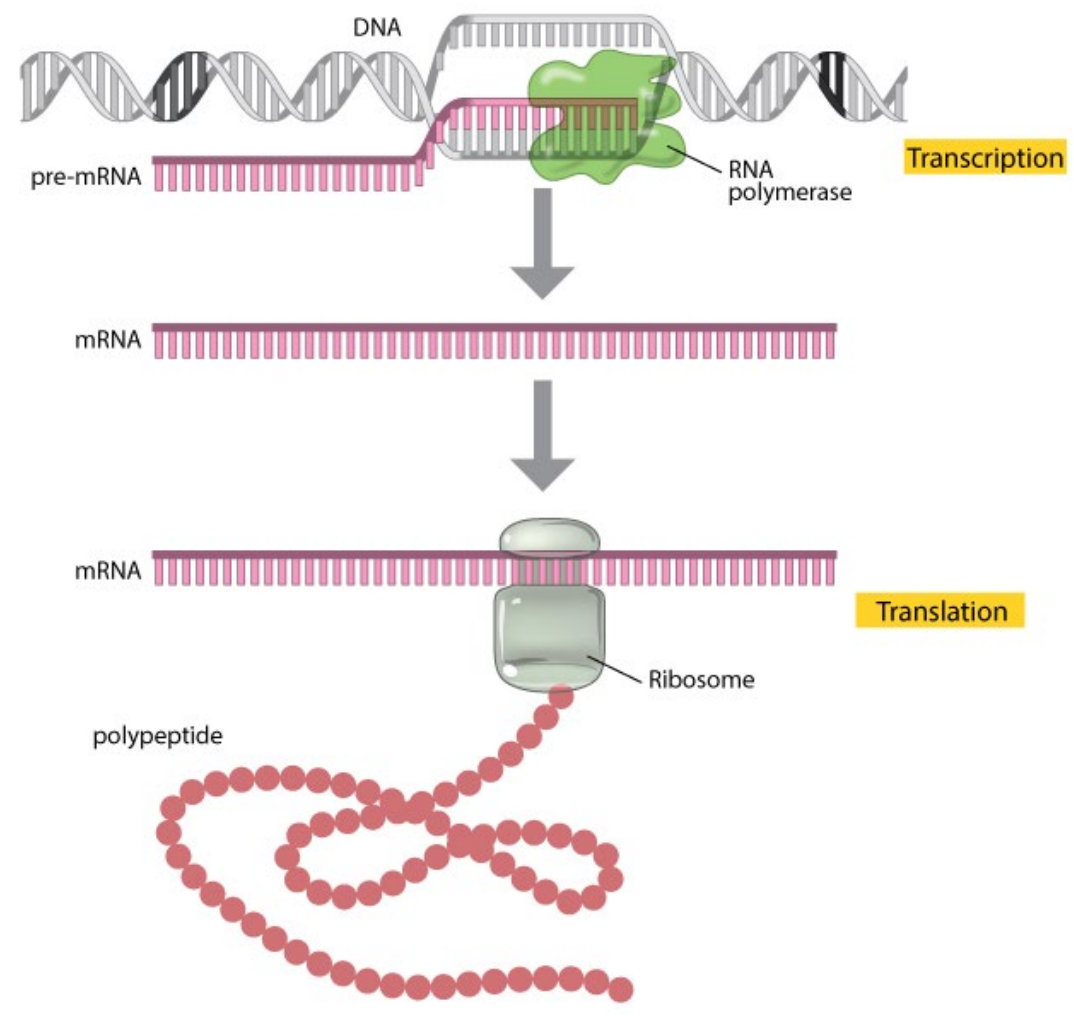

Translation

Figure 2-6: Gene expression process [15]

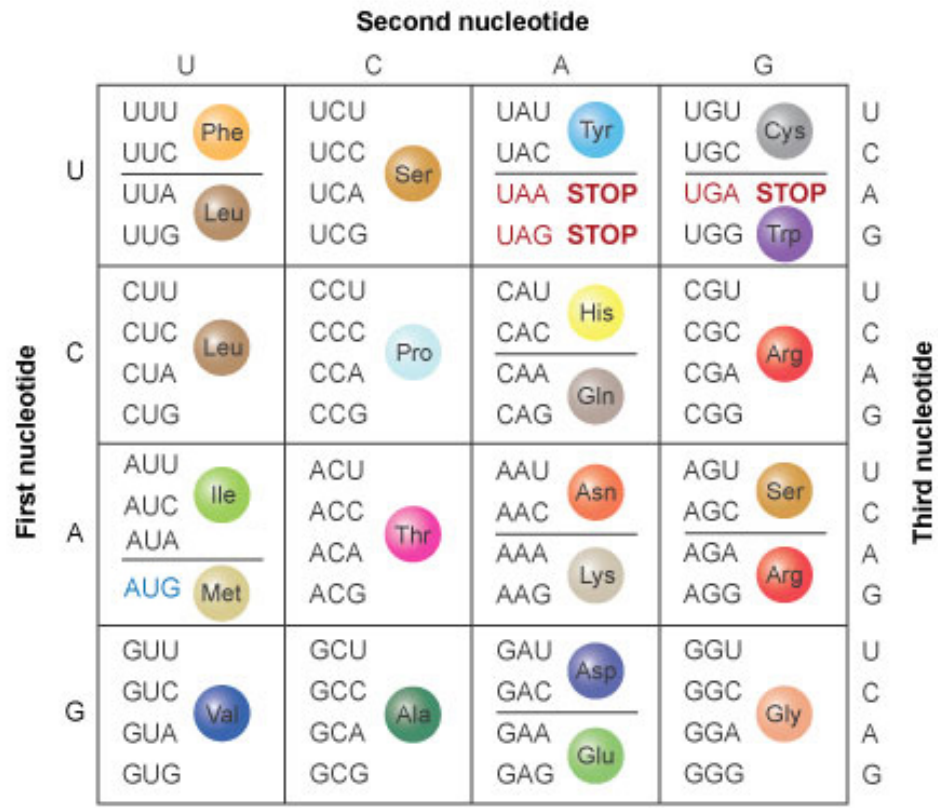

Figure 2-7: Genetic code [15] 


\subsubsection{Regulation of gene expression}

The process of gene expression involves decoding genetic instructions encoded in the DNA to synthesize proteins. The set of proteins expressed in a cell determines the structure and function of this cell. Although all cells in a multicellular organism (e.g. animals, plants, ...) have the same copy of the DNA sequence, different sets of genes are expressed in different cell types and some genes are only expressed in a specific cell type, for example, Hemoglobin (which is used to carry oxygen) is expressed specifically in red blood cells. Another protein, tyrosine aminotransferase (which is used to break down tyrosine in food), is specifically expressed in liver cells [8].

The process of gene expression goes through multiple steps from DNA to proteins through RNA, therefore the amount of expression can be controlled at each step. There are multiple levels of regulation as detailed below.

\subsubsection{Epigenetic alterations}

In which genes are switched on or off without genetic changes (changes in DNA sequence) but in response to external factors like development, aging, exercise, and diet [17]. There are two main types of epigenetic changes as shown in Figure 2-8. The first mechanism is called methylation and is facilitated by adding a methyl group to a DNA molecule. If specific regions in the DNA (for example promotor regions) are methylated, this will repress the expression of the nearby gene. The second mechanism which is called histone modification happens when chemical groups are added to histones. Since DNA is wrapped around histones, these modifications can determine which genes are available for expression (unwrapped) or turned off (wrapped). 


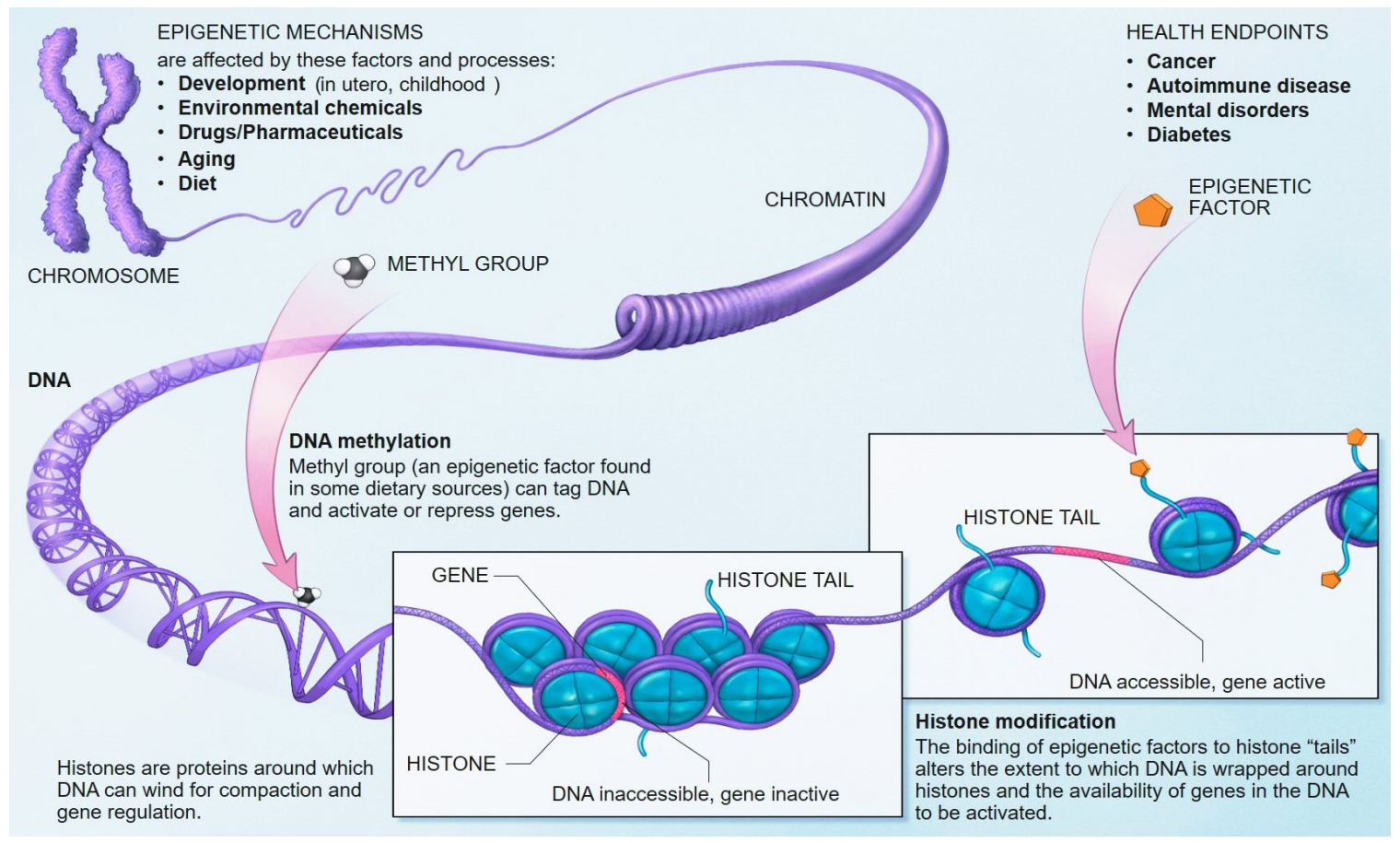

Figure 2-8: Epigenetic mechanisms for gene regulation [18]

\subsubsection{Transcriptional regulation}

In addition to epigenetic mechanisms, a group of protein-coding genes called transcriptional regulators (factors) activate or repress the expression of a gene by binding to a specific DNA sequence usually 5-10 nucleotides near that gene. This binding initiates a sequence of reactions that determines which genes to be transcribed and additionally the rate of transcription [19]. 


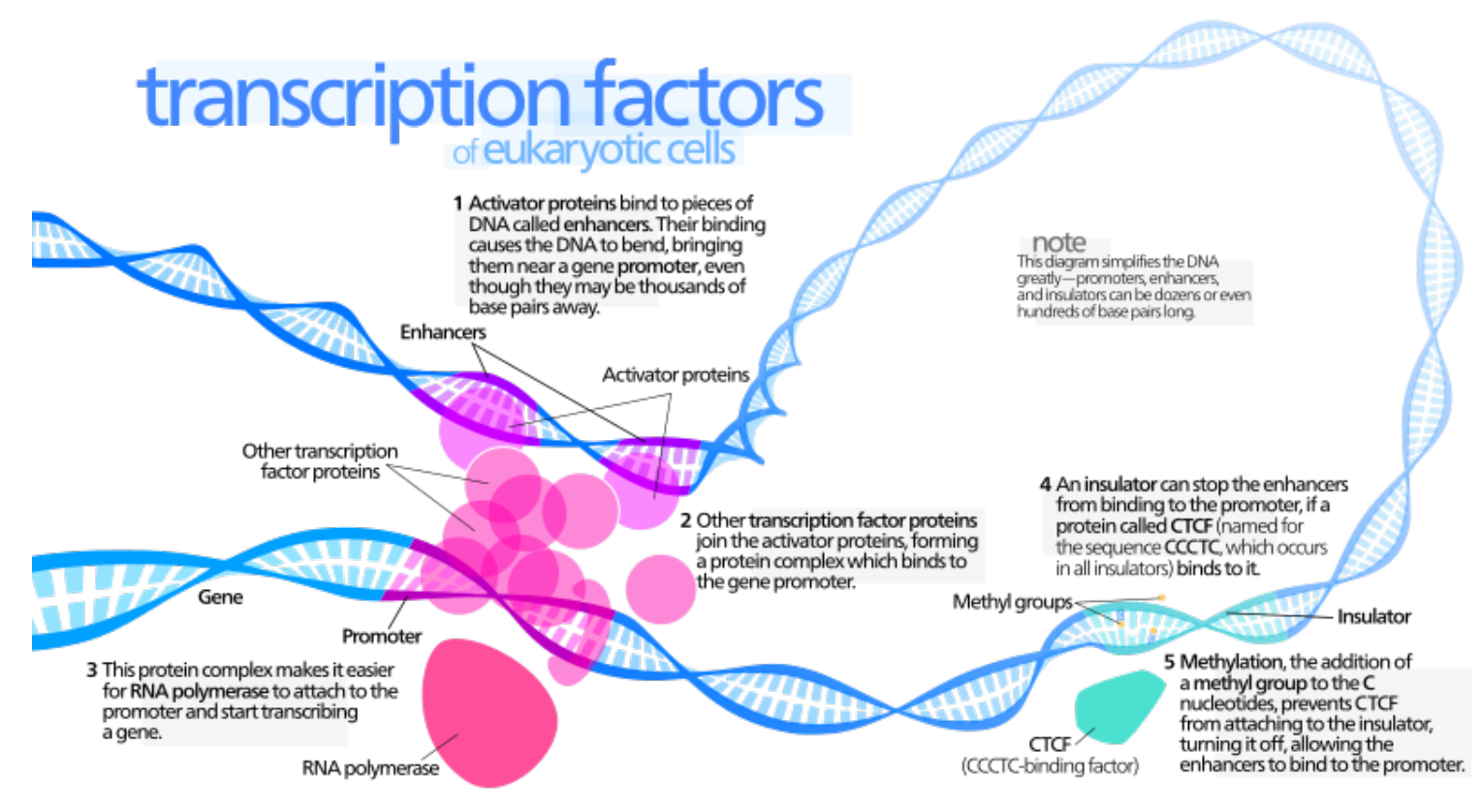

Figure 2-9: Transcription factors initiate the control of gene expression [20]

\subsubsection{Alternative splicing}

Transcription of a gene from a DNA sequence produces a long RNA transcript called precursor mRNA (pre-mRNA) transcript. Pre-mRNA transcripts typically undergo a process called RNA splicing in which non-coding sequences of the gene (introns) are removed and protein-coding sequences (exons) are joined back together to form mature RNA (mRNA) transcript [21] that has the code to synthesis a specific protein. Some genes are alternatively spliced meaning that some exons are either included or excluded in the final mRNA transcript. Alternative splicing (AS) makes it possible for a single gene to produces multiple proteins as shown in Figure 2-10. 


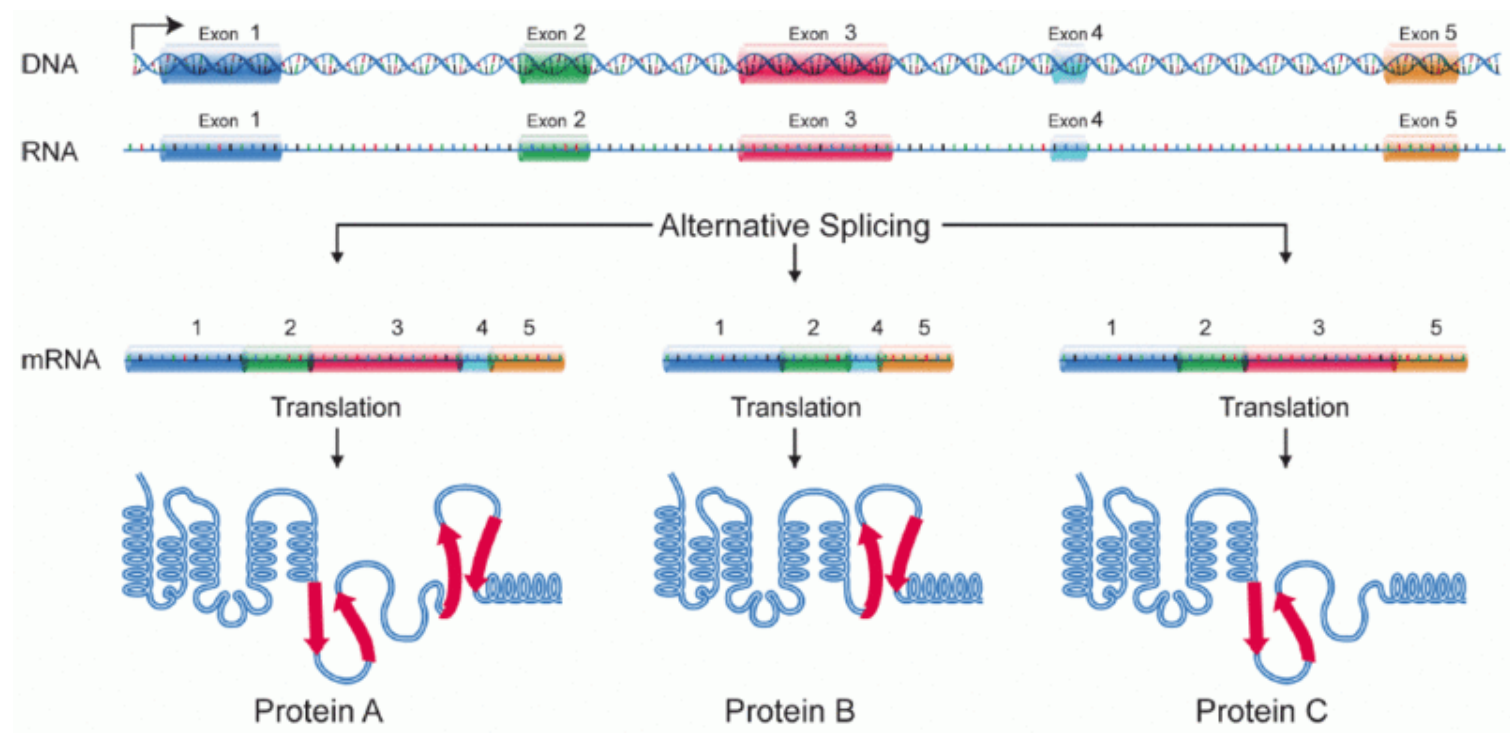

Figure 2-10: An example of an alternatively spliced gene [22]

\subsection{MicroRNAs}

MicroRNAs (miRNAs) are small non-coding RNA molecules that are $\sim 22$ nucleotides and are known to be involved in the regulation of the expression of other protein-coding genes (target genes) and have an essential role in many biological processes including development and diseases like cancer. The first miRNA was discovered in Caenorhabditis elegans (C. elegans) (the worm) in 1993 [23] [24] by Ambros and Ruvkun groups [25]. This miRNA (lin-4) was found to be essential to the normal development of C. elegans by regulating the expression of the lin-14 protein.

\subsubsection{Biogenesis of miRNAs}

miRNA genes can be found within introns of other protein-coding genes (Mitrons) or independent from other genes (intergenic miRNAs) [25]. Biogenesis of miRNAs starts with transcribing miRNA genes into primary transcripts (pri-miRNAs) using RNA polymerase II/III. Processing of pri-miRNAs to produce mature miRNAs 
follows different pathways depending on the locus of the miRNA gene as shown in Figure 2-11.

In the canonical pathway, longer pri-mRNA transcripts ( $\sim 1 \mathrm{~K}$ nucleotides $)$ are processed by a microprocessor complex, consists of two proteins (DGCR8 and Drosha) to produce a transcript with a stem-loop structure known as pre-miRNA ( $\sim 60$ nucleotides in animals). After producing pre-miRNAs, they are exported to the cytoplasm where the loop is removed by Dicer protein, and the double-stranded RNA is released. Each strand of the mature miRNA can be loaded into one of the Argonaute (AGO) family of proteins to form a miRNA-induced silencing complex (miRISC).

In the non-canonical pathway, some intronic sequences following the splicing process have the structural features of pre-miRNAs, therefore bypassing the Droshamediated processing [26]. 


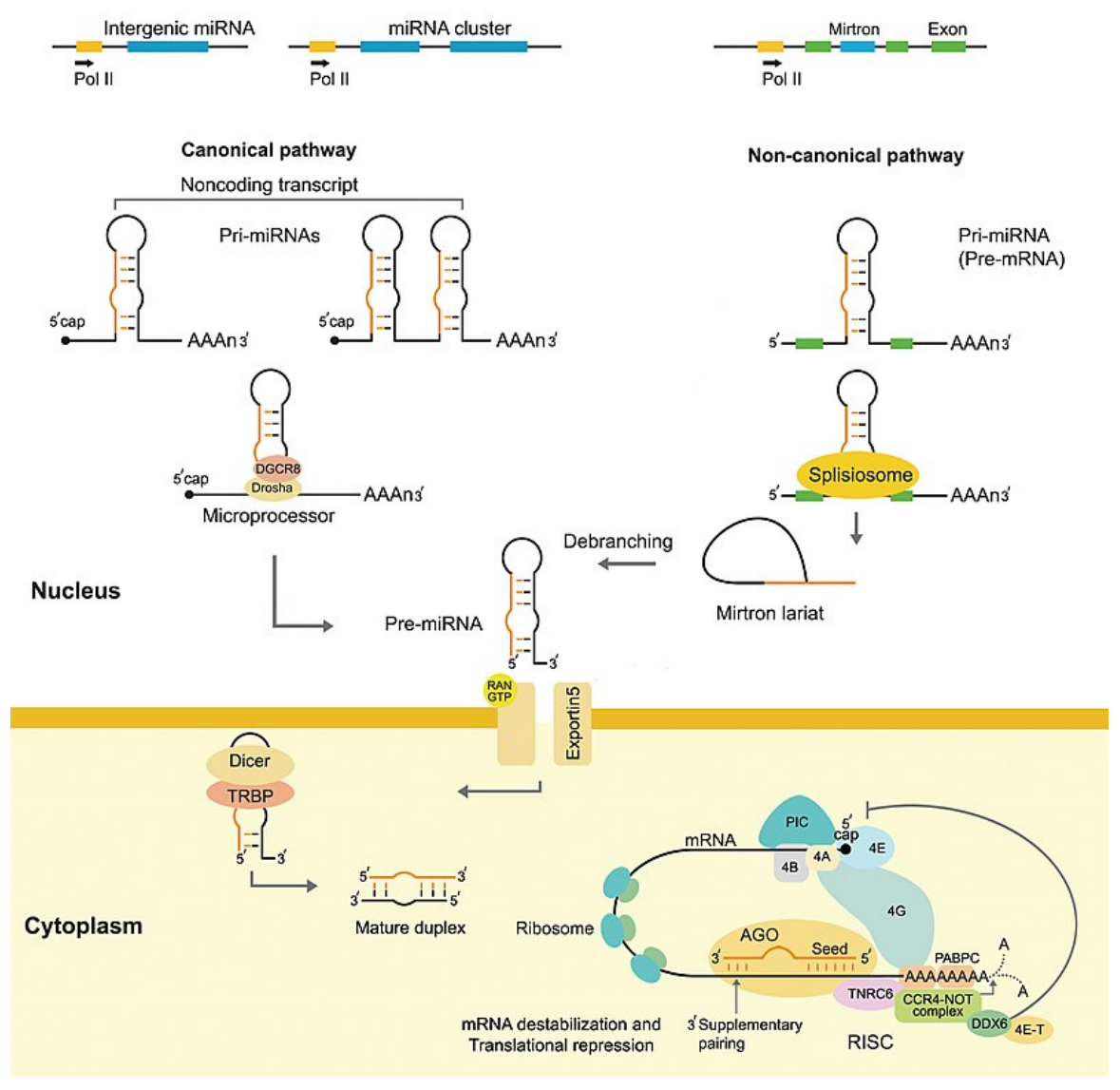

Figure 2-11: Different pathways of animal miRNA biogenesis [27]

\subsubsection{MicroRNA targeting mechanism in animals}

The following papers in this section cover the process of miRNA-based gene silencing in animals. Such information could enhance the performance of tools developed for the computational prediction of miRNA targets.

Cisse, et al. [28] addressed the question of what the minimum number of basepairings is needed to establish a stable association of two DNA/RNA strands. This could be used to infer some of the rules governing small RNA-based gene silencing, including miRNA-based gene regulation. To answer this question, they synthesized 8 nucleotides (nt) sequences representing the seed of human miR125 with mismatches at the $1^{\text {st }} \mathrm{nt}$ 
(leaving 7 contiguous nts) and at the $2^{\text {nd }} \mathrm{nt}$ (leaving 6 contiguous nts). The association rate with seven contiguous nts was 450 times bigger than the one with 6 nts. This finding supports the hypothesis that at least seven Watson-Crick base pairs in the miRNA seed region are needed for rapid and effective targeting.

Wee, et al. [29] provided an insight into how the Argonaute (Ago2) protein in RISC (RNA-induced silencing complex) shapes the miRNA guide. They showed that Ago2 divides a miRNA sequence into five functional domains. These domains are the

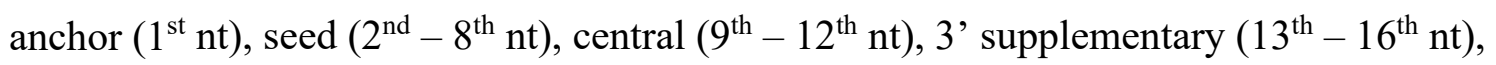
and tail region $\left(17^{\text {th }}-21^{\text {st }} \mathrm{nt}\right)$. Their results showed that the miRNA-guided silencing complex is used for translation inhibition without cleaving target mRNA transcript. On the other hand, small-intervening RNAs (siRNAs) are responsible for mRNA cleavage. Unlike mismatches at the seed ends, mismatches in the center of the seed regions are not favorable for effective gene silencing. Although G-U wobbles in the seed region were considered by existing miRNA target prediction tools, this paper suggests that G-U wobbles should be treated like mismatches and should not be allowed.

Salomon, et al. [30] studied the binding properties of guide RNA that are bound to Ago protein within the RISC complex. They found that seed nucleotides $\left[2^{\text {nd }}-5^{\text {th }} \mathrm{nt}\right]$ are involved more at the initial binding to target mRNA and then Ago is conformed to expose nucleotides $\left[6^{\text {th }}-8^{\text {th }} \mathrm{nt}\right]$ and $\left[13^{\text {th }}-16^{\text {th }} \mathrm{nt}\right]$ for more stable binding. Also,

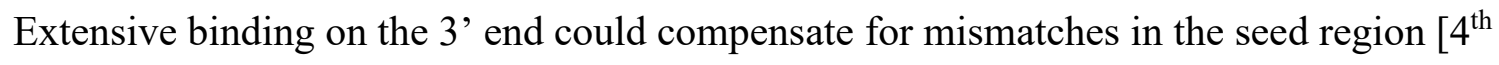
$\left.-5^{\text {th }} \mathrm{nt}\right]$. They also suggested that the binding of nucleotides $\left[9^{\text {th }}, 10^{\text {th }}\right]$ of miRNA should be penalized in miRNA target prediction algorithms due to the unfavorable conformation in Argonaute. 
Broughton, et al. [31] investigated the specificity of seed-based miRNA targeting. To answer this question, they used individual-nucleotide resolution cross-linking immunoprecipitation (iCLIP) to extract miRNA-target chimeras by ligating each miRNA to its target. Since miRNA families have common seed regions but different 3' sequences, they were used to determine if all miRNAs in a family have common targets or not. The results suggest that miRNA family members have shared targets in addition to targets specific to each member. This paper highlights the importance of pairing the miRNA 3' supplementary sequence for enhancing the predictive power of current miRNA target prediction tools.

Chandradoss, et al. [32] studied how the Ago protein finds target sites in mRNA. They used a single-molecule FRET (Förster resonance energy transfer) assay to visualize the search process used by Ago2 to find miRNA target sites. They found that the miRNA-bound Ago employs a lateral diffusion mechanism for searching and identifying target sites. First, the sub-seed region [nt 2-4] is used for initial searching and once a complete seed pairing is found [nt 2-8], the binding becomes stable. This model suggests that target regions might be enriched in the trinucleotides [nt 2-4] of the seed region which could be an additional feature to be added to miRNA target prediction tools. 


\subsubsection{Computational prediction of miRNA targets in animals}

Saito et al. [33] discussed six main features currently used by miRNA target prediction tools. These features are listed as follows,

1. miRNA-mRNA base pairing at the $5^{\prime}$ miRNA seed region $\left[1^{\text {st }}\right.$ to $8^{\text {th }}$ nucleotide]: this feature is considered the most relevant feature used by the silencing complex to find target genes. Stringent seed paring is considered more effective than seed pairing with mismatches.

2. Location of target sites within mRNA transcript: although miRNA-guided silencing complex may target 5'UTR and CDS regions, the 3'UTR contains most of the target sites.

3. Conservation of miRNAs and their targets: miRNA targets tend to be in regions conserved among closely related species. Using conservation information in miRNA target prediction tools could increase specificity. Of course, this increase occurs with a cost to sensitivity.

4. Site accessibility: to enable miRNA-mRNA hybridization, a target site must be easily accessible. Estimation of site accessibility can be achieved by calculating the minimum free energy of an mRNA secondary structure. Although theoretically, an mRNA secondary structure with the minimum free energy is most likely to occur naturally, this might not be the actual structure because RNA secondary structure is dynamic [34]. Also, the computational complexity of these algorithms is $O\left(n^{3}\right)$ [35], where $\mathrm{n}$ is the length of the RNA transcript.

5. Multiple target sites Having more than one potential miRNA target site could enhance the role of miRNA as a translation inhibitor as it increases the chances of binding of silencing complex and mRNA transcript.

6. Expression profiles of miRNAs and mRNAs: due to their role in translation inhibition and mRNA degradation, the expression of miRNAs is expected to be negatively correlated with the expression of targeted mRNAs. Although using this feature could help exclude some of the false positives, it could overlook some true miRNAmRNA pairs that are negatively correlated at the protein level only. 
Saito et al. [33] provided a useful comparison of approximately 30 different prediction tools based on the presence or absence of these six features. On the other hand, it did not provide a performance analysis (accuracy and computational complexity) for these tools.

Bradley, et al. [36] provided a review of two classes of miRNA target prediction tools, namely, classical tools and tools trained by data generated from CLIP (crosslinking and immunoprecipitation) or CLIPL (cross-linking and immunoprecipitation and ligation) high-throughput experiments. This new class of prediction tools (CLIP \& CLIPL-based) is an improvement in the identification of transcriptome-wide miRNA targets.

In CLIP-based experiments, RNAs bound to the AGO protein are directly sequenced, but there is still ambiguity linking specific miRNA to a specific mRNA. Although CLIPL-based experiments use a similar process, an additional step is added that ligates a miRNA to its mRNA fragment. By sequencing miRNA-mRNA chimeras, a specific miRNA can be linked to its target site.

Although the high-throughput nature of CLIP\&CLIPL experiments makes it suitable for training machine learning-based target prediction algorithms, these methods still suffer from technical difficulties that require well-trained personnel to manage. Another issue with these experiments is that several non-canonical target sites (seed pairing with mismatches and bulges) have been reported, which are thought to be ineffective sites. 
Fan, et al. [37] provided an overview of 38 sequence-based miRNA target prediction tools and a comparison of seven popular tools based on their predictive performance, ease of use, availability, and impact. The authors compared TargetScan 6.2 [38], PicTar [39], DIANA-microT-CDS [40], miRanda [41], EIMMo3[42], mirTarget2 v4 [43], miRmap v1.1 [44]. They assessed the predictive performance based on four different datasets, duplex-level (the actual site within mRNA transcript), gene-level, mRNA expression-level, and protein-level.

The results of these assessments suggest that there is no globally best tool. Although TargetScan and miRmap provided high overall predictive performance, PicTar and MirTarget2 showed high specificity. As expected, gene-level prediction performance was better than duplex-level predictions, as gene-level predictions can make use of more information (enrichment of multiple seed pairings). Finally, many (>83\%) of nonfunctional target sites have at least 6bp in their seed-pairings, which makes the miRNA target prediction more challenging.

Oliveira, et al. [45] focused on finding the best approach for using miRNA prediction tools. The authors argue that the current trend of using the intersection of targets identified with different prediction tools is not the best way to combine results, as this approach suffers low sensitivity and often misses many true targets. To address this question, they compared the targets generated from four different individual tools (TargetScan [46], miRanda-mirSVR [41], Pita [47], and RNA22 [48]) and the intersection/union of different subsets of these tools. In terms of prediction performance, the authors suggest using the union of target prediction results from Targetscan and miRanda when high specificity is needed and the union of target prediction results from 
Targetscan, miRanda, and RNA22 if higher sensitivity is need while preserving good specificity. Although this paper addressed a practical aspect to solve the miRNA target prediction problem, it has some limitations. For its test dataset, true negatives were defined as those that are neither validated (according to mirTarbase database) nor predicted. However, this assumption is not accurate since some true targets might not be validated till this point in time Also, they did not provide a plausible explanation for why this particular combination of tools might have the best predictive performance.

Gumienny, et al. [49] introduced MIRZA-G tool for predicting miRNA targets and siRNA off-targets. Since siRNA off-target sites are not likely to be conserved, using conservation-based miRNA target prediction tools is not suitable. In addition to the classical features (site accessibility, position within 3'UTR, flanking G/flanking U content, conservation information), MIRZA-G employs miRNA-target interaction energy as a new feature. A logistic regression model was used to predict the efficacy of the target site based on the previous features.

Agarwal, et al. [46] introduced the prediction model used in the latest version of TargetScan (v7). Although TargetScan is considered the leading tool for miRNA target prediction, previous versions were mainly focusing on conserved target sites which reduces its sensitivity and increases the likelihood of missing siRNA off-targets. The new multiple regression model employs 14 features and covers information regarding seed type, context around the target site, 3' pairing, target transcript, and site accessibility.

Since TargetScan considers only canonical seed types (no mismatches or GU wobbles), the authors examined the efficacy of non-canonical target sites which are abundantly discovered in the new CLIP-based experiments. Surprisingly, they found that 
these sites are not functional concerning translation inhibition. Although the proposed model surpassed other miRNA target prediction tools, there are still some limitations. First, despite being simple and easy to interpret, the multiple regression model assumes that there is a linear relationship between target site efficacy and each of the input features which may not be the case for some features. Second, regarding test data, only gene expression at the mRNA level was used which may not be sufficient for detecting translation inhibition. Third, only target sites within the 3'UTR are included which could miss other functional targets in the CDS/5'UTR regions. 


\section{PREDICTION OF POTENTIAL BACTERIAL GENES TARGETED BY PLANT MIRNAS}

\subsection{Introduction}

Previous studies have shown the role of small non-coding RNAs especially miRNAs in the regulation of cross-kingdom gene expression. As described in Liang, et al.'s study [50], cross-kingdom regulation occurs when a microRNA and a target gene belong to two different species (e.g., different kingdoms such as animals, plants, bacteria, viruses, etc.).

Although the way cells within the same species communicate is known (e.g. communication between neurons through hormones in humans [51]), the way cells from two different species exchange signals was not discovered until recently.

In this chapter, we propose a computational framework to investigate a new type of cross-kingdom gene regulation by predicting potential gut bacterial genes targeted by edible plant miRNAs (e.g. ginger miRNAs).

\subsection{Background}

\subsubsection{Cross-kingdom gene regulation}

Liang, et al.'s study [50] provided four different examples of the new role of miRNA in cross-kingdom gene regulation. Firstly, Plant miRNAs were found to exist in human tissue and sera and at relevant concentrations. Of these plant miRNAs, MIR168a was shown to target low-density lipoprotein receptor adaptor protein 1 (LDLR API) [52]. 
Also, Human miRNAs were found within the malaria parasite Plasmodium falciparum and were shown to affect its growth [53]. On the other hand, Viral miRNA KSHV-miR-K12-11 was found to mimic and share common targets with human miRNA miR-155 [54]. Lastly, Human miRNA miR-122 has a role in stimulating the replication of the hepatitis $\mathrm{C}$ virus by stabilizing its viral RNA and prevent its degradation [55] by targeting two 5' UTR sites.

Liu et al. [3] provided additional evidence of the role of cross-kingdom miRNAbased gene regulation. They showed that human miRNAs from epithelial and other cells can enter gut bacteria and affect its growth. They also discussed how miRNAs manipulate the composition of the gut microbiota. Interestingly, they mentioned that miRNAs could target ribosomal RNAs, and they could either repress or promote gene expression.

\subsection{Methods}

\subsubsection{Datasets}

Top 49 expressed ginger miRNAs (Appendix I) are detected from miRNA-seq data of exosomes-like nanoparticles (SRA accession numbers SRX5085431, SRX5085432, SRX5085433). Reference genome sequences of 8 common gut bacteria (see Table 3-1) were downloaded from NCBI RefSeq database [56] (ftp://ftp.ncbi.nlm.nih.gov/genomes/refseq/bacteria/)

Table 3-1: Common gut bacteria and their RefSeq accession numbers

\begin{tabular}{|c|c|}
\hline Bacterial strain & NCBI RefSeq Accession Number \\
\hline Akkermansia muciniphila & NC_010655.1 \\
\hline Bacteroides fragilis & NC_006347.1 \\
\hline Clostridium perfringens & NC_008261.1 \\
\hline
\end{tabular}




\begin{tabular}{|c|c|}
\hline Escherichia coli & NC_000913.3 \\
\hline Enterococcus faecalis & NC_004668.1 \\
\hline Helicobacter pylori & NC_000915.1 \\
\hline Lactobacillus rhamnosus GG & NC_013198.1 \\
\hline Lactobacillus ruminis & NC_015975.1 \\
\hline
\end{tabular}

\subsubsection{Overall pipeline}

Our pipeline (Figure 3-1) takes as inputs sequences of plant miRNAs and sequences of bacterial genes. Then, for each miRNA-gene pair, we search for hits for both miRNA seed and its reverse complement (This because miRNAs can target both bacterial DNA and mRNA [3]). For fast searching, bacterial gene sequences are indexed into a hash-table as detailed in the next section. Finally, for each miRNA-gene, we compare the actual number of hits with the expected number to find genes with enriched miRNA seed binding sites.

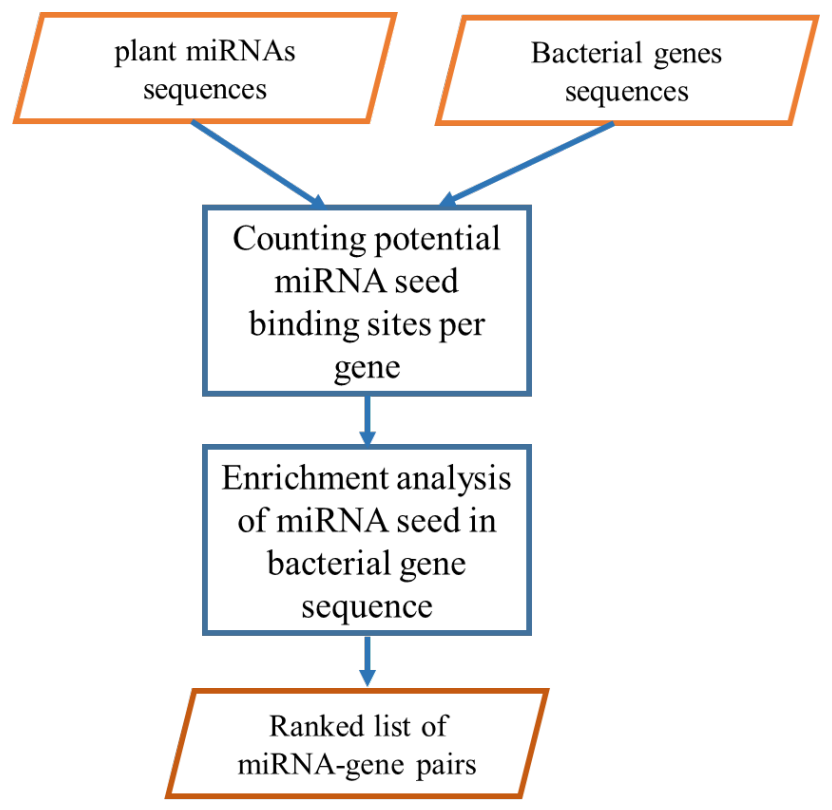

Figure 3-1: Overall pipeline to detect potential bacterial genes targeted by plant miRNAs 


\subsubsection{Hash table-based miRNA seed binding site detection}

Let $T$ represents the sequences of bacterial genes, $p$ to the pattern (e.g. miRNA seed sequence) we are searching for in $T$, and $H(p)$ to be the hash function that converts $p$ into an integer number. Our hash table will have $H(k$-mer) (where $k$-mer is a subsequence of length $k$ of text $T$ ) as key and a list of locations of this $p$ in $T$ as value as shown in Table 3-2

Since our set of keys are static and relatively not too big (for example, the set of all $4^{8}$ possible 8 -mers if $\mathrm{k}=8$ ), we use a perfect hash function, where each key is mapped to a unique row without collisions. Since DNA/RNA has 4 different nucleotides (A, C, G, T/U), their integer representation can be as follows $I(A)=0, I(C)=1, I(G)=2$ and $I(T)=3$. Then the hash value of pattern $p$ of length $\mathrm{k}(\mathrm{k}-\mathrm{mer})$ can be calculated as follows,

$$
H(\mathrm{p})=\sum_{i=0}^{k-1}\left(I(p[i]) \times 4^{i}\right)
$$

For example, $H\left({ }^{\prime} A T G^{\prime}\right)=2 \times 4^{0}+3 \times 4^{1}+0 \times 4^{2}=14$.

Table 3-2: Target bacterial gene sequences represented as a hash table

\begin{tabular}{l|l}
\hline Key & Value \\
\hline$\ldots$ & $\ldots$ \\
$H\left({ }^{\circ}\right.$ ATACACTG') & {$[<$ gene1,offset $>,<$ gene656,offset $>]$} \\
$\ldots$ & $\ldots$ \\
$H\left({ }^{\circ}\right.$ CATCAGGG') & {$[<$ gene100,offset $>,<$ gene45,offset $>,<$ gene98,offset $>]$} \\
$\ldots$ & $\ldots$ \\
\hline
\end{tabular}




\subsubsection{Enrichment analysis}

In order to find bacterial genes that are more likely to be targeted, we employ a technique proposed by Murphy et al. [6] initially to predict targets of viral miRNAs. To quantify overrepresentation (enrichment) of a k-mer in a sequence, the actual count $C_{\text {actual }}$ is compared to an expected count $C_{\text {expected }}$ (how many times we expect to see this k-mer $\mathrm{X}$ by chance). $C_{\text {expected }}$ is calculated by the following equation,

$$
C_{\text {expected }}=(L-k+1) \times P(X)
$$

Where $P$ is the probability of seeing this k-mer in a target sequence of length $L$ given a specific model of this sequence. We use a first-order Markov chain of the target sequence to model it. $P$ can be calculated using the following equation,

$$
P(X)=p\left(x_{1}\right) \prod_{i=2}^{k} p\left(x_{i} \mid x_{i-1}\right)
$$

Where $x_{i}$ is nucleotide at position $i$ of k-mer $\mathrm{X}, p\left(x_{i} \mid x_{i-1}\right)$ is the probability of having nucleotide $x_{i}$ after nucleotide $x_{i-1}$ and can be represented as a matrix (Figure 3-2) and $p\left(x_{1}\right)$ is probability of seeing nucleotide $x_{1}$. 


\begin{tabular}{|c|c|c|c|c|}
\hline & \multicolumn{3}{|c|}{$x_{i}$} & \\
\hline & $A$ & C & G & $\mathrm{T}$ \\
\hline A & 0.2 & 0.2 & 0.3 & 0.3 \\
\hline C & 0.4 & 0.4 & 0.1 & 0.1 \\
\hline G & 0.1 & 0.2 & 0.3 & 0.4 \\
\hline $\mathrm{T}$ & 0.1 & 0.1 & 0.4 & 0.4 \\
\hline
\end{tabular}

Figure 3-2: Example of $1^{\text {st }}$ order Markov chain for a DNA sequence

For example, if $\mathrm{X}=$ 'ATGC', then the probability of seeing this 4 -mer given the $1^{\text {st }}$ order Markov chain model in Figure 3-2 will be calculated as follows,

$$
\begin{gathered}
P\left({ }^{\prime} A T G C^{\prime}\right)=p\left(x_{1}\right)\left[p\left(x_{2} \mid x_{1}\right) \times p\left(x_{3} \mid x_{2}\right) \times p\left(x_{4} \mid x_{3}\right)\right] \\
P\left({ }^{\prime} A T G C^{\prime}\right)=p\left({ }^{\prime} A^{\prime}\right)\left[p\left({ }^{\prime} T^{\prime} \mid{ }^{\prime} A^{\prime}\right) \times p\left({ }^{\prime} G^{\prime} \mid ' T^{\prime}\right) \times p\left({ }^{\prime} C^{\prime} \mid{ }^{\prime} G^{\prime}\right)\right] \\
P\left({ }^{\prime} A T G C^{\prime}\right)=0.25[0.3 \times 0.4 \times 0.2]=0.006
\end{gathered}
$$

And if we assume that the length of the target sequence $(L)$ is 1000 , then the expected count $C_{\text {expected }}$ will be $1000 \times 0.006$ which is 6 .

Using first-order Markov chain allows us to capture any dinucleotide biases, for example, CG content. Also, given that the average length of a bacterial gene is $\sim 900$, there may not be long enough to train higher-order chain models

To quantify the likelihood of one miRNA to target a specific target gene, we calculate $P_{\text {value }}$. Assuming a binomial distribution, $P_{\text {value }}$ is the probability of having at least $C_{\text {actual }}$ binding sites and is calculated by the following formula, 


$$
P_{\text {value }}=\sum_{i=C_{\text {actual }}}^{L-k+1}\left(\begin{array}{c}
L-k+1 \\
i
\end{array}\right) P(X)^{i}(1-P(X))^{L-k+1-i}
$$

\subsection{Results}

\subsubsection{Identification of potential gut bacterial genes targeted by ginger miRNAs}

Bacterial mRNAs potentially targeted by ginger miRNAs were identified by enrichment analysis of the reverse complement of the miRNA seed sequence $(8 \mathrm{mer}=$ nucleotides $1-8$ from 5' end) in the coding sequence (CDS). The enrichment analysis adopted a framework that utilizes the $1^{\text {st }}$ order Markov model (MM). In this framework, the observed 8mer count in the CDS region of each bacterial mRNA was compared against the background count derived from the $1^{\text {st }}$ order Markov chain model. A p-value was calculated for each miRNA-mRNA pair to estimate the likelihood of having a functional pair. Once all p-values were calculated, the false discovery rate (FDR) was obtained using the Benjamini-Hochberg method [57] for multiple p-value correction.

Table 3-3: Number of potential genes targeted by ginger miRNAs

\begin{tabular}{|c|c|c|c|}
\hline Bacterial strain & $\begin{array}{c}\text { Number of } \\
\text { potential target } \\
\text { genes }\end{array}$ & $\begin{array}{c}\text { Percentage of total } \\
\text { genes (\%) }\end{array}$ & GC content (\%) \\
\hline Akkermansia muciniphila & 677 & 30.0 & 55.8 \\
\hline Bacteroides fragilis & 1088 & 26.5 & 43.1 \\
\hline Clostridium perfringens & 320 & 11.2 & 28.4 \\
\hline Escherichia coli & 1168 & 26.7 & 50.8 \\
\hline Enterococcus faecalis & 866 & 32.5 & 37.5 \\
\hline Helicobacter pylori & 372 & 24.5 & 38.8 \\
\hline Lactobacillus rhamnosus & 726 & 28.1 & 47.0 \\
\hline GG & 429 & 21.3 & 43.3 \\
\hline Lactobacillus ruminis & & & \\
\hline
\end{tabular}


Table 3-3 shows that hundreds of bacterial genes are potentially targeted by ginger miRNAs. The percentage of potentials targets varies for different bacterial strains and ranges from $11.2 \%$ for Clostridium perfringens to $32.5 \%$ for Enterococcus faecalis. To see if these variations are related to the nucleotide composition of different bacterial genomes, we calculated GC content of each of these genomes. Some bacterial genomes with high GC content like Akkermansia muciniphila, Escherichia coli, and Lactobacillus rhamnosus $G G$ tend to have a higher percentage of potential target genes. On the other hand, bacterial genomes with a low percentage of potential target genes like Clostridium perfringens has low GC content.

\subsubsection{Case study 1: Ginger miRNA ath-miR167a-5p targets LGG SpaC gene}

Using the top 49 expressed miRNAs from ginger exosomes, we used our tool to find potential bacterial (LGG strain) genes targeted by these miRNAs. We search for potential binding sites for the miRNA seed region ( $7 \mathrm{mer})$ in both reverse and forward strands (targeting at the DNA level [3]). Of these genes, LGG pilus gene $\mathrm{SpaC}$ has a role in the colonization of bacteria into host tissues [58]. Table 3-4 shows potential ginger miRNAs targeting the LGG pilus gene. Only six miRNAs have potential binding sites in SpaC coding sequence. Of these, miR-167a-5p has shown significant targeting (p-value $<$ 0.05 ) with 2 potential seed binding sites.

Teng et al. [59] showed that $\mathrm{SpaC}$ gene is downregulated at both transcriptional and protein levels when LGG was treated by ginger exosomes. Also, the authors showed that scrambled miR-167a-5p (with mutations at seed region) did not affect the expression of SpaC. 
Table 3-4: potential ginger miRNAs targeting pilus gene (SpaC)

\begin{tabular}{ccccc}
\hline miRNA ID & seed (7mer) & \# of hits & $\begin{array}{c}\text { length of } \\
\text { transcript }\end{array}$ & p-value \\
\hline ath-miR167a-5p & GAAGCTG & 2 & 2688 & 0.0118 \\
ppt-miR319a & TTGGACT & 1 & 2688 & 0.1496 \\
mdm-miR535a & GACAACG & 1 & 2688 & 0.2078 \\
aly-miR396a-3p & TTCAATA & 1 & 2688 & 0.2473 \\
gma-miR396a-3p & TCAATAA & 1 & 2688 & 0.2566 \\
aly-miR166a-5p & GAATGTT & 1 & 2688 & 0.2664 \\
\hline
\end{tabular}

\subsubsection{Case study 2: Ginger miRNAs targeting LGG lexA gene}

Teng et. al. [59] showed that lexA gene is downregulated at both transcriptional and protein levels when LGG was treated by ginger exosomes. To find potential ginger miRNAs targeting LGG lexA gene, we searched for potential binding sites for all 13 miRNA seed regions with length equals to 8 nucleotides (with different start positions from the 5 ' end). We found that only miRNA seeds from miR396 microRNA family have potential binding sites on LGG lexA sequence as shown in Table 3-5.

Table 3-5: potential Ginger miRNAs targeting lexA gene

\begin{tabular}{ccccc}
\hline miRNA ID & Seed (8mer) & $\begin{array}{c}\text { miRNA seed } \\
\text { start site }\end{array}$ & $\begin{array}{c}\text { Target start } \\
\text { site }\end{array}$ & $\begin{array}{c}\text { length of } \\
\text { transcript }\end{array}$ \\
\hline aly-miR396a-5p & TTTCTTGA & 10 & 427 & 626 \\
gma-miR396e & TTTCTTGA & 10 & 427 & 626
\end{tabular}




\begin{tabular}{ccccc} 
aly-miR396b-5p & TTTCTTGA & 10 & 427 & 626 \\
osa-miR396d & TTTCTTGA & 10 & 427 & 626 \\
gma-miR396h & TTTCTTGA & 9 & 427 & 626 \\
\hline
\end{tabular}

\subsubsection{Computational complexity analysis}

To evaluate the computational complexity of the proposed method, we run our program to search for potential binding sites of nucleotides 10 to 17 ( 8 nucleotides) from the 5 'end of the miRNA sequence in different numbers of human gut bacterial genomes (1 to 8 strains) to see how the program scales with more input sequences. We also used different orders of the Markov chain models $\left(0^{\text {th }}\right.$ to $4^{\text {th }}$ order $)$ to measure the effect of model order on the program performance. Running time was measured using cProfile Python package. For each combination of parameters (number of bacterial genomes and model order), we repeated the experiment 3 times and calculated the average run time. Figure 3-3 shows that running time linearly increases with an increased number of bacterial genomes. Using higher-order Markov chain models to model bacterial sequences slightly increased the run time, $4^{\text {th }}$ order models. 


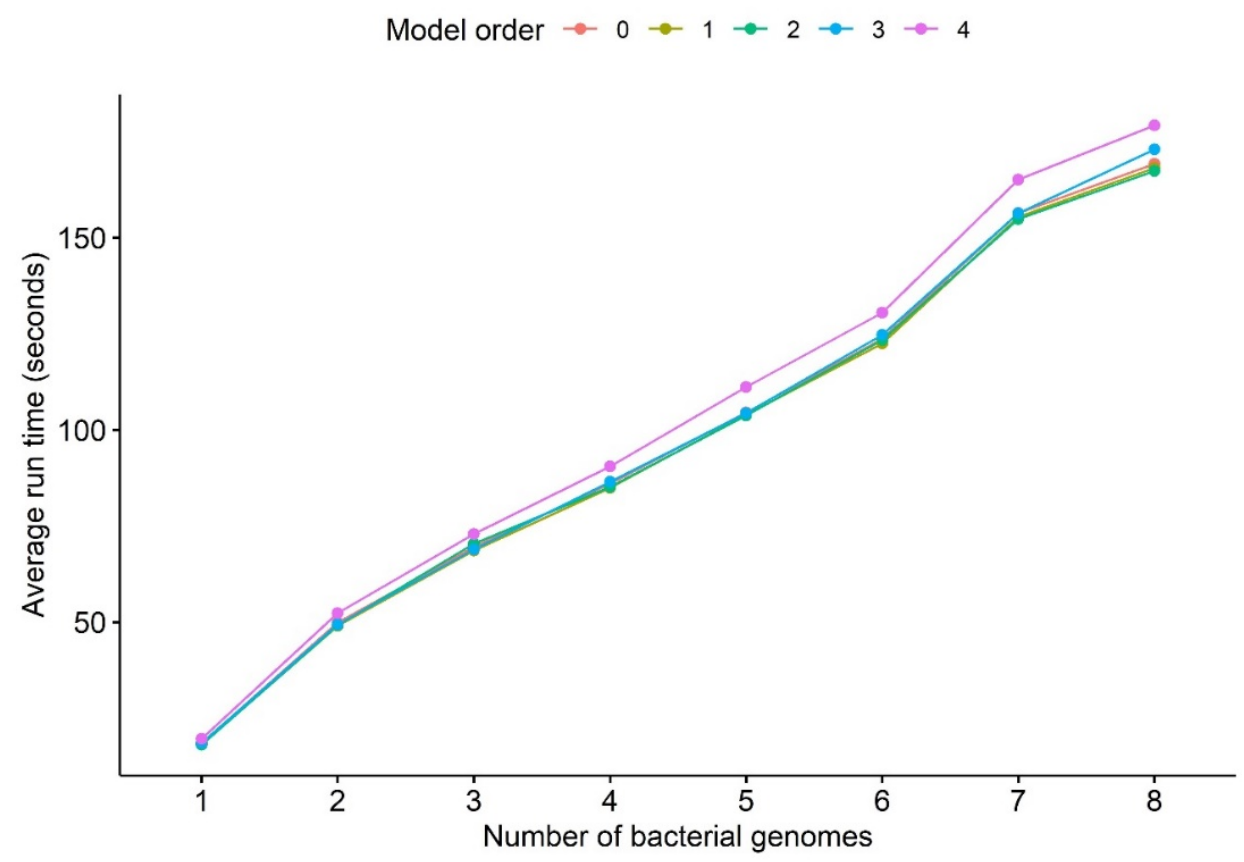

Figure 3-3: Average running time with different number of bacterial genomes and Markov chain model order

We also wanted to measure the effect of the number of input miRNA seeds (query patterns) on the run time of hashing-based pattern searching algorithm. We used different numbers of query patterns ( 1 to 41 miRNA seeds) and different numbers of target sequences ( 1 to 6 bacterial genomes). Note that for this experiment, we only included the pattern searching step and excluded other steps (e.g. counting of the number of hits, enrichment analysis using Markov chain models, and writing results to output files).

Figure 3-4 shows that the average run time of the hashing-based pattern searching method remains almost constant with increasing the number of miRNAs. On the other hand, the run time of the naïve pattern matching algorithm increases linearly with increasing the number of miRNAs. 


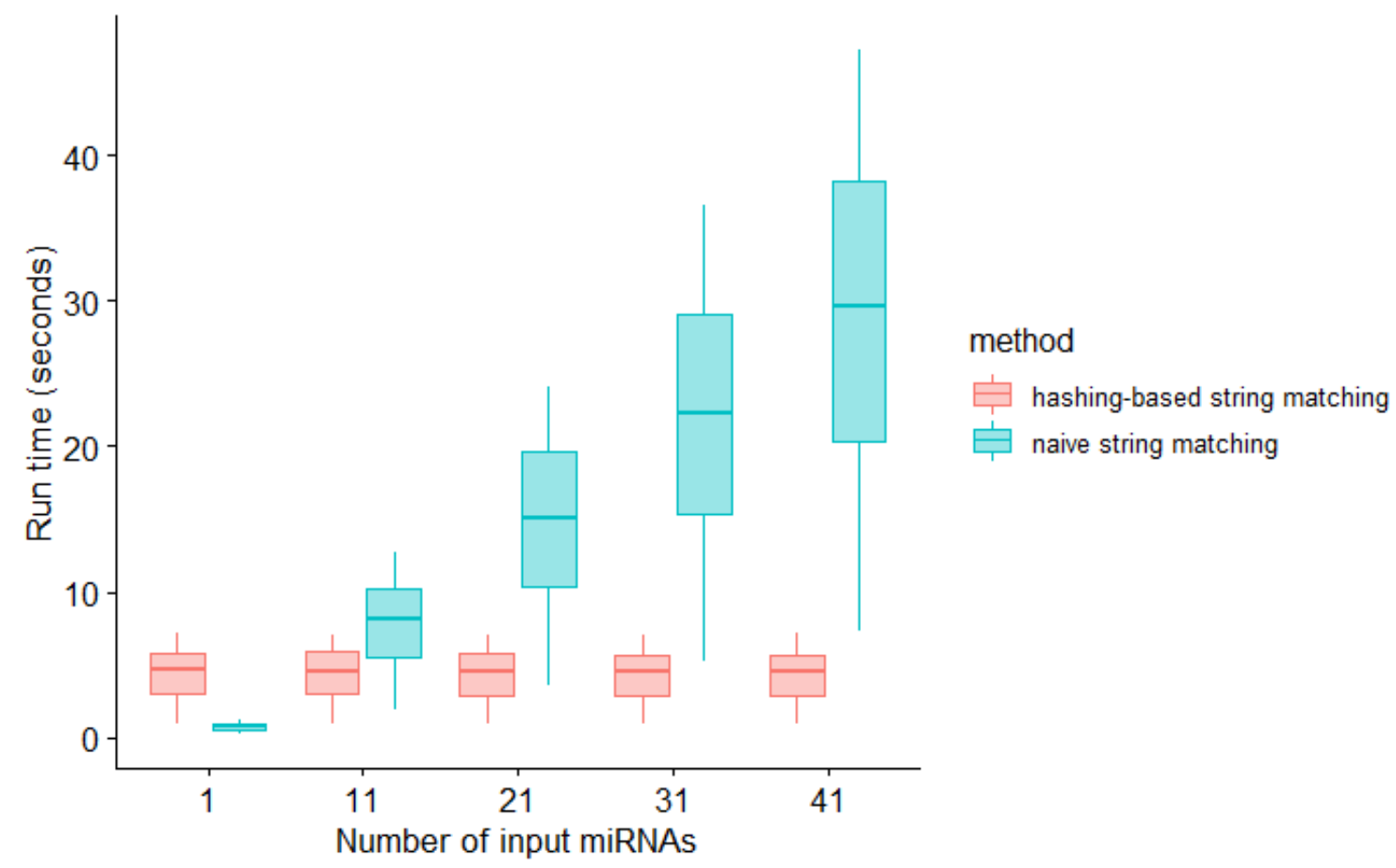

Figure 3-4: hashing-based vs naïve string matching

\subsection{Discussion}

Our results provide a proof of concept of the use of miRNA seed-based targeting mechanism to predict gut bacterial genes targeted by plant miRNAs. We showed that using our tool we can identify ginger miRNAs experimentally validated to target two LGG genes (SpaC and LexA). Although, miRNA targeting mechanism is studied in other species in the case of both miRNAs and target genes belong to the same species e.g. plants and animals, to our knowledge there is no known mechanism for cross-species miRNA targeting. Although this framework was used to predict potential mouse bacterial genes targeted by ginger miRNAs, it can be applied to human gut bacteria and miRNAs from any edible plant. 
In our framework, we employ a seed-based targeting technique in which we perform an overrepresentation analysis of miRNA seed on the target sequence. This approach was first introduced to predict miRNA targets in humans [60] and also used with viral miRNAs [6]. we search for potential binding sites of miRNA seeds of $7 \& 8$ nucleotides long. This is based on previous research by Cisse et. al. [28] that suggests at least seven Watson-Crick base pairs in the miRNA seed region are needed for rapid and effective targeting.

We showed that our computational framework can efficiently find potential target genes and the positions of individual binding sites in up to 8 bacterial genomes (more than 23 million nucleotides) in less than 3 minutes. The run time is a linear function of input size, this is because our framework utilizes hash-table and it takes $\mathrm{O}(\mathrm{n})$ to build the index of target sequences. But once the index is built, one query takes an $\mathrm{O}(\mathrm{m})$ time, where $\mathrm{m}$ is the length of the query pattern (miRNA seed in our case), and since $\mathrm{m}$ is a constant (usually 7 or 8 ), the time complexity of one query can be $\mathrm{O}(1)$.

Although our proposed framework is promising, it has some limitations. Of these, it only takes into sequence information to predict potential binding sites. Other features like conservation, site accessibility can be utilized to increase the accuracy of our predictions. Also, experimentally validating more targets in bacterial genes is essential to accurately validate our framework and to infer the mechanism by which plant miRNAs target gut bacterial genes. 


\subsection{Conclusions}

In this chapter, we proposed a computational framework to efficiently predict potential bacterial genes targeted by plant miRNA. To decrease the computational complexity of our tool, we employed a hash-table-based index to identify and count potential miRNA binding sites. We employed a Markov chain model to quantify how likely we see these binding sites by chance. Our tool successfully predicted ginger miRNAs that target two experimentally validated LGG target genes. Although our tool can be used to predict potential targeting between other plants and bacterial strains, more wet-lab experiments are needed to infer the inter-kingdom miRNA targeting mechanism. 


\section{PATHWAY ANALYSIS OF MICRORNA TARGETS IN ANIMALS}

\subsection{Introduction}

Recent studies have suggested that microRNAs (miRNAs) are involved in many diverse biological processes and pathways including normal development and diseases [61]. Animal miRNAs bind to 3'UTR of mRNAs mainly through the short sequence (6-8 NTs) called seed region and act as repressors of target gene expression [62]. Taking into account this short sequence binding, one miRNA can target hundreds or even thousands of genes and subsequently perturb many biological pathways [38].

To computationally predict miRNA-targeted pathways, typically potential target genes are compiled using one or more miRNA target prediction tools and a standard gene enrichment analysis [4] is used to find potential enriched pathways or gene ontology (GO) terms. Although the conventional pipeline is widely used, it has some limitations. Of these, existing tools consider only direct targets (post-transcriptionally regulated) of miRNAs but do not consider indirect targets (transcriptionally regulated) that are not necessarily enriched in miRNA seed-binding sites [5]. Indirect target genes are mainly regulated transcriptionally through transcription factors (TFs) [63, 64]. Furthermore, a study suggested that TFs are preferentially targeted by miRNAs [65].

Figure 4-1 shows a scenario where a biological pathway/process can be missed by classical miRNA pathway analysis tools. Using the classical method, the percentage of 
targeted genes is $(11 \%)$, on the other hand, if we include TF targets (i.e. indirect targets), the percentage of targeted genes will be (67\%).
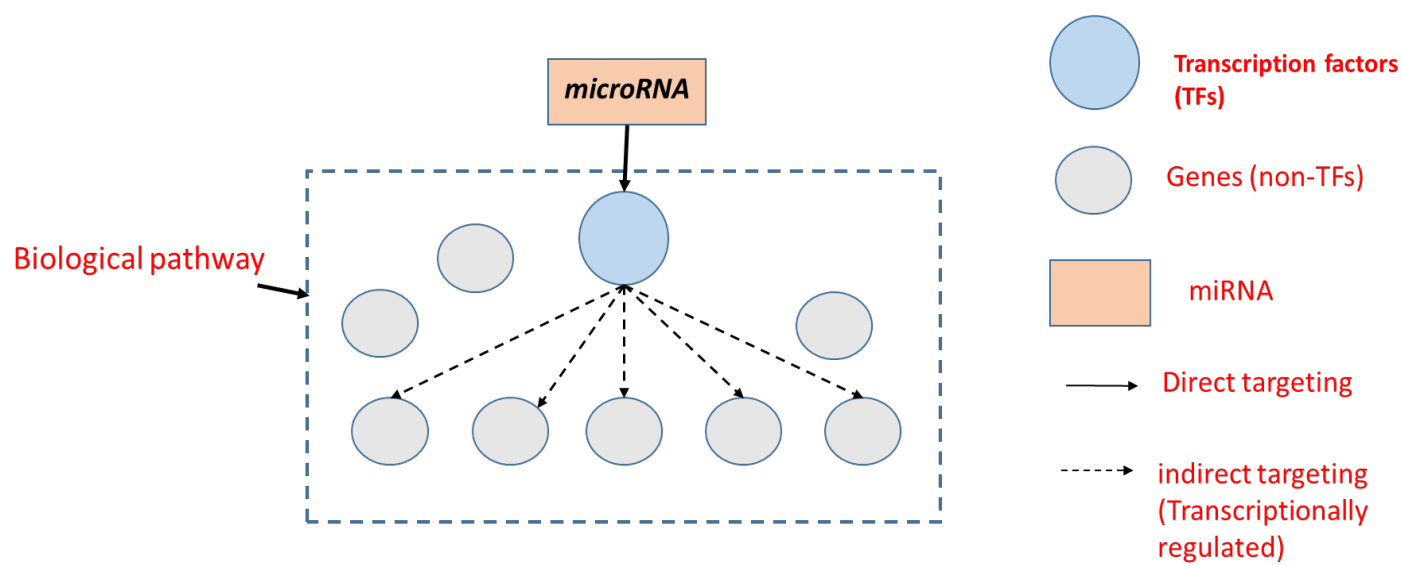

Figure 4-1: miRNAs can indirectly target biological pathways through transcriptions factors

Indirectly regulated genes can be enriched in a specific biological pathway or phenotype. One notable example is the role of miR-200 family and miR-205 in controlling epithelial to mesenchymal transition (EMT) pathway through targeting ZEB1 and $Z E B 2$ transcription factors [66]. Other studies have shown how miRNAs regulate cell differentiation through targeting TFs. Of these, Tay et al [67] demonstrated the role of miR-134 in embryonic stem cell differentiation through targeting Nanog and LRH1. Another study showed that miR-143 and miR-145 can work together to regulate smooth muscle cell differentiation and proliferation through targeting Klf4 and ELK1 transcription factors [68].

Several tools and web servers have been developed to predict potential biological pathways targeted by miRNAs [69-73]. While they are all similar in terms of using direct targets only, they use different databases for both miRNA targets and gene ontology annotations [74-78]. miTALOS [70] is the only tool that filters potential targets by 
incorporating tissue-specific genes. All tools except for StarBase [71] accept multiple miRNAs as input. A comprehensive comparison of widely used miRNA pathway analysis tools is shown in Table 4-1. In this study, we introduce miRinGO (miRNA

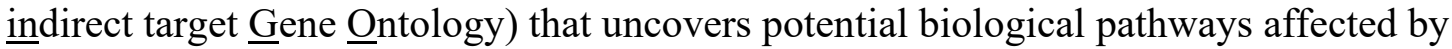
indirect targets of human miRNAs especially ones related to cell differentiation and development.

Table 4-1: A comparison of current tools of miRNAs pathway analysis

\begin{tabular}{|c|c|c|c|c|}
\hline Features/Tools & mirPath v3.0 & StarBase & miTALOS & $\begin{array}{l}\text { miRWalk } \\
\text { v3.0 }\end{array}$ \\
\hline $\begin{array}{c}\text { Predicted targets } \\
\text { databases }\end{array}$ & $\begin{array}{l}\text { TargetScan } \\
\text { (v6) / microT- } \\
\text { CDS (v5.0) }\end{array}$ & $\begin{array}{c}\text { TargetScan / } \\
\text { miRanda/ PITA/ } \\
\text { RNA22/ } \\
\text { PicTar/... }\end{array}$ & $\begin{array}{l}\text { TargetScan/ } \\
\text { miRanda }\end{array}$ & $\begin{array}{l}\text { TargetScan } \\
\text { (v7.1)/ } \\
\text { miRDB }\end{array}$ \\
\hline $\begin{array}{c}\text { Validated targets } \\
\text { databases }\end{array}$ & TarBase v7.0 & CLIP-Seq data & CLIP-Seq data & miRTarbase \\
\hline $\begin{array}{l}\text { Pathways / GO } \\
\text { terms databases }\end{array}$ & $\begin{array}{l}\text { KEGG/GO } \\
\text { categories }\end{array}$ & $\begin{array}{c}\text { KEGG/GO/ } \\
\text { Reactome/ } \\
\text { BioCarta }\end{array}$ & $\begin{array}{c}\text { KEGG/ } \\
\text { WikiPathways/ } \\
\text { Reactome }\end{array}$ & $\begin{array}{l}\text { KEGG/GO/ } \\
\text { Reactome }\end{array}$ \\
\hline $\begin{array}{l}\text { Inclusion of } \\
\text { indirect } \\
\text { targets? }\end{array}$ & No & No & No & No \\
\hline Tissue-specific? & No & No & Yes & No \\
\hline $\begin{array}{l}\text { Allows multiple } \\
\text { miRNAs? }\end{array}$ & Yes & No & Yes & Yes \\
\hline
\end{tabular}




\subsection{Methods}

\subsubsection{Overall pipeline}

Our pipeline to predict indirectly targeted biological processes by miRNAs consists of three steps as depicted in Figure 4-2. First, for each miRNA, potential directly-targeted TFs were compiled from the TargetScan database v7.2 [46]. Second, computationally predicted tissue-specific TF-gene associations were collected from the resources' website of (Sonawane et al., 2017) [79]. In the case of multiple input miRNAs, we use the intersection of indirect targets of each miRNA. Third, a hypergeometric test is conducted to find potential targeted biological processes.

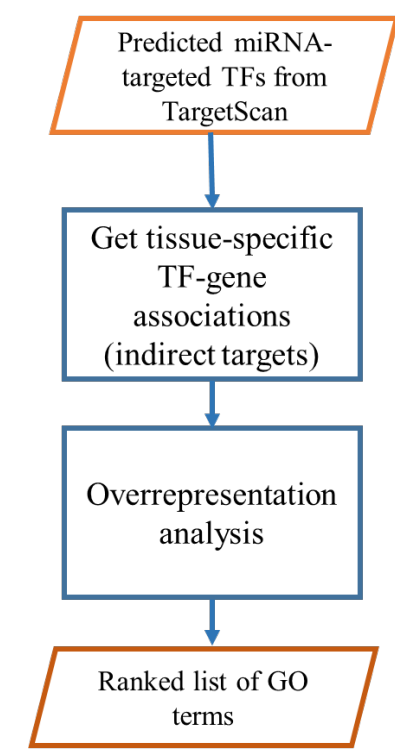

Figure 4-2: Pipeline of our miRNA GO enrichment analysis tool

\subsubsection{Input Data}

Data used by our tool was compiled from publicly available databases. Putative miRNA targets were downloaded from TargetScan v7.2 [46]. We downloaded the file with all predictions regardless of conservation of miRNA family or miRNA binding sites 
and kept high-confidence human miRNA targets (Cumulative weighted context ++ score $<-0.1)$

Computationally predicted tissue-specific TF targets were downloaded from the resources website of (Sonawane et al., 2017) [79]. These TF targets were predicted using the PANDA (Passing Attributes between Networks for Data Assimilation) algorithm [80]. PANDA integrates three complimentary sources of information i.e. TF sequences motif data, protein-protein interactions of TFs, and gene co-expression from GenotypeTissue Expression (GTEx) RNA-Seq data [81]. It contains TF-gene associations from 38 different tissues/tissue locations. We aggregated TF-gene associations from different locations but belong to the same tissue. We had 29 broad tissues after aggregation.

Gene ontology annotations were downloaded using Ensembl Biomart [82] (version GRCh38). GO terms with less than five genes were removed.

\subsubsection{Test dataset}

To validate our method, we used a 'gold standard' dataset of miRNAs and their experimentally validated functions (GO terms) [83] from ftp://ftp.ebi.ac.uk/pub/databases/GO/ goa/HUMAN/goa_human_rna.gaf. We filtered the dataset to include only high confidence annotations (excluded annotations with "Inferred from Sequence or Structural Similarity" (ISS), "Non-traceable Author Statement" (NAS), and "Traceable Author Statement" (TAS) evidence codes). We also removed annotations with no reference article. To keep only relevant annotations, we removed generic GO terms shared by most miRNAs (e.g. "miRNA mediated inhibition of translation", "gene silencing by miRNA" and "gene silencing by $\left.R N A^{\prime \prime}\right)$. Cell/tissue ontology was downloaded from http://www.ontobee.org/listTerms/CL?format=tsv . GO terms with less than five genes were 
removed. The filtered dataset consists of 335 pairs of miRNAs and their associated GO terms and is available in Supplementary Table S1.

\subsection{Results}

\subsubsection{MicroRNA indirect vs direct targeting}

To test the ability of our methodology to predict functions associated with a miRNA, we used a dataset with 335 known miRNA-GO term pairs. All TargetScanpredicted targets were included in this analysis. For each miRNA-GO term pair, resulting GO terms were ranked by the hypergeometric test $p$-value in ascending order, then rank values were converted to a percentile rank by dividing by the total number of GO terms. Finally, we picked the related GO term with the smallest $p$-value (smallest rank value). Known GO terms predicted by the indirect targeting method have a significantly lower (Wilcox signed-rank test, one-sided $p$-value $=0.002417$ ) rank compared to canonical direct targeting as shown in Figure 4-3. 


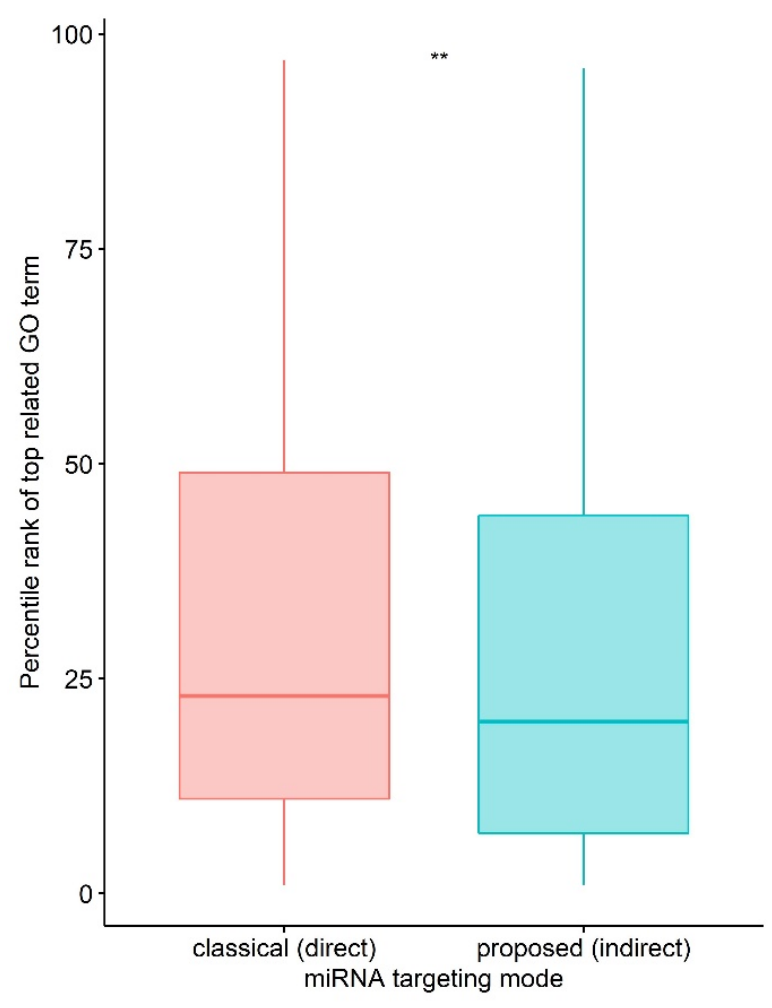

Figure 4-3: Comparison of indirect targeting with direct targeting $\left({ }^{* *}\right.$ represents $p$-value $<$ $0.01)$

\subsubsection{Effect of number of miRNA targets}

Since miRNA GO enrichment analysis is affected by targets of the miRNA and TargetScan-predicted targets can have false positives, we investigated the effect of the number of predicted miRNA targets on predicting the known GO terms. We repeated the same analysis but instead of using all predicted targets, we used top $(20 \%, 40 \%, 60 \%$, $80 \%$ and $100 \%$ ) of potential targets (sorted by TargetScan context++ score [46]). Figure 4-4 shows that in all cases, the average percentile rank of GO terms predicted by IT methodology is lower than DT. Although increasing the number of miRNA targets yielded a lower average rank (better performance), using all of the targets did not give significantly better results compared to using the top $80 \%$ of targets and $40 \%$ of targets in case of indirect and direct targeting respectively. 


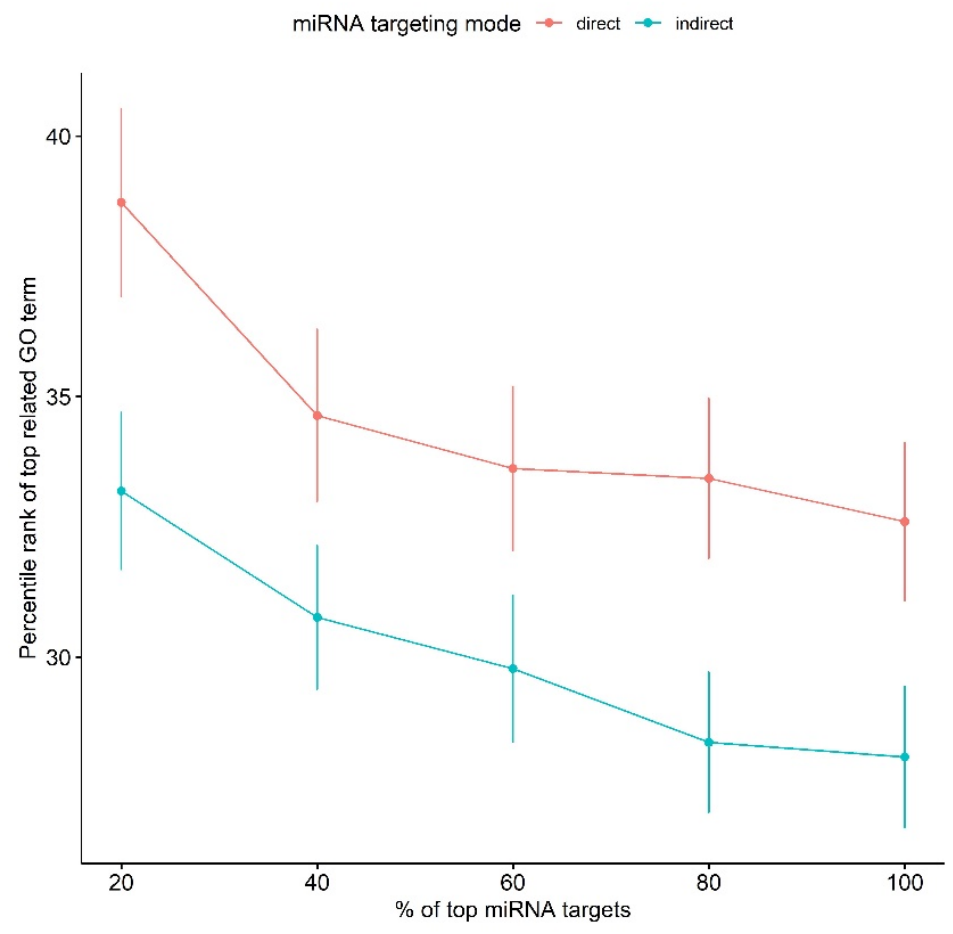

Figure 4-4: Effect of the number of miRNA targets on miRNA GO enrichment analysis. Error bars represent one standard error.

4.3.3 Indirect targeting reveals the role of miRNAs in developmental processes

To investigate biological processes that are more likely to be affected by indirect targeting of miRNAs, we calculated TF density per GO term as defined by equation 1.

$$
T F \text { density }=\frac{\text { number of transcription factors in a GO term }}{\text { total number of genes in a GO term }}
$$

Table 4-2 shows the top 5 GO BP terms with the highest TF density. All these GO terms are related to the "developmental process" and all genes involved are transcription factors.

Table 4-2: Top 5 GO terms with the highest TF density

\begin{tabular}{llll}
\hline GO term ID $\quad$ GO term $\quad$ \# of TFs $\quad$ \# of genes & Parent Process \\
\hline
\end{tabular}




\begin{tabular}{|c|c|c|c|c|}
\hline GO:0001714 & $\begin{array}{l}\text { endodermal cell } \\
\text { fate } \\
\text { specification }\end{array}$ & 5 & 5 & $\begin{array}{c}\text { developmental } \\
\text { process }\end{array}$ \\
\hline GO:0003211 & $\begin{array}{l}\text { cardiac ventricle } \\
\text { formation }\end{array}$ & 5 & 5 & $\begin{array}{c}\text { developmental } \\
\text { process }\end{array}$ \\
\hline GO:0003357 & $\begin{array}{l}\text { noradrenergic } \\
\text { neuron } \\
\text { differentiation }\end{array}$ & 5 & 5 & $\begin{array}{c}\text { developmental } \\
\text { process }\end{array}$ \\
\hline GO:0021520 & $\begin{array}{l}\text { spinal cord } \\
\text { motor neuron } \\
\text { cell fate } \\
\text { specification }\end{array}$ & 7 & 7 & $\begin{array}{c}\text { developmental } \\
\text { process }\end{array}$ \\
\hline GO:0021902 & $\begin{array}{l}\text { commitment of } \\
\text { neuronal cell to } \\
\text { specific neuron } \\
\text { type in forebrain }\end{array}$ & 7 & 7 & $\begin{array}{c}\text { developmental } \\
\text { process }\end{array}$ \\
\hline
\end{tabular}

To see if transcription factors are enriched in development-related GO terms compared to other terms, we divided the GO terms (that have at least one TF) into two groups; one with development-related terms and the second with other terms or processes. We selected development-related terms by searching for GO biological process terms with the following keywords ("development", "cell fate", "differentiation", "stem cell", "morphogenesis", "cell specification", "formation"). Figure 4-5 shows that development-related terms $(n=613)$ tend to have significantly $(p$-value $<2.2 \mathrm{e}-16$, Wilcoxon rank-sum test) higher TF density compared to other terms $(n=1767)$. 


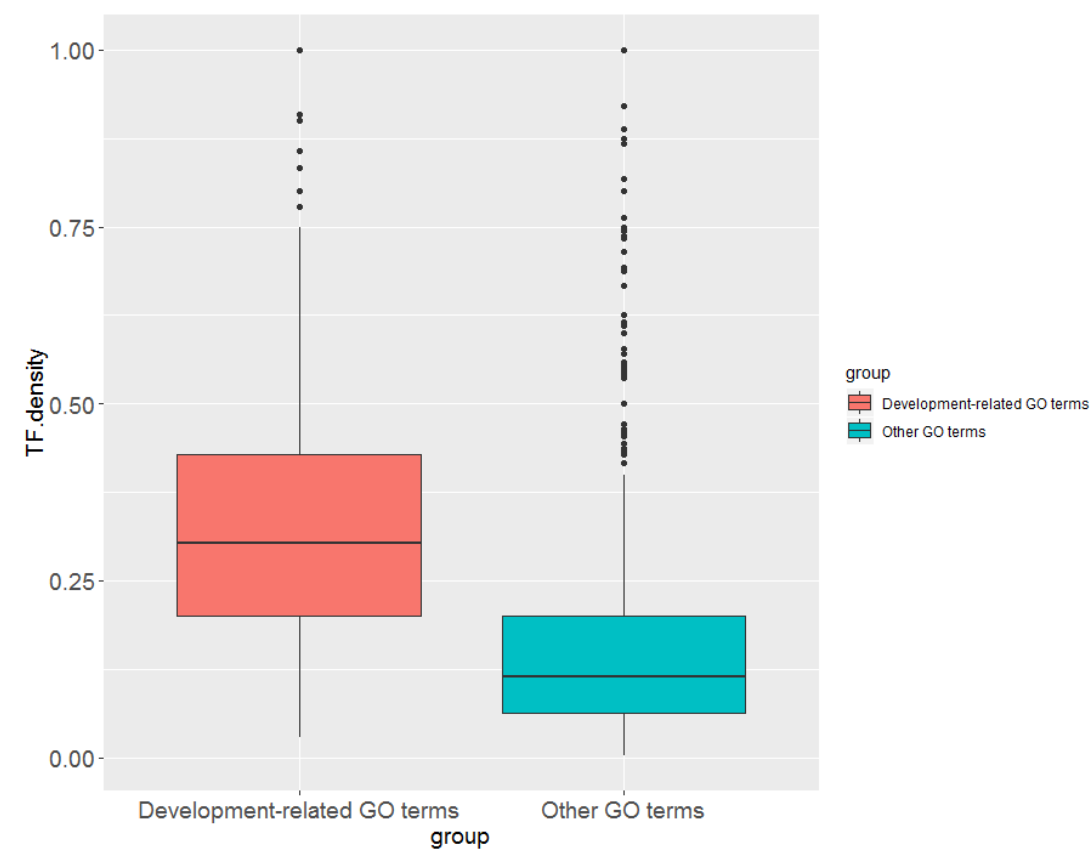

Figure 4-5: Comparison of TF density in development-related GO terms vs. all other terms

\subsubsection{Case Study: role of miR-9 in Neurogenesis}

To test the ability of our tool to capture relevant targeted development-related GO terms, we picked a miRNA with a known function to be able to compare our predicted GO terms with known ones. Of these miRNAs, miR-9 is a brain-enriched miRNA and has a prominent role in neurogenesis [84-86]. We ran our tool with the following inputs, we selected "brain" as the tissue type, "biological process" as the GO category, "indirect" as the targeting mode, and " 100 " as the percentage of miRNA targets. Two out of the top 5 GO terms predicted are related to neurogenesis ("Nervous system development" and "brain development").

To compare our results with existing miRNA pathway analysis tools, we downloaded predicted GO biological process terms for "miR-9" from 4 different web servers (accessed January 15, 2019): mirPath v3.0 [69], StarBase (mirTarPathway 
module) v3.0 [71], miTALOS v2 [70] and miRWalk v3.0 [72]. We searched for the highest-ranking GO term related to neurogenesis as shown in Table 4-3. Our tool ranked neurogenesis-related GO terms higher than other tools.

Table 4-3: Comparison of highest-ranking GO terms related to neurogenesis from different miRNA GO enrichment tools

\begin{tabular}{ccc}
\hline Tool & $\begin{array}{c}\text { Highest ranking GO term related to } \\
\text { Neurogenesis }\end{array}$ & Rank \\
\hline miRinGO & Nervous system development & 1 \\
mirPath v3 & regulation of neuron maturation & 11 \\
miRWalk v3 & axonogenesis & 13 \\
StarBase v3 & Neurogenesis & 23 \\
miTALOS v2 & N/A & N/A \\
\hline
\end{tabular}

\subsubsection{Multiple miRNAs GO analysis}

In all miRNA GO analyses so far, we have used one miRNA as an input. Several studies have shown that miRNAs can work together to regulate certain targets and biological processes [87]. Of these, Gregory et al. [66] showed that the miR-200 family and miR-205 together regulate epithelial to mesenchymal transition (EMT). The miR-200 family consists of miRNAs with two different seed sequences: miR-200a/miR-141 and miR-200b/miR-200c/miR-429. We ran our tool with the following inputs: "kidney" as the tissue type, "biological process" as the GO category, and "indirect" as the targeting mode and " 100 " as the percentage of miRNA targets. The rank of "epithelial to mesenchymal transition" GO term (GO: 0001837) was lower when we used the intersection of indirect 
targets of these three miRNAs compared to ranks of GO terms predicted by each miRNA indirect targets as shown in Table 4-4.

Table 4-4: Effect of using multiple miRNAs in capturing EMT-related GO terms

\begin{tabular}{cc}
\hline miRNAs & $\begin{array}{c}\text { Rank of top GO } \\
\text { term related to } \\
\text { EMT }\end{array}$ \\
\hline miR-200a/miR-141 & 132 \\
miR-200b/miR-200c/miR-429 & 147 \\
miR-205-5p & 105 \\
All three miRNAs & 70 \\
\hline
\end{tabular}

\subsubsection{R Shiny Application}

For ease of use of our method by researchers, we developed an interactive web application, miRin $G O$, using R Shiny package [7]. It is freely available from GitHub at https://github.com/Fadeel/miRinGO. A screenshot of the application is shown in Figure 4-6.

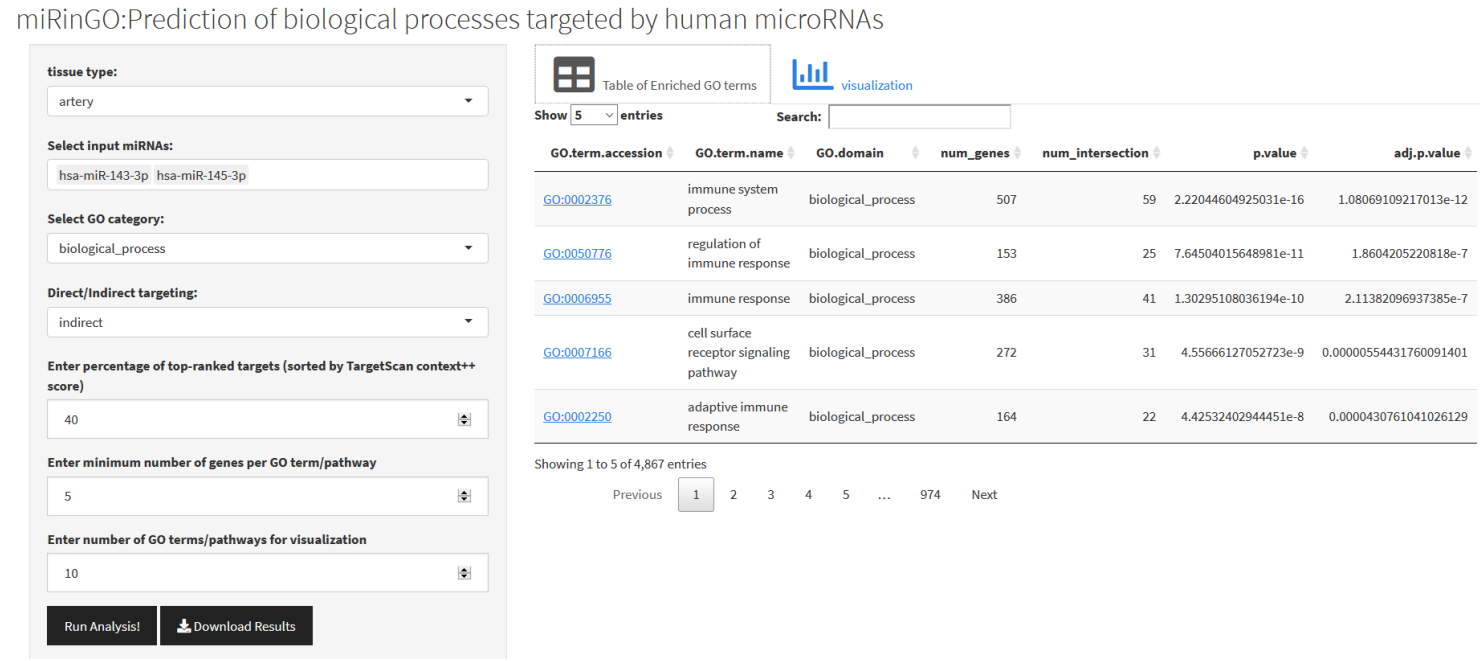

Figure 4-6: A screenshot of the R Shiny application (miRinGO) 
The application has two panels, the left one for input data and parameters

selection. A description of different input parameters and possible values is detailed in

Table 4-5.

Table 4-5: A description of different parameters of the Shiny application

\begin{tabular}{|c|c|c|}
\hline Parameter & Description & Possible values \\
\hline Tissue type & 29 different tissues & Brain, colon, lung, ... \\
\hline input miRNAs & miRBase miRNA ID & $h s a-m i R-9-5 p$ \\
\hline GO category & $\begin{array}{l}\text { Choose the category of GO } \\
\text { annotation }\end{array}$ & $\begin{array}{l}\text { Biological process OR cellular } \\
\text { component OR molecular function }\end{array}$ \\
\hline Targeting mode & $\begin{array}{l}\text { Choose mode of miRNA } \\
\text { targeting }\end{array}$ & Direct OR indirect \\
\hline $\begin{array}{c}\text { Percentage of TargetScan } \\
\text { target genes }\end{array}$ & $\begin{array}{c}\text { percentage of top-ranked } \\
\text { targeted genes ( } \text { sorted by } \\
\text { TargetScan } \mathrm{v} 7.2 \text { context }++ \text { score) }\end{array}$ & {$[20 \%-100 \%]$, step size $20 \%$} \\
\hline $\begin{array}{l}\text { minimum number of } \\
\text { genes per GO term }\end{array}$ & $\begin{array}{l}\text { A threshold to filter out GO } \\
\text { terms with small number of genes }\end{array}$ & $\begin{array}{l}\text { Integer value } \\
\text { (default value is } 5 \text { ) }\end{array}$ \\
\hline $\begin{array}{l}\text { number of GO terms for } \\
\text { visualization }\end{array}$ & $\begin{array}{l}\text { Top k enriched GO terms to be } \\
\text { visualized }\end{array}$ & $\begin{array}{l}\text { Integer value } \\
\text { (default value is } 10)\end{array}$ \\
\hline
\end{tabular}

The right panel has two tabs for showing the results of GO enrichment analysis. One tab named "Table of Enriched GO term" to show GO terms more likely to be targeted by selected miRNAs and ranked by the hypergeometric p-value. The table includes information about GO term, number of genes in that term, number of potential miRNA targets that overlap with genes in this term, hypergeometric $\mathrm{p}$-value, and the Benjamini \& Hochberg [57] adjusted p-value. To get more details about a specific GO term, GO term accession numbers are linked to their QuickGO [88] webpages. 
The other tab named "visualization" provides a visual summary of the enriched GO term. It contains a bar plot with bar height represents the -log10(adjusted p-value) and bar color represents the proportion of potential target genes out of the total number of genes in that GO term. Bar plot of top $15 \mathrm{GO}$ terms indirectly targeted by miR-9-5p in the brain is shown in Figure 4-7.

田

III visualization

\section{Bar plot}

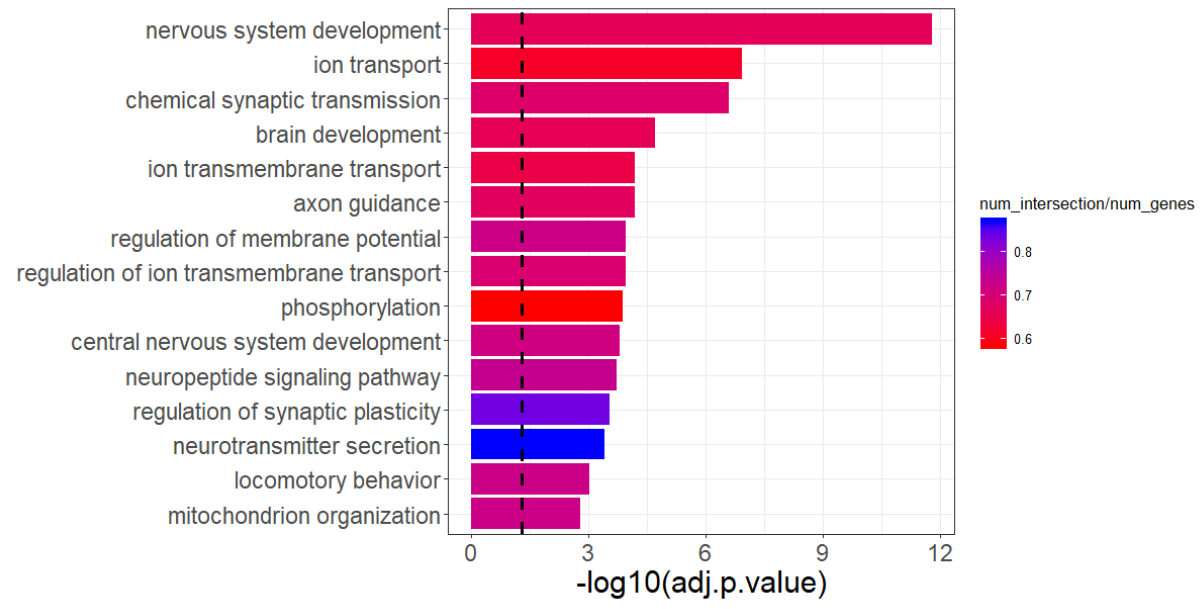

Figure 4-7: Bar plot of top $15 \mathrm{GO}$ terms indirectly targeted by miR-9-5p in brain miRinGO also provides a visual summary of the top enriched GO terms as WordCloud. To generate the WordCloud, we need to find high-frequency words. First, top enriched GO terms are preprocessed to remove punctuation, numbers, English stop words, and common biological terms (process, cell, miRNA). We used "tm" R package [89] for text preprocessing steps. A snapshot of the WordCloud of top 30 enriched GO terms predicted to be indirectly targeted by miR-16 in the colon is shown in Figure 4-8. We can see that words like mitotic, cycle, segregation, and division are related to cell 
cycle. Linsley et. al, had previously shown that overexpression of miR-16 family in HCT116 (human colorectal carcinoma) cell lines regulates cell cycle progression [5].

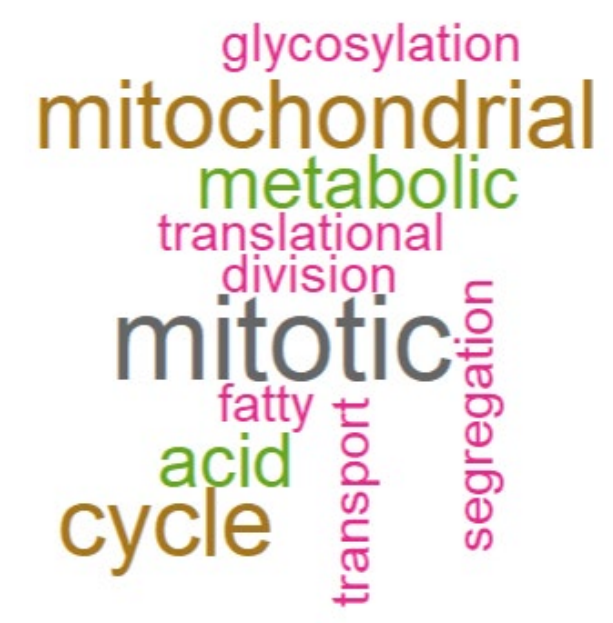

Figure 4-8: WordCloud of top 30 enriched GO terms predicted to be indirectly targeted by miR-16 in the colon

\subsection{Discussion}

We propose, miRinGO, a tool that detects biological processes indirectly targeted by miRNAs transcriptionally through transcription factors. Using miRinGO, we can include potential target genes even if there is no physical interaction between miRNA and the regulated genes. To validate this method, we used a dataset of miRNAs and their known targeted GO terms [83]. Although this dataset is considered a significant step towards having a gold standard to validate different miRNA pathway or GO analysis tools, it is still limited to a fraction of human miRNAs and focused more on cardiovascular-related processes. Using this dataset, however, indirect targeting showed better performance in predicting known targeted processes compared to the direct targeting method, even if we use different fractions of input miRNA targets. It is also worth noting that although increasing the number of miRNA targets yielded better 
performance, using all of the targets did not give significantly better results compared to using the top $80 \%$ of targets and $40 \%$ of targets in case of indirect and direct targeting, respectively. This could be because miRNA target prediction tools suffer from having many false positives [90].

Since our method is mainly focused on miRNA-targeted TFs and developmentrelated GO terms or pathways have more TFs than other terms, it is more suitable to use this tool to uncover the tissue-specific roles of miRNAs in development and cell differentiation. Using this method, we predicted biological pathways known to be targeted by miR-9, a miRNA with a known role in neurogenesis. Tan et al. [91] showed that miR-9 regulates neural stem cell differentiation and proliferation by targeting HESI transcription factor. Using indirect targeting, three genes related to neuron differentiation (FEZF2, SOX3, and ZHX2) that are predicted to be targeted by HES1 (but are not direct targets of miR-9-5p) are now included in GO enrichment analysis as indirect targets of miR-9-5p.

One limitation of our method is that we use two sets of computationally predicted targets: one for miRNA direct targets and the other for tissue-specific TF targets. This might increase the effect of false positives in miRNA GO enrichment analysis. This limitation can be partly alleviated by using only high-confidence miRNA targets (i.e. ones with smaller TargetScan context ++ score). Although our method outperformed the current miRNA GO analysis method, it is not intended to replace the standard miRNA GO analysis method but on the other hand, to give a different perspective of miRNA roles in regulating biological processes and to uncover ones that are previously 
overlooked by current tools, especially ones related to development and cell differentiation.

\subsection{Conclusions}

Although miRNAs have emerged as important players in gene regulation, the field still lacks computational tools and methods that can predict their functions accurately. We propose a method to predict biological processes that are indirectly targeted by miRNAs transcriptionally through transcription factors. The proposed method provided better performance compared to the existing method. We also developed an interactive web application to make it easier for researchers to investigate the function of miRNA(s) of choice. 


\section{SUMMARY AND FUTURE WORK}

Given the recent advances in DNA/RNA sequencing, new genes/transcripts are being discovered and the need to assign functions to these genes grows. Of these genes, miRNAs are non-protein-coding genes and act as regulators of gene expression of other genes. Recent studies have suggested that miRNAs have a role in many biological processes e.g., cell cycle, proliferation, and development. Moreover, miRNAs may function as tumor suppressors and oncogene. Current experimental techniques for discovering miRNA target genes are either low throughput, costly, or suffer from high false-positive rates. For the above reasons, computational tools are needed to predict targeted genes and ultimately targeted biological processes.

In the first part of this dissertation, we developed a tool to predict gut bacterial genes potentially targeted by miRNAs from edible plants like ginger. To our knowledge, it is the only known tool dedicated to inter-kingdom miRNA targeting. Although we were able to correctly predict ginger miRNAs targeting two bacterial genes, there is still a need in the future for more experimentally validated targets to get a better idea regarding interkingdom targeting mechanisms.

Although this tool can find potential target genes of 49 miRNAs in eight different bacterial genomes in less than three minutes, there is still room to improve the scalability of this tool in the future. For instance, we use an integer representation of miRNA seed 
sequences ( 8 nucleotides) which requires 28 bytes in Python 3 . This can be reduced by taking advantage of the fact that DNA/RNA sequences have 4 letters, and each nucleotide can be represented by 2 bits. Using this representation, miRNA seed regions can be represented as a vector of 16 bits ( 2 bytes).

In the second part, we addressed the problem of functional annotation of human miRNAs. Current tools consider only target genes with binding sites. To address this limitation, we developed $\operatorname{miRinGO}$, an R Shiny web application that allows researchers to include other indirect target genes e.g., genes regulated through transcription factors. Indirect targeting showed better performance compared to direct targeting in predicting known miRNA-biological process associations. $\operatorname{miRin} G O$ provides an easy-to-use GUI for researchers with no coding experience to explore potential functions of over 2,000 miRNAs in 38 tissues. Moreover, it provides visual summaries of the results. miRinGO is available at https://github.com/Fadeel/miRinGO. Potential future work includes supporting miRNAs from other species e.g. mouse and giving the user the ability to filter target genes based on the existing experimental evidence. 


\section{REFERENCES}

[1] G. Raposo, and W. Stoorvogel, "Extracellular vesicles: exosomes, microvesicles, and friends," J Cell Biol, vol. 200, no. 4, pp. 373-383, 2013.

[2] H. Zhang, Y. Li, Y. Liu, H. Liu, H. Wang, W. Jin, Y. Zhang, C. Zhang, and D. $\mathrm{Xu}$, "Role of plant MicroRNA in cross-species regulatory networks of humans," BMC systems biology, vol. 10, no. 1, pp. 60, 2016.

[3] S. Liu, A. P. da Cunha, R. M. Rezende, R. Cialic, Z. Wei, L. Bry, L. E. Comstock, R. Gandhi, and H. L. Weiner, "The host shapes the gut microbiota via fecal microRNA," Cell host \& microbe, vol. 19, no. 1, pp. 32-43, 2016.

[4] D. W. Huang, B. T. Sherman, and R. A. Lempicki, "Systematic and integrative analysis of large gene lists using DAVID bioinformatics resources," Nature protocols, vol. 4, no. 1, pp. 44, 2008.

[5] P. S. Linsley, J. Schelter, J. Burchard, M. Kibukawa, M. M. Martin, S. R. Bartz, J. M. Johnson, J. M. Cummins, C. K. Raymond, and H. Dai, "Transcripts targeted by the microRNA-16 family cooperatively regulate cell cycle progression," Molecular and cellular biology, vol. 27, no. 6, pp. 2240-2252, 2007.

[6] E. Murphy, J. Vaníček, H. Robins, T. Shenk, and A. J. Levine, "Suppression of immediate-early viral gene expression by herpesvirus-coded microRNAs: implications for latency," Proceedings of the National Academy of Sciences, vol. 105, no. 14, pp. 5453-5458, 2008.

[7] C. J. Chang W, Allaire JJ, Xie Y, McPherson J, "shiny: Web Application Framework for R," R package 2019.

[8] B. Alberts, Molecular Biology of the Cell: W.W. Norton, 2017.

[9] A. Zien, "A primer on molecular biology," pp. 3-34, 2004.

[10] C. M. O'Connor, J. U. Adams, and J. J. C. Fairman, MA: NPG Education, "Essentials of cell biology," vol. 1, pp. 54, 2010.

[11] "Cell Types," https://en.wikipedia.org/wiki/File:Celltypes.svg.

[12] L. J. N. E. Pray, "Discovery of DNA structure and function: Watson and Crick," vol. 1, no. 1, 2008.

[13] "Protein function," https://www.nature.com/scitable/topicpage/protein-function14123348/.

[14] F. H. Crick, "On protein synthesis." p. 8.

[15] S. Clancy, and W. Brown, "Translation: DNA to mRNA to," Nature Education, 2008.

[16] L. J. A. i. Hunter, and m. biology, "Molecular biology for computer scientists," pp. 1-46, 1993.

[17] "What is Epigenetics?," https://www.cdc.gov/genomics/disease/epigenetics.htm. 
[18] "Epigenetic mechanisms,"

https://commons.wikimedia.org/w/index.php?title=File:Epigenetic_mechanisms.j pg\&oldid $=508703722$.

[19] D. S. Latchman, "Transcription factors: an overview," vol. 29, no. 12, pp. 13051312, 1997.

[20] "Transcription Factors," https://en.wikipedia.org/wiki/File:Transcription_Factors.svg.

[21] D. Most, L. Ferguson, and R. A. Harris, "Chapter 6 - Molecular basis of alcoholism," Handbook of Clinical Neurology, E. V. Sullivan and A. Pfefferbaum, eds., pp. 89-111: Elsevier, 2014.

[22] "Alternative Splicing," 03/06, 2021; https://en.wikipedia.org/wiki/File:DNA_alternative_splicing.gif.

[23] R. C. Lee, R. L. Feinbaum, and V. J. c. Ambros, "The C. elegans heterochronic gene lin-4 encodes small RNAs with antisense complementarity to lin-14," vol. 75 , no. 5 , pp. 843-854, 1993.

[24] B. Wightman, I. Ha, and G. J. C. Ruvkun, "Posttranscriptional regulation of the heterochronic gene lin-14 by lin-4 mediates temporal pattern formation in $\mathrm{C}$. elegans," vol. 75, no. 5, pp. 855-862, 1993.

[25] J. O'Brien, H. Hayder, Y. Zayed, and C. J. F. i. e. Peng, "Overview of microRNA biogenesis, mechanisms of actions, and circulation," vol. 9, pp. 402, 2018.

[26] J. G. Ruby, C. H. Jan, and D. P. J. N. Bartel, "Intronic microRNA precursors that bypass Drosha processing," vol. 448, no. 7149, pp. 83-86, 2007.

[27] "File:MicroRNA biogenesis.jpg," https://commons.wikimedia.org/wiki/File:MicroRNA_biogenesis.jpg.

[28] I. I. Cisse, H. Kim, and T. Ha, "A rule of seven in Watson-Crick base-pairing of mismatched sequences," Nature structural \& molecular biology, vol. 19, no. 6, pp. 623-627, 2012.

[29] L. M. Wee, C. F. Flores-Jasso, W. E. Salomon, and P. D. Zamore, "Argonaute divides its RNA guide into domains with distinct functions and RNA-binding properties," Cell, vol. 151, no. 5, pp. 1055-1067, 2012.

[30] W. E. Salomon, S. M. Jolly, M. J. Moore, P. D. Zamore, and V. Serebrov, "Single-molecule imaging reveals that argonaute reshapes the binding properties of its nucleic acid guides," Cell, vol. 162, no. 1, pp. 84-95, 2015.

[31] J. P. Broughton, M. T. Lovci, J. L. Huang, G. W. Yeo, and A. E. Pasquinelli, "Pairing beyond the seed supports microRNA targeting specificity," Molecular cell, vol. 64, no. 2, pp. 320-333, 2016.

[32] S. D. Chandradoss, N. T. Schirle, M. Szczepaniak, I. J. MacRae, and C. Joo, "A dynamic search process underlies microRNA targeting," Cell, vol. 162, no. 1, pp. 96-107, 2015.

[33] T. Saito, and P. Sætrom, "MicroRNAs-targeting and target prediction," New biotechnology, vol. 27, no. 3, pp. 243-249, 2010.

[34] X. Li, H. Kazan, H. D. Lipshitz, and Q. D. Morris, "Finding the target sites of RNA-binding proteins," Wiley Interdisciplinary Reviews: RNA, vol. 5, no. 1, pp. 111-130, 2014. 
[35] R. Aguirre-Hernández, H. H. Hoos, and A. Condon, "Computational RNA secondary structure design: empirical complexity and improved methods," $B M C$ bioinformatics, vol. 8, no. 1, pp. 34, 2007.

[36] T. Bradley, and S. Moxon, "An Assessment of the Next Generation of Animal miRNA Target Prediction Algorithms," MicroRNA Detection and Target Identification: Methods and Protocols, pp. 175-191, 2017.

[37] X. Fan, and L. Kurgan, "Comprehensive overview and assessment of computational prediction of microRNA targets in animals," Briefings in bioinformatics, vol. 16, no. 5, pp. 780-794, 2014.

[38] R. C. Friedman, K. K.-H. Farh, C. B. Burge, and D. P. Bartel, "Most mammalian mRNAs are conserved targets of microRNAs," Genome research, vol. 19, no. 1, pp. 92-105, 2009.

[39] D. Grün, Y.-L. Wang, D. Langenberger, K. C. Gunsalus, and N. Rajewsky, "microRNA target predictions across seven Drosophila species and comparison to mammalian targets," PLoS computational biology, vol. 1, no. 1, pp. e13, 2005.

[40] M. D. Paraskevopoulou, G. Georgakilas, N. Kostoulas, I. S. Vlachos, T. Vergoulis, M. Reczko, C. Filippidis, T. Dalamagas, and A. G. Hatzigeorgiou, "DIANA-microT web server v5. 0: service integration into miRNA functional analysis workflows," Nucleic acids research, vol. 41, no. W1, pp. W169-W173, 2013.

[41] D. Betel, A. Koppal, P. Agius, C. Sander, and C. Leslie, "Comprehensive modeling of microRNA targets predicts functional non-conserved and noncanonical sites," Genome biology, vol. 11, no. 8, pp. R90, 2010.

[42] D. Gaidatzis, E. van Nimwegen, J. Hausser, and M. Zavolan, "Inference of miRNA targets using evolutionary conservation and pathway analysis," $B M C$ bioinformatics, vol. 8, no. 1, pp. 69, 2007.

[43] X. Wang, and I. M. El Naqa, "Prediction of both conserved and nonconserved microRNA targets in animals," Bioinformatics, vol. 24, no. 3, pp. 325-332, 2007.

[44] C. E. Vejnar, and E. M. Zdobnov, "MiRmap: comprehensive prediction of microRNA target repression strength," Nucleic acids research, vol. 40, no. 22, pp. 11673-11683, 2012.

[45] A. C. Oliveira, L. A. Bovolenta, P. G. Nachtigall, M. E. Herkenhoff, N. Lemke, and D. Pinhal, "Combining results from distinct microRNA target prediction tools enhances the performance of analyses," Frontiers in genetics, vol. 8, 2017.

[46] V. Agarwal, G. W. Bell, J.-W. Nam, and D. P. Bartel, "Predicting effective microRNA target sites in mammalian mRNAs," elife, vol. 4, pp. e05005, 2015.

[47] M. Kertesz, N. Iovino, U. Unnerstall, U. Gaul, and E. Segal, "The role of site accessibility in microRNA target recognition," Nature genetics, vol. 39, no. 10, pp. 1278-1284, 2007.

[48] K. C. Miranda, T. Huynh, Y. Tay, Y.-S. Ang, W.-L. Tam, A. M. Thomson, B. Lim, and I. Rigoutsos, "A pattern-based method for the identification of MicroRNA binding sites and their corresponding heteroduplexes," Cell, vol. 126, no. 6, pp. 1203-1217, 2006.

[49] R. Gumienny, and M. Zavolan, "Accurate transcriptome-wide prediction of microRNA targets and small interfering RNA off-targets with MIRZA-G," Nucleic acids research, vol. 43, no. 3, pp. 1380-1391, 2015. 
[50] H. Liang, K. Zen, J. Zhang, C.-Y. Zhang, and X. Chen, "New roles for microRNAs in cross-species communication," RNA biology, vol. 10, no. 3, pp. 367-370, 2013.

[51] W. D. Branton, E. Mayeri, P. Brownell, and S. B. Simon, "Evidence for local hormonal communication between neurones in Aplysia," Nature, vol. 274, no. 5666, pp. 70-72, 1978.

[52] L. Zhang, D. Hou, X. Chen, D. Li, L. Zhu, Y. Zhang, J. Li, Z. Bian, X. Liang, and X. Cai, "Exogenous plant MIR168a specifically targets mammalian LDLRAP1: evidence of cross-kingdom regulation by microRNA," Cell research, vol. 22, no. 1, pp. 107-126, 2012.

[53] G. LaMonte, N. Philip, J. Reardon, J. R. Lacsina, W. Majoros, L. Chapman, C. D. Thornburg, M. J. Telen, U. Ohler, and C. V. Nicchitta, "Translocation of sickle cell erythrocyte microRNAs into Plasmodium falciparum inhibits parasite translation and contributes to malaria resistance," Cell host \& microbe, vol. 12, no. 2, pp. 187-199, 2012.

[54] E. Gottwein, N. Mukherjee, C. Sachse, C. Frenzel, W. H. Majoros, J.-T. A. Chi, R. Braich, M. Manoharan, J. Soutschek, and U. Ohler, "A viral microRNA functions as an orthologue of cellular miR-155," Nature, vol. 450, no. 7172, pp. 1096-1099, 2007.

[55] C. L. Jopling, M. Yi, A. M. Lancaster, S. M. Lemon, and P. Sarnow, "Modulation of hepatitis C virus RNA abundance by a liver-specific MicroRNA," science, vol. 309, no. 5740, pp. 1577-1581, 2005.

[56] K. D. Pruitt, T. Tatusova, and D. R. Maglott, "NCBI reference sequences (RefSeq): a curated non-redundant sequence database of genomes, transcripts and proteins," Nucleic acids research, vol. 35, no. suppl 1, pp. D61-D65, 2007.

[57] Y. Benjamini, and Y. J. J. o. t. R. s. s. s. B. Hochberg, "Controlling the false discovery rate: a practical and powerful approach to multiple testing," vol. 57, no. 1, pp. 289-300, 1995.

[58] R. Lowry, S. Balboa, J. L. Parker, and J. G. Shaw, "Aeromonas flagella and colonisation mechanisms," Advances in microbial physiology, pp. 203-256: Elsevier, 2014.

[59] Y. Teng, Y. Ren, M. Sayed, X. Hu, C. Lei, A. Kumar, E. Hutchins, J. Mu, Z. Deng, and C. Luo, "Plant-derived exosomal MicroRNAs shape the gut microbiota," Cell host \& microbe, vol. 24, no. 5, pp. 637-652. e8, 2018.

[60] H. Robins, and W. H. J. P. o. t. N. A. o. S. Press, "Human microRNAs target a functionally distinct population of genes with AT-rich 3' UTRs," vol. 102, no. 43, pp. 15557-15562, 2005.

[61] J. A. Vidigal, and A. Ventura, "The biological functions of miRNAs: lessons from in vivo studies," Trends in cell biology, vol. 25, no. 3, pp. 137-147, 2015.

[62] Y. Tomari, and P. D. Zamore, "Perspective: machines for RNAi," Genes Dev, vol. 19, no. 5, pp. 517-29, Mar 1, 2005.

[63] C. P. Bracken, H. S. Scott, and G. J. Goodall, "A network-biology perspective of microRNA function and dysfunction in cancer," Nature Reviews Genetics, vol. 17, no. 12, pp. 719, 2016.

[64] S. J. Gosline, A. M. Gurtan, C. K. JnBaptiste, A. Bosson, P. Milani, S. Dalin, B. J. Matthews, Y. S. Yap, P. A. Sharp, and E. J. C. r. Fraenkel, "Elucidating 
microRNA regulatory networks using transcriptional, post-transcriptional, and histone modification measurements," vol. 14, no. 2, pp. 310-319, 2016.

[65] R. Shalgi, D. Lieber, M. Oren, and Y. J. P. c. b. Pilpel, "Global and local architecture of the mammalian microRNA-transcription factor regulatory network," vol. 3, no. 7, pp. e131, 2007.

[66] P. A. Gregory, A. G. Bert, E. L. Paterson, S. C. Barry, A. Tsykin, G. Farshid, M. A. Vadas, Y. Khew-Goodall, and G. J. J. N. c. b. Goodall, "The miR-200 family and miR-205 regulate epithelial to mesenchymal transition by targeting ZEB1 and SIP1," vol. 10, no. 5, pp. 593-601, 2008.

[67] Y. Tay, J. Zhang, A. M. Thomson, B. Lim, and I. J. N. Rigoutsos, "MicroRNAs to Nanog, Oct4 and Sox 2 coding regions modulate embryonic stem cell differentiation," vol. 455, no. 7216, pp. 1124-1128, 2008.

[68] K. R. Cordes, N. T. Sheehy, M. P. White, E. C. Berry, S. U. Morton, A. N. Muth, T.-H. Lee, J. M. Miano, K. N. Ivey, and D. J. N. Srivastava, "miR-145 and miR143 regulate smooth muscle cell fate and plasticity," vol. 460, no. 7256, pp. 705, 2009.

[69] I. S. Vlachos, K. Zagganas, M. D. Paraskevopoulou, G. Georgakilas, D. Karagkouni, T. Vergoulis, T. Dalamagas, and A. G. Hatzigeorgiou, "DIANAmiRPath v3.0: deciphering microRNA function with experimental support," Nucleic Acids Res, vol. 43, no. W1, pp. W460-6, Jul 1, 2015.

[70] M. Preusse, F. J. Theis, and N. S. Mueller, "miTALOS v2: analyzing tissue specific microRNA function," PLoS One, vol. 11, no. 3, pp. e0151771, 2016.

[71] J. H. Li, S. Liu, H. Zhou, L. H. Qu, and J. H. Yang, "starBase v2.0: decoding miRNA-ceRNA, miRNA-ncRNA and protein-RNA interaction networks from large-scale CLIP-Seq data," Nucleic Acids Res, vol. 42, no. Database issue, pp. D92-7, Jan, 2014.

[72] C. Sticht, C. De La Torre, A. Parveen, and N. Gretz, "miRWalk: An online resource for prediction of microRNA binding sites," PLoS One, vol. 13, no. 10, pp. e0206239, 2018.

[73] I. Ulitsky, L. C. Laurent, and R. J. N. a. r. Shamir, "Towards computational prediction of microRNA function and activity," vol. 38, no. 15, pp. e160-e160, 2010.

[74] M. Kanehisa, and S. Goto, "KEGG: kyoto encyclopedia of genes and genomes," Nucleic acids research, vol. 28, no. 1, pp. 27-30, 2000.

[75] A. Fabregat, S. Jupe, L. Matthews, K. Sidiropoulos, M. Gillespie, P. Garapati, R. Haw, B. Jassal, F. Korninger, and B. May, "The reactome pathway knowledgebase," Nucleic acids research, vol. 46, no. D1, pp. D649-D655, 2017.

[76] D. N. Slenter, M. Kutmon, K. Hanspers, A. Riutta, J. Windsor, N. Nunes, J. Mélius, E. Cirillo, S. L. Coort, and D. Digles, "WikiPathways: a multifaceted pathway database bridging metabolomics to other omics research," Nucleic acids research, vol. 46, no. D1, pp. D661-D667, 2017.

[77] D. Nishimura, "BioCarta," Biotech Software \& Internet Report: The Computer Software Journal for Scient, vol. 2, no. 3, pp. 117-120, 2001.

[78] M. Ashburner, C. A. Ball, J. A. Blake, D. Botstein, H. Butler, J. M. Cherry, A. P. Davis, K. Dolinski, S. S. Dwight, and J. T. Eppig, "Gene ontology: tool for the unification of biology," Nature genetics, vol. 25, no. 1, pp. 25, 2000. 
[79] A. R. Sonawane, J. Platig, M. Fagny, C.-Y. Chen, J. N. Paulson, C. M. LopesRamos, D. L. DeMeo, J. Quackenbush, K. Glass, and M. L. J. C. r. Kuijjer, "Understanding tissue-specific gene regulation," vol. 21, no. 4, pp. 1077-1088, 2017.

[80] K. Glass, C. Huttenhower, J. Quackenbush, and G.-C. J. P. o. Yuan, "Passing messages between biological networks to refine predicted interactions," vol. 8, no. 5, pp. e64832, 2013.

[81] M. Uhlén, L. Fagerberg, B. M. Hallström, C. Lindskog, P. Oksvold, A. Mardinoglu, Å. Sivertsson, C. Kampf, E. Sjöstedt, and A. Asplund, "Tissue-based map of the human proteome," Science, vol. 347, no. 6220, pp. 1260419, 2015.

[82] D. R. Zerbino, P. Achuthan, W. Akanni, M. R. Amode, D. Barrell, J. Bhai, K. Billis, C. Cummins, A. Gall, and C. G. Girón, "Ensembl 2018," Nucleic acids research, vol. 46, no. D1, pp. D754-D761, 2017.

[83] R. P. Huntley, B. Kramarz, T. Sawford, Z. Umrao, A. Kalea, V. Acquaah, M. J. Martin, M. Mayr, and R. C. Lovering, "Expanding the horizons of microRNA bioinformatics," $R N A$, vol. 24, no. 8, pp. 1005-1017, 2018.

[84] M. Coolen, S. Katz, and L. Bally-Cuif, "miR-9: a versatile regulator of neurogenesis," Frontiers in cellular neuroscience, vol. 7, pp. 220, 2013.

[85] R. Madelaine, S. A. Sloan, N. Huber, J. H. Notwell, L. C. Leung, G. Skariah, C. Halluin, S. P. Paşca, G. Bejerano, and M. A. Krasnow, "MicroRNA-9 couples brain neurogenesis and angiogenesis," Cell reports, vol. 20, no. 7, pp. 1533-1542, 2017.

[86] K. N. Ivey, and D. Srivastava, "MicroRNAs as regulators of differentiation and cell fate decisions," Cell stem cell, vol. 7, no. 1, pp. 36-41, 2010.

[87] C. P. Bracken, H. S. Scott, and G. J. J. N. R. G. Goodall, "A network-biology perspective of microRNA function and dysfunction in cancer," vol. 17, no. 12, pp. 719-732, 2016.

[88] D. Binns, E. Dimmer, R. Huntley, D. Barrell, C. O'donovan, and R. J. B. Apweiler, "QuickGO: a web-based tool for Gene Ontology searching," vol. 25, no. 22, pp. 3045-3046, 2009.

[89] D. Meyer, K. Hornik, and I. J. J. o. s. s. Feinerer, "Text mining infrastructure in R," vol. 25, no. 5, pp. 1-54, 2008.

[90] N. Pinzón, B. Li, L. Martinez, A. Sergeeva, J. Presumey, F. Apparailly, and H. J. G. r. Seitz, "microRNA target prediction programs predict many false positives," vol. 27, no. 2, pp. 234-245, 2017.

[91] S. L. Tan, T. Ohtsuka, A. González, and R. Kageyama, "Micro RNA 9 regulates neural stem cell differentiation by controlling $\mathrm{H}$ es 1 expression dynamics in the developing brain," Genes to cells, vol. 17, no. 12, pp. 952-961, 2012. 
APPENDIX I

\begin{tabular}{|c|c|}
\hline miRNA ID & mature sequence \\
\hline gma-miR319a & TTGGACTGAAGGGAGCTCCC \\
\hline aly-miR319a-3p & TTGGACTGAAGGGAGCTCCCT \\
\hline ppt-miR319a & CTTGGACTGAAGGGAGCTCC \\
\hline ppt-miR319c & CTTGGACTGAAGGGAGCTCCC \\
\hline aly-miR396a-5p & TTCCACAGCTTTCTTGAACTG \\
\hline gma-miR396e & TTCCACAGCTTTCTTGAACTGT \\
\hline gma-miR396h & TCCACAGCTTTCTTGAACTG \\
\hline ptc-miR319e & TTGGACTGAAGGGAGCTCCT \\
\hline aly-miR159a-3p & TTTGGATTGAAGGGAGCTCTA \\
\hline mtr-miR319c-3p & TTGGACTGAAGGGAGCTCCCA \\
\hline aly-miR166a-3p & TCGGACCAGGCTTCATTCCCC \\
\hline gma-miR166p & TCGGACCAGGCTTCATTCCC \\
\hline bdi-miR166f & TCTCGGACCAGGCTTCATTCC \\
\hline gma-miR166m & CGGACCAGGCTTCATTCCCC \\
\hline gma-miR166u & TCTCGGACCAGGCTTCATTC \\
\hline bdi-miR166e-3p & CTCGGACCAGGCTTCATTCCC \\
\hline gma-miR319p & TTTTGGACTGAAGGGAGCTCC \\
\hline
\end{tabular}




\begin{tabular}{|c|c|}
\hline aly-miR396b-5p & TTCCACAGCTTTCTTGAACTT \\
\hline miRNA ID & mature sequence \\
\hline gma-miR6300 & GTCGTTGTAGTATAGTGG \\
\hline sbi-miR166k & TCGGACCAGGCTTCATTCCT \\
\hline osa-miR396d & TCCACAGGCTTTCTTGAACGG \\
\hline aly-miR168a-5p & TCGCTTGGTGCAGGTCGGGAA \\
\hline gma-miR168b & TCGCTTGGTGCAGGTCGGG \\
\hline aly-miR162a-3p & TCGATAAACCTCTGCATCCAG \\
\hline gma-miR162a & TCGATAAACCTCTGCATCCA \\
\hline aly-miR858-5p & TTTCGTTGTCTGTTCGACCTT \\
\hline ath-miR858b & TTCGTTGTCTGTTCGACCTTG \\
\hline zma-miR396g-3p & GTTCAAGAAAGCTGTGGAAGA \\
\hline gma-miR4995 & AGGCAGTGGCTTGGTTAAGGG \\
\hline mtr-miR166c & TCGGACCAGGCTTCATTCCTC \\
\hline aly-miR156a-5p & TGACAGAAGAGAGTGAGCAC \\
\hline aly-miR396a-3p & GTTCAATAAAGCTGTGGGAAG \\
\hline ath-miR $156 \mathrm{j}$ & TGACAGAAGAGAGAGAGCAC \\
\hline bdi-miR156a & TGACAGAAGAGAGAGAGCACA \\
\hline gma-miR156f & TTGACAGAAGAGAGAGAGCACA \\
\hline gma-miR396a-3p & TTCAATAAAGCTGTGGGAAG \\
\hline
\end{tabular}




\begin{tabular}{cc}
\hline miRNA ID & mature sequence \\
\hline mdm-miR156t & TTGACAGAAGAGAGAGAGCAC \\
mdm-miR535a & TGACAACGAGAGAGAGCACGC \\
osa-miR396a-3p & GTTCAATAAAGCTGTGGGAA \\
ptc-miR156k & TGACAGAAGAGAGGGAGCAC \\
stu-miR156f-5p & CTGACAGAAGAGAGTGAGCA \\
aly-miR167a-5p & TGAAGCTGCCAGCATGATCTA \\
aly-miR167d-5p & TGAAGCTGCCAGCATGATCTGG \\
bdi-miR398a & TGTGTTCTCAGGTCGCCCCTG \\
gma-miR167c & TGAAGCTGCCAGCATGATCTG \\
aly-miR157a-5p & TTGACAGAAGATAGAGAGCAC \\
& \\
\hline TGACAGAAGATAGAGAGCAC \\
\end{tabular}




\section{APPENDIX II}

\begin{tabular}{|c|c|c|c|c|c|c|}
\hline Tissue name & miRNA & GO term name & GO ID & reference & Cell IDs & Cell types \\
\hline artery & hsa-let-7b-5p & positive regulation of angiogenesis & GO:0045766 & PMID:28159509 & CL:0000071 & blood vessel endothelial cell \\
\hline artery & hsa-let-7e-5p & $\begin{array}{l}\text { negative regulation of DNA-binding transcription } \\
\text { factor activity }\end{array}$ & GO:0043433 & PMID:30670152 & CL:0002618 & endothelial cell of umbilical vein \\
\hline artery & hsa-let-7e-5p & $\begin{array}{c}\text { negative regulation of tyrosine phosphorylation } \\
\text { of STAT protein }\end{array}$ & GO:0042532 & PMID:30670152 & CL:0002618 & endothelial cell of umbilical vein \\
\hline artery & hsa-let-7f-5p & $\begin{array}{l}\text { negative regulation of transforming growth } \\
\text { factor beta receptor signaling pathway }\end{array}$ & GO:0030512 & PMID:28345812 & CL:0002618 & endothelial cell of umbilical vein \\
\hline artery & hsa-let-7g-5p & negative regulation of inflammatory response & GO:0050728 & PMID:24291274 & CL:0002618 & endothelial cell of umbilical vein \\
\hline artery & hsa-let-7g-5p & $\begin{array}{l}\text { negative regulation of pathway-restricted SMAD } \\
\text { protein phosphorylation }\end{array}$ & GO:0060394 & PMID:24291274 & CL:0002618 & endothelial cell of umbilical vein \\
\hline artery & hsa-let-7g-5p & $\begin{array}{l}\text { negative regulation of transforming growth } \\
\text { factor beta receptor signaling pathway }\end{array}$ & GO:0030512 & PMID:24291274 & CL:0002618 & endothelial cell of umbilical vein \\
\hline artery & hsa-let-7g-5p & positive regulation of angiogenesis & GO:0045766 & PMID:24291274 & CL:0002618 & endothelial cell of umbilical vein \\
\hline artery & hsa-miR-1-3p & $\begin{array}{l}\text { positive regulation of vascular associated } \\
\text { smooth muscle cell apoptotic process }\end{array}$ & GO:1905461 & PMID:26166810 & CL:0002539 & aortic smooth muscle cell \\
\hline artery & hsa-miR-101-3p & negative regulation of protein ubiquitination & GO:0031397 & PMID:24844779 & CL:0002618 & endothelial cell of umbilical vein \\
\hline artery & hsa-miR-106b-5p & negative regulation of angiogenesis & GO:0016525 & PMID:26956882 & CL:0000071 & blood vessel endothelial cell \\
\hline artery & hsa-miR-10a-5p & $\begin{array}{l}\text { positive regulation of blood vessel endothelial } \\
\text { cell proliferation involved in sprouting } \\
\text { angiogenesis }\end{array}$ & GO:1903589 & PMID:22955733 & CL:0002618 & endothelial cell of umbilical vein \\
\hline artery & hsa-miR-10a-5p & $\begin{array}{l}\text { positive regulation of cell migration involved in } \\
\text { sprouting angiogenesis }\end{array}$ & GO:0090050 & PMID:22955733 & CL:0002618 & endothelial cell of umbilical vein \\
\hline artery & hsa-miR-10a-5p & $\begin{array}{l}\text { positive regulation of vascular endothelial } \\
\text { growth factor receptor signaling pathway }\end{array}$ & GO:0030949 & PMID:22955733 & CL:0002618 & endothelial cell of umbilical vein \\
\hline artery & hsa-miR-10b-5p & $\begin{array}{l}\text { positive regulation of blood vessel endothelial } \\
\text { cell proliferation involved in sprouting } \\
\text { angiogenesis }\end{array}$ & GO:1903589 & PMID:22955733 & CL:0002618 & endothelial cell of umbilical vein \\
\hline artery & hsa-miR-10b-5p & $\begin{array}{l}\text { positive regulation of cell migration involved in } \\
\text { sprouting angiogenesis }\end{array}$ & GO:0090050 & PMID:22955733 & CL:0002618 & endothelial cell of umbilical vein \\
\hline
\end{tabular}




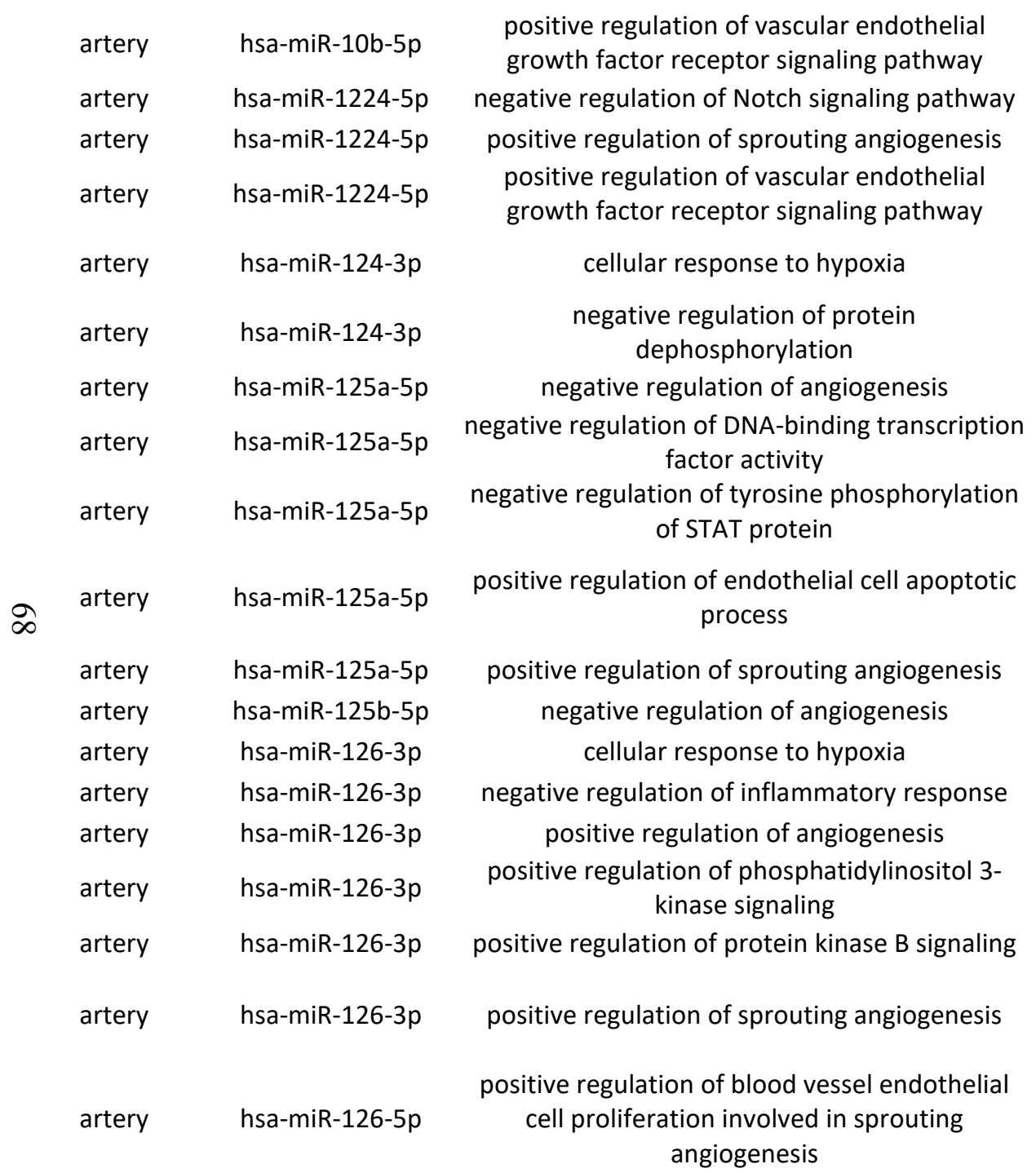

\section{$\mathrm{GO}: 19$}

\section{$\mathrm{GO}$}

GO:0071456 PMID:23853098 CL:0002591

GO:0035308 PMID:23853098 CL:0002591

GO:0016525 PMID:25116893 CL:0002618

GO:0043433 PMID:30670152 CL:0002618

GO:0042532 PMID:30670152 CL:0002618

PMID:25116893 CL:0002618

GO:2000353 ,PMID:2846751 ,CL:000261

\section{4}

GO:1903672 PMID:27252357 CL:0002618

GO:0016525 PMID:22391569 CL:0002618

GO:0071456 PMID:28578351 CL:2000008

GO:0050728 PMID:28578351 CL:2000008

GO:0045766 PMID:23136161 CL:0002544

GO:0014068 PMID:28578351 CL:2000008

GO:0051897 PMID:28578351 CL:2000008

PMID:27780851 CL:0002618

GO:1903672 ,PMID:2857835 ,CL:200000

1 endothelial cell of umbilical vein

endothelial cell of umbilical vein

endothelial cell of umbilical vein

endothelial cell of umbilical vein

smooth muscle cell of the pulmonary artery

smooth muscle cell of the pulmonary artery

endothelial cell of umbilical vein

endothelial cell of umbilical vein

endothelial cell of umbilical vein

endothelial cell of umbilical

vein,endothelial cell of umbilical vein

endothelial cell of umbilical vein endothelial cell of umbilical vein microvascular endothelial cell microvascular endothelial cell aortic endothelial cell

microvascular endothelial cell

microvascular endothelial cell endothelial cell of umbilical vein,microvascular endothelial cell

GO:1903589 PMID:28124060 CL:0002618 endothelial cell of umbilical vein 


$\begin{array}{ll}\text { artery } & \text { hsa-miR-126-5p } \\ \text { artery } & \text { hsa-miR-130a-3p } \\ \text { artery } & \text { hsa-miR-130a-3p } \\ \text { artery } & \text { hsa-miR-130a-3p } \\ \text { artery } & \text { hsa-miR-132-3p } \\ \text { artery } & \text { hsa-miR-132-3p } \\ \text { artery } & \text { hsa-miR-132-5p } \\ \text { artery } & \text { hsa-miR-132-5p } \\ \text { artery } & \text { hsa-miR-132-5p } \\ \text { artery } & \text { hsa-miR-133a-3p } \\ \text { artery } & \text { hsa-miR-133a-3p } \\ \text { artery } & \text { hsa-miR-138-5p } \\ \text { artery } & \text { hsa-miR-138-5p } \\ \text { artery } & \text { hsa-miR-138-5p } \\ \text { artery } & \text { hsa-miR-138-5p } \\ \text { artery } & \text { hsa-miR-140-5p } \\ \text { artery } & \text { hsa-miR-140-5p } \\ \text { artery } & \text { hsa-miR-140-5p } \\ \text { artery } & \text { hsa-miR-143-3p } \\ \text { artery } & \text { hsa-miR-143-3p }\end{array}$

positive regulation of cell migration involved in sprouting angiogenesis

positive regulation of angiogenesis

positive regulation of vascular endothelial cell proliferation

positive regulation of vascular smooth muscle cell proliferation

positive regulation of angiogenesis

positive regulation of protein kinase $B$ signaling

cholesterol homeostasis

fatty acid homeostasis

positive regulation of endothelial cell apoptotic

$$
\text { process }
$$

cellular response to cytokine stimulus

negative regulation of low-density lipoprotein

$$
\text { particle clearance }
$$

negative regulation of $\mathrm{G} 1 / \mathrm{S}$ transition of mitotic

$$
\text { cell cycle }
$$

negative regulation of nitric-oxide synthase activity

negative regulation of $p 38$ MAPK cascade

negative regulation of sprouting angiogenesis

$$
\text { cellular response to hypoxia }
$$

positive regulation of BMP signaling pathway

positive regulation of vascular associated smooth muscle cell apoptotic process negative regulation of angiogenesis positive regulation of angiogenesis
GO:0090050

GO:0045766

PMID:23136161

GO:1905564

PMID:24960162

GO:1904707

GO:0045766

GO:0051897

GO:0042632

PMID:24960162

PMID:24924687

GO:0055089

PMID:24924687

GO:2000353

GO:0071345

PMID:28257760

GO:0010989

PMID:28257760

GO:200013

PMID:28450935

GO:005100

$P$

GO:1903753

GO:1903671

PMID:24244340

GO:0071456

GO:0030513

PMID:27214554

GO:1905461

PMID:27021683

GO:0016525

PMID:25801897

GO:0045766
PMID:28124060

PMID:21868695

PMID:21868695

PMID:24924687

PMID:28450935

PMID:27021683

$\mathrm{C}$

L:0002618

CL:0002544 UBERON:0 002012 UBERON:0 002012

$\mathrm{CL}: 0000071$

$\mathrm{CL}: 0000071$

$\mathrm{CL}: 0002618$

$\mathrm{CL}: 0002618$

CL:0002618

LL:0000359

L:0000359

CL:0002546

L:2000008

L:0002546

$\mathrm{CL}: 2000008$

CL:0002591

CL:0002591

CL:0002591

CL:0002618

PMID:26311719 CL:1001568 endothelial cell of umbilical vein

aortic endothelial cell

pulmonary artery

pulmonary artery

blood vessel endothelial cell blood vessel endothelial cell endothelial cell of umbilical vein endothelial cell of umbilical vein endothelial cell of umbilical vein

vascular associated smooth muscle cell

vascular associated smooth muscle cell

embryonic blood vessel endothelial progenitor cell

microvascular endothelial cell

embryonic blood vessel endothelial progenitor cell microvascular endothelial cell

smooth muscle cell of the pulmonary artery

smooth muscle cell of the pulmonary artery

smooth muscle cell of the pulmonary artery

endothelial cell of umbilical vein pulmonary artery endothelial cell 


$\begin{array}{cc}\text { artery } & \text { hsa-miR-145-5p } \\ \text { artery } & \text { hsa-miR-146a-5p } \\ \text { artery } & \text { hsa-miR-146a-5p } \\ \text { artery } & \text { hsa-miR-146a-5p } \\ \text { artery } & \text { hsa-miR-146a-5p } \\ \text { artery } & \text { hsa-miR-146a-5p } \\ \text { artery } & \text { hsa-miR-146a-5p } \\ \text { artery } & \text { hsa-miR-146a-5p } \\ \text { artery } & \text { hsa-miR-149-3p } \\ \text { artery } & \text { hsa-miR-149-5p } \\ \text { artery } & \text { hsa-miR-149-5p } \\ \text { artery } & \text { hsa-miR-152-3p } \\ \text { artery } & \text { hsa-miR-155-5p } \\ \text { artery } & \text { hsa-miR-155-5p } \\ \text { artery } & \text { hsa-miR-15a-5p } \\ \text { artery } & \text { hsa-miR-15a-5p } \\ \text { artery } & \text { hsa-miR-15a-5p } \\ \text { artery } & \text { hsa-miR-15a-5p } \\ \text { artery } & \text { hsa-miR-15a-5p } \\ \text { artery } & \text { hsa-miR-15a-5p } \\ & \end{array}$

$$
\begin{aligned}
& \text { negative regulation of angiogenesis } \\
& \text { cellular response to cytokine stimulus } \\
& \text { cellular response to glucose stimulus } \\
& \text { negative regulation of angiogenesis }
\end{aligned}
$$

negative regulation of interleukin- 6 production

negative regulation of NIK/NF-kappaB signaling

negative regulation of tyrosine phosphorylation of STAT protein

positive regulation of fibroblast growth factor receptor signaling pathway

negative regulation of fibroblast growth factor receptor signaling pathway

negative regulation of fibroblast growth factor receptor signaling pathway

negative regulation of interleukin-6 production negative regulation of tumor necrosis factormediated signaling pathway

negative regulation of inflammatory response positive regulation of sprouting angiogenesis

cellular response to glucose stimulus

negative regulation of angiogenesis negative regulation of cell migration involved in sprouting angiogenesis

negative regulation of $\mathrm{G} 1 / \mathrm{S}$ transition of mitotic

$$
\text { cell cycle }
$$

negative regulation of inflammatory response

negative regulation of NF-kappaB transcription factor activity
GO:0016525

PMID:25801897 CL:0002618

GO:0071345 PMID:25515214 CL:2000044

GO:0071333 PMID:28433754 CL:0002585

GO:0016525 PMID:23619365 CL:0002618

GO:0032715 PMID:28433754 CL:0002585

GO:1901223 PMID:25515214 CL:2000044

GO:0042532 PMID:28433754 CL:0002585

GO:0045743 PMID:27121396 CL:0002618

GO:0040037 PMID:24463821 CL:0002544

GO:0040037 PMID:24463821 CL:0002544

GO:0032715 PMID:24299952 CL:0002618

GO:0010804 PMID:24813629 CL:0002618

GO:0050728 PMID:21310411 CL:0000071

GO:1903672 PMID:27731397 CL:0002618

GO:0071333 PMID:30365148 CL:0002585

GO:0016525 PMID:23867820 CL:0002618

GO:0090051 PMID:22692216 CL:0002618

GO:2000134 PMID:23867820 CL:0002618

GO:0050728 PMID:30365148 CL:0002585

GO:0032088 PMID:30365148 CL:0002585 endothelial cell of umbilical vein brain microvascular endothelial cell

retinal blood vessel endothelial cell

endothelial cell of umbilical vein retinal blood vessel endothelial cell

brain microvascular endothelial cell

retinal blood vessel endothelial cell

endothelial cell of umbilical vein

$$
\text { aortic endothelial cell }
$$

aortic endothelial cell

endothelial cell of umbilical vein endothelial cell of umbilical vein

blood vessel endothelial cell endothelial cell of umbilical vein retinal blood vessel endothelial cell

endothelial cell of umbilical vein endothelial cell of umbilical vein endothelial cell of umbilical vein retinal blood vessel endothelial cell

retinal blood vessel endothelial cell 


$\begin{array}{cc}\text { artery } & \text { hsa-miR-15b-5p } \\ \text { artery } & \text { hsa-miR-15b-5p } \\ \text { artery } & \text { hsa-miR-16-5p } \\ \text { artery } & \text { hsa-miR-16-5p } \\ \text { artery } & \text { hsa-miR-16-5p } \\ \text { artery } & \text { hsa-miR-16-5p } \\ \text { artery } & \text { hsa-miR-16-5p } \\ \text { artery } & \text { hsa-miR-16-5p } \\ \text { artery } & \text { hsa-miR-17-5p } \\ \text { artery } & \text { hsa-miR-17-5p } \\ \text { artery } & \text { hsa-miR-185-3p } \\ \text { artery } & \text { hsa-miR-185-5p } \\ \text { artery } & \text { hsa-miR-193a-3p } \\ \text { artery } & \text { hsa-miR-196a-5p } \\ \text { artery } & \text { hsa-miR-196a-5p } \\ \text { artery } & \text { hsa-miR-19b-3p } \\ \text { artery } & \text { hsa-miR-19b-3p } \\ \text { artery } & \text { hsa-miR-19b-3p }\end{array}$

branching involved in blood vessel morphogenesis

negative regulation of angiogenesis branching involved in blood vessel morphogenesis

cellular response to glucose stimulus

negative regulation of fibroblast growth factor receptor signaling pathway

negative regulation of inflammatory response

negative regulation of NF-kappaB transcription factor activity

negative regulation of vascular endothelial growth factor signaling pathway

cellular response to hypoxia

positive regulation of vascular smooth muscle cell proliferation

negative regulation of ERK1 and ERK2 cascade

negative regulation of angiogenesis

negative regulation of $\mathrm{G} 1 / \mathrm{S}$ transition of mitotic cell cycle

cellular response to vascular endothelial growth factor stimulus

negative regulation of cell migration involved in sprouting angiogenesis

negative regulation of cell migration involved in sprouting angiogenesis

negative regulation of $\mathrm{G} 2 / \mathrm{M}$ transition of mitotic cell cycle

negative regulation of serine-type endopeptidase activity

\begin{tabular}{|c|c|c|c|}
\hline GO:0001569 & PMID:23688497 & $\begin{array}{l}\text { UBERON:0 } \\
007777\end{array}$ & umbilical vein endothelium \\
\hline GO:0016525 & PMID:27208409 & $C L: 0002618$ & endothelial cell of umbilical vein \\
\hline GO:0001569 & PMID:23083510 & $\begin{array}{c}\text { UBERON:0 } \\
007777\end{array}$ & umbilical vein endothelium \\
\hline 50:0071333 & PMID:30365148 & CL:0002585 & $\begin{array}{c}\text { retinal blood vessel endothelial } \\
\text { cell }\end{array}$ \\
\hline GO:0040037 & PMID:21885851 & $C L: 0002544$ & aortic endothelial cell \\
\hline GO:0050728 & PMID:30365148 & CL:0002585 & $\begin{array}{c}\text { retinal blood vessel endothelial } \\
\text { cell }\end{array}$ \\
\hline GO:0032088 & PMID:30365148 & CL:0002585 & $\begin{array}{c}\text { retinal blood vessel endothelial } \\
\text { cell }\end{array}$ \\
\hline GO:1900747 & PMID:21885851 & $C L: 0002544$ & aortic endothelial cell \\
\hline GO:0071456 & PMID:27640178 & CL:0002591 & $\begin{array}{l}\text { smooth muscle cell of the } \\
\text { pulmonary artery }\end{array}$ \\
\hline GO:1904707 & PMID:22161164 & $\begin{array}{l}\text { UBERON:0 } \\
002012\end{array}$ & pulmonary artery \\
\hline GO:0070373 & PMID:28277742 & CL:0002539 & aortic smooth muscle cell \\
\hline GO:0016525 & PMID:26694763 & $C L: 2000008$ & microvascular endothelial cell \\
\hline GO:2000134 & PMID:28276476 & CL:0002546 & $\begin{array}{l}\text { embryonic blood vessel } \\
\text { endothelial progenitor cell }\end{array}$ \\
\hline GO:0035924 & PMID:22773844 & $\mathrm{CL}: 0002618$ & endothelial cell of umbilical vein \\
\hline GO:0090051 & PMID:22773844 & $\mathrm{CL}: 0002618$ & endothelial cell of umbilical vein \\
\hline GO:0090051 & PMID:22197821 & CL:0002618 & endothelial cell of umbilical vein \\
\hline GO:0010972 & PMID:22197821 & CL:0002618 & endothelial cell of umbilical vein \\
\hline 9000 & 11 & 2618 & in \\
\hline
\end{tabular}




$\begin{array}{cc}\text { artery } & \text { hsa-miR-200a-3p } \\ \text { artery } & \text { hsa-miR-200b-3p } \\ \text { artery } & \text { hsa-miR-200b-3p } \\ \text { artery } & \text { hsa-miR-20a-5p } \\ \text { artery } & \text { hsa-miR-20a-5p } \\ \text { artery } & \text { hsa-miR-20a-5p } \\ \text { artery } & \text { hsa-miR-20a-5p } \\ \text { artery } & \text { hsa-miR-20a-5p } \\ \text { artery } & \text { hsa-miR-20b-5p } \\ \text { artery } & \text { hsa-miR-20b-5p } \\ \text { artery } & \text { hsa-miR-20b-5p } \\ \text { artery } & \text { hsa-miR-21-3p } \\ \text { artery } & \text { hsa-miR-21-5p } \\ \text { artery } & \text { hsa-miR-21-5p } \\ \text { artery } & \text { hsa-miR-21-5p } \\ \text { artery } & \text { hsa-miR-21-5p } \\ \text { artery } & \text { hsa-miR-21-5p } \\ \text { artery } & \text { hsa-miR-21-5p } \\ \text { artery } & \text { hsa-miR-21-5p }\end{array}$

positive regulation of blood vessel endothelial

$$
\text { cell migration }
$$

negative regulation of angiogenesis

negative regulation of blood vessel endothelial cell migration

cellular response to vascular endothelial growth factor stimulus

negative regulation of cell migration involved in sprouting angiogenesis

negative regulation of protein kinase activity

positive regulation of angiogenesis

positive regulation of vascular smooth muscle cell proliferation

cellular response to tumor necrosis factor

negative regulation of angiogenesis

positive regulation of cellular senescence negative regulation of NF-kappaB transcription

$$
\text { factor activity }
$$

BMP signaling pathway

cellular response to lipopolysaccharide

negative regulation of GTPase activity

positive regulation of angiogenesis positive regulation of blood vessel endothelial cell proliferation involved in sprouting angiogenesis

positive regulation of inflammatory response

positive regulation of vascular associated smooth muscle cell migration
GO:0043536

GO:0016525

GO:0043537

GO:003592

GO:00900

GO:0006469

GO:0045766

GO:1904707

GO:0071356

GO:0016525

GO:2000774

GO:0032088

GO:0030509

GO:007122

GO:0034260

GO:0045766

GO:1903589

GO:00507

G0.190475

GO:1904754
PMID:21698760

PMID:21081489

PMID:21081489

PMID:22696064

PMID:22696064

PMID:25447536

PMID:28097093

PMID:22450430

PMID:28595801

PMID:24048733

PMID:28595801

PMID:25327529

PMID:18548003

PMID:29039542

PMID:22158624

PMID:27708252

PMID:30106099

PMID:21636785 PMID:20693317 ,PMID:2069331 7,PMID:218171

07
$\mathrm{CL}: 0002618$

$\mathrm{CL}: 2000008$

CL:2000008

$\mathrm{CL}: 0002618$

$\mathrm{CL}: 0002618$

$\mathrm{LL}: 0002591$

CL:0002618

CL:0002591

$\mathrm{CL}: 2000008$

$\mathrm{CL}: 0002618$

$\mathrm{CL}: 2000008$

$\mathrm{CL}: 0002544$

UBERON:0

002012

$C L: 0002618$

$\mathrm{CL}: 0000359$

CL:2000008

$\mathrm{CL}: 0002618$

$\mathrm{CL}: 0000071$

UBERON:0

002012,UB ERON:0002 endothelial cell of umbilical vein

microvascular endothelial cell

microvascular endothelial cell

endothelial cell of umbilical vein

endothelial cell of umbilical vein

smooth muscle cell of the pulmonary artery

endothelial cell of umbilical vein smooth muscle cell of the pulmonary artery

microvascular endothelial cell endothelial cell of umbilical vein microvascular endothelial cell

aortic endothelial cell

pulmonary artery

endothelial cell of umbilical vein vascular associated smooth muscle cell

microvascular endothelial cell

endothelial cell of umbilical vein

blood vessel endothelial cell

pulmonary artery, pulmonary artery,femoral artery 
012,UBERO

$\mathrm{N}: 0002060$

artery hsa-miR-21-5p

artery hsa-miR-21-5p

artery

artery

artery

artery

artery

artery

artery

artery

artery

artery

artery

artery

artery

artery

artery

artery

artery

artery

hsa-miR-21-5p

hsa-miR-210-3p

hsa-miR-210-3p

hsa-miR-210-3p

hsa-miR-212-3p

hsa-miR-212-3p

hsa-miR-214-3p

hsa-miR-214-3p

hsa-miR-214-3p

hsa-miR-214-3p

hsa-miR-214-3p

hsa-miR-214-3p

hsa-miR-214-5p

hsa-miR-218-5p

hsa-miR-22-3p

hsa-miR-221-3p

hsa-miR-221-3p

hsa-miR-221-3p positive regulation of vascular endothelial growth factor signaling pathway

positive regulation of vascular smooth muscle cell proliferation regulation of cell shape

positive regulation of angiogenesis

positive regulation of cell migration tube formation

negative regulation of angiogenesis positive regulation of Notch signaling pathway

cellular response to hypoxia

negative regulation of cell migration

negative regulation of cell proliferation

negative regulation of vascular associated smooth muscle cell migration

negative regulation of vascular smooth muscle cell proliferation

positive regulation of $\mathrm{G} 1 / \mathrm{S}$ transition of mitotic cell cycle

positive regulation of vascular smooth muscle cell proliferation

negative regulation of MAP kinase activity positive regulation of inflammatory response negative regulation of inflammatory response negative regulation of sprouting angiogenesis platelet-derived growth factor receptor signaling pathway
GO:1900748 PMID:30106099

PMID:20693317

GO:1904707 ,PMID:2181710 7

GO:0008360

PMID:21817107

PMID:18417479

GO:004576

GO:0030335

GO:0035148

PMID:23322395

PMID:23322395

GO:0016525

PMID:25217442

GO:0045747

PMID:25217442

GO:0071456

PMID:27144530

GO:003033

GO:0008285

PMID:25656649

PMID:25656649

GO:1904753 PMID.27927633

GO:1904706 PMID:27927633

PMID:27144530

GO:1900087

GO:1904707

PMID:21385766

PMID:28112401

G0:0050729

PID:28112401

GO:0050728

21310411

GO:1903671

PMID:27780851

GO:0048008

PMID:19088079
CL:0002618

UBERON:0

002012,UB

ERON:0002

060

CL:0000359

CL:0002618

CL:2000008

$\mathrm{CL}: 2000008$

$\mathrm{CL}: 0002618$

$\mathrm{CL}: 0000071$

$\mathrm{CL}: 0002591$

$\mathrm{CL}: 0002618$

$\mathrm{CL}: 0002618$

UBERON:0

000947

UBERON:0 000947

$\mathrm{CL}: 0002591$

UBERON:0 002012

$\mathrm{CL}: 0000071$

$\mathrm{CL}: 0002618$

$\mathrm{CL}: 0000071$

$\mathrm{CL}: 0002618$

$\mathrm{CL}: 0002591$ endothelial cell of umbilical vein

pulmonary artery,femoral artery

vascular associated smooth muscle cell

endothelial cell of umbilical vein microvascular endothelial cell microvascular endothelial cell endothelial cell of umbilical vein blood vessel endothelial cell smooth muscle cell of the pulmonary artery endothelial cell of umbilical vein endothelial cell of umbilical vein

aorta

aorta

smooth muscle cell of the pulmonary artery

pulmonary artery

blood vessel endothelial cell endothelial cell of umbilical vein blood vessel endothelial cell endothelial cell of umbilical vein smooth muscle cell of the pulmonary artery 


$\begin{array}{cc}\text { artery } & \text { hsa-miR-221-3p } \\ \text { artery } & \text { hsa-miR-222-3p } \\ \text { artery } & \text { hsa-miR-223-3p } \\ \text { artery } & \text { hsa-miR-23a-3p } \\ \text { artery } & \text { hsa-miR-23a-3p } \\ \text { artery } & \text { hsa-miR-23a-3p } \\ \text { artery } & \text { hsa-miR-23a-3p } \\ \text { artery } & \text { hsa-miR-23a-3p } \\ \text { artery } & \text { hsa-miR-23b-3p } \\ \text { artery } & \text { hsa-miR-23b-3p } \\ \text { artery } & \text { hsa-miR-23b-3p } \\ \text { artery } & \text { hsa-miR-23b-3p } \\ \text { artery } & \text { hsa-miR-23b-3p } \\ \text { artery } & \text { hsa-miR-23b-3p } \\ \text { artery } & \text { hsa-miR-24-3p } \\ \text { artery } & \text { hsa-miR-24-3p } \\ \text { artery } & \text { hsa-miR-24-3p } \\ \text { artery } & \text { hsa-miR-24-3p } \\ \text { artery } & \text { hsa-miR-26a-5p }\end{array}$

positive regulation of blood vessel endothelial

$$
\text { cell migration }
$$

negative regulation of inflammatory response

negative regulation of GTPase activity

cellular response to vascular endothelial growth factor stimulus

negative regulation of vascular permeability positive regulation of blood vessel endothelial

cell proliferation involved in sprouting angiogenesis

positive regulation of cell migration involved in sprouting angiogenesis

positive regulation of ERK1 and ERK2 cascade cellular response to vascular endothelial growth

$$
\text { factor stimulus }
$$

negative regulation of sprouting angiogenesis positive regulation of blood vessel endothelial

cell proliferation involved in sprouting angiogenesis

positive regulation of cell migration involved in sprouting angiogenesis

positive regulation of ERK1 and ERK2 cascade positive regulation of vascular permeability

negative regulation of angiogenesis positive regulation of endothelial cell apoptotic process

positive regulation of reactive oxygen species biosynthetic process

positive regulation of vascular associated

smooth muscle cell apoptotic process

negative regulation of BMP signaling pathway
GO:0043536

GO:0050728

PMID:19351599

$\mathrm{CL}: 0002618$

PMID:21310411 CL:0000071

GO:0034260 PMID:27121304 CL:0002591

GO:0035924

GO:0043116

PMID:21536891 CL:0002618

GO:1903589

PMID:21536891

GO:0090050

GO:0070374

$1 \quad C$

\section{$\mathrm{CL}$}

0002618

\section{GO:0035924}

PMID:21536891

$\mathrm{CL}: 0002618$

18

PMID:21536891 CL:0002618

GO:1903671

PMID:27741223

GO:1903589

PMID:21536891

CL:0002618

618

end

encott

GO:0090050 PMID:21536891 CL:0002618 endothelial cell of umbilical vein

GO:0070374 PMID:21536891 CL:0002618 endothelial cell of umbilical vein

GO:0043117 PMID:27741223 CL:0002618 endothelial cell of umbilical vein

GO:0016525 PMID:23774796 CL:2000008 microvascular endothelial cell

GO:2000353 PMID:21788589 CL:0000071 blood vessel endothelial cell

GO:1903428 PMID:21788589 CL:0000071 blood vessel endothelial cell

GO:1905461 PMID:23774796 CL:2000008 microvascular endothelial cell

GO:0030514 PMID:24047927 CL:0002618 endothelial cell of umbilical vein 


$\begin{array}{cc}\text { artery } & \text { hsa-miR-26a-5p } \\ \text { artery } & \text { hsa-miR-26a-5p } \\ \text { artery } & \text { hsa-miR-26a-5p } \\ \text { artery } & \text { hsa-miR-26a-5p } \\ \text { artery } & \text { hsa-miR-26a-5p } \\ \text { artery } & \text { hsa-miR-26a-5p } \\ \text { artery } & \text { hsa-miR-27a-3p } \\ \text { artery } & \text { hsa-miR-27a-3p } \\ \text { artery } & \text { hsa-miR-27a-3p } \\ \text { artery } & \text { hsa-miR-27a-3p } \\ \text { artery } & \text { hsa-miR-27a-5p } \\ \text { artery } & \text { hsa-miR-27b-3p } \\ \text { artery } & \text { hsa-miR-27b-3p } \\ \text { artery } & \text { hsa-miR-27b-3p } \\ \text { artery } & \text { hsa-miR-27b-3p } \\ \text { artery } & \text { hsa-miR-296-5p } \\ \text { artery } & \text { hsa-miR-296-5p }\end{array}$

negative regulation of cell migration involved in sprouting angiogenesis

negative regulation of DNA-binding transcription factor activity

negative regulation of $\mathrm{G} 1 / \mathrm{S}$ transition of mitotic cell cycle

negative regulation of nitric-oxide synthase activity

transforming growth factor beta receptor signaling pathway

vascular endothelial growth factor signaling pathway

cellular response to vascular endothelial growth factor stimulus

positive regulation of blood vessel endothelial cell proliferation involved in sprouting angiogenesis

positive regulation of cell migration involved in sprouting angiogenesis

positive regulation of ERK1 and ERK2 cascade negative regulation of NF-kappaB transcription factor activity

cellular response to vascular endothelial growth factor stimulus positive regulation of blood vessel endothelial cell proliferation involved in sprouting angiogenesis

positive regulation of cell migration involved in sprouting angiogenesis

positive regulation of ERK1 and ERK2 cascade

positive regulation of cell migration involved in sprouting angiogenesis

positive regulation of vascular endothelial growth factor receptor signaling pathway
PMID:24047927 CL:0002618

GO:0090051

PMID:2860216 2

8

GO:0043433

PMID:240

GO:2000134

$\mathrm{CL}: 0002618$

PMID:24047927

CL:0002618

GO:0051001

PMID:28602162

$\mathrm{CL}: 0002618$

GO:0007179

PMID:20857419 CL:0002539

GO:0038084

PMID:28602162

$\mathrm{CL}: 0002618$

GO:0035924

PMID:21536891

CL:0002618

GO:1903589

PMID:21536891

$C L: 0002618$

GO:0090050

PMID:21536891

GO:0070374

PMID:21536891

$\mathrm{CL} \cdot 0002618$

GO:0032088

PMID:25327529

CL:0002544

GO:0035924

PMID:21536891

CL:0002618

GO:1903589

PMID:21536891

CL:0002618

GO:0090050

PMID:21536891

CL:0002618

GO:0070374

PMID:21536891

CL:0002618

GO:009005

PMID:18977327

$C L: 2000044$

GO:0030949 endothelial cell of umbilical vein,endothelial cell of umbilical vein

endothelial cell of umbilical vein endothelial cell of umbilical vein endothelial cell of umbilical vein aortic smooth muscle cell

endothelial cell of umbilical vein endothelial cell of umbilical vein endothelial cell of umbilical vein

endothelial cell of umbilical vein endothelial cell of umbilical vein aortic endothelial cell

endothelial cell of umbilical vein

endothelial cell of umbilical vein

endothelial cell of umbilical vein

endothelial cell of umbilical vein

brain microvascular endothelial cell

brain microvascular endothelial cell 


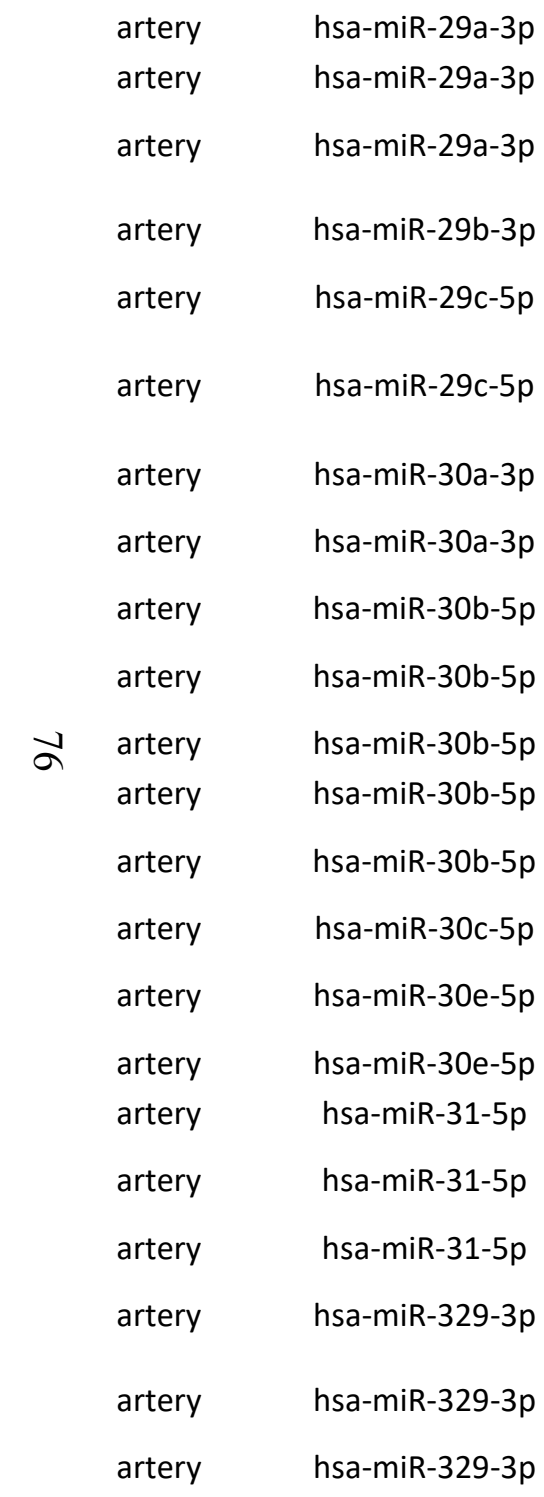

negative regulation of angiogenesis

positive regulation of angiogenesis

positive regulation of $\mathrm{G} 1 / \mathrm{S}$ transition of mitotic cell cycle

negative regulation of collagen biosynthetic process

negative regulation of angiogenesis

negative regulation of insulin-like growth factor receptor signaling pathway

positive regulation of angiogenesis

transforming growth factor beta receptor signaling pathway

negative regulation of angiogenesis

negative regulation of endothelial cell apoptotic process

positive regulation of protein phosphorylation

positive regulation of sprouting angiogenesis

positive regulation of transforming growth factor

beta receptor signaling pathway

negative regulation of sprouting angiogenesis

negative regulation of endothelial cell apoptotic process

negative regulation of sprouting angiogenesis

positive regulation of angiogenesis

positive regulation of blood vessel endothelial cell migration

positive regulation of sprouting angiogenesis

negative regulation of cell migration involved in sprouting angiogenesis

negative regulation of vascular endothelial growth factor signaling pathway NIK/NF-kappaB signaling
PMID:28637396 CL:0002618

GO:0045766 PMID:23541945 CL:0002618

GO:1900087 PMID:23541945 CL:0002618

GO:0032966 PMID:22269326 CL:0002547

GO:0016525 PMID:26175848 CL:0002618

PMID:26045889 CL:0002618

GO:0043569 ,PMID:2617584 ,CL:000261

8

GO:0045766 PMID:23960241 CL:0002618

GO:0007179 PMID:23960241 CL:0002618

GO:0016525 PMID:28977001 CL:0000071

GO:2000352 PMID:27464494 CL:2000018

GO:0001934 PMID:28977001 CL:0000071

GO:1903672 PMID:23086751 CL:0000071

GO:0030511 PMID:28977001 CL:0000071

GO:1903671 PMID:27780851 CL:0002618

GO:2000352 PMID:27464494 CL:2000018

GO:1903671 PMID:27780851 CL:0002618

GO:0045766 PMID:28097093 CL:0002618

GO:0043536 PMID:26933040 CL:0002618

GO:1903672 PMID:26933040 CL:0002618

GO:0090051

PMID:23878390

CL:0002618

GO:190074

PMID:23878390

$C L: 0002618$

GO:0038061 PMID:23878390 endothelial cell of umbilical vein endothelial cell of umbilical vein

endothelial cell of umbilical vein

fibroblast of the aortic adventitia

endothelial cell of umbilical vein endothelial cell of umbilical

vein,endothelial cell of umbilical vein

endothelial cell of umbilical vein

endothelial cell of umbilical vein

blood vessel endothelial cell

endothelial cell of coronary artery

blood vessel endothelial cell

blood vessel endothelial cell

blood vessel endothelial cell

endothelial cell of umbilical vein endothelial cell of coronary artery

endothelial cell of umbilical vein endothelial cell of umbilical vein

endothelial cell of umbilical vein

endothelial cell of umbilical vein

endothelial cell of umbilical vein

endothelial cell of umbilical vein

endothelial cell of umbilical vein 


$\begin{array}{cc}\text { artery } & \text { hsa-miR-342-5p } \\ \text { artery } & \text { hsa-miR-342-5p } \\ \text { artery } & \text { hsa-miR-342-5p } \\ \text { artery } & \text { hsa-miR-34a-5p } \\ \text { artery } & \text { hsa-miR-34a-5p } \\ \text { artery } & \text { hsa-miR-34a-5p } \\ \text { artery } & \text { hsa-miR-34a-5p } \\ \text { artery } & \text { hsa-miR-34a-5p } \\ \text { artery } & \text { hsa-miR-34a-5p } \\ \text { artery } & \text { hsa-miR-361-5p } \\ \text { artery } & \text { hsa-miR-362-3p } \\ \text { artery } & \text { hsa-miR-377-3p } \\ \text { artery } & \text { hsa-miR-424-5p } \\ \text { artery } & \text { hsa-miR-424-5p } \\ \text { artery } & \text { hsa-miR-424-5p } \\ \text { artery } & \text { hsa-miR-424-5p } \\ \text { artery } & \text { hsa-miR-424-5p } \\ \text { artery } & \text { hsa-miR-424-5p } \\ \text { artery } & \text { hsa-miR-424-5p }\end{array}$

negative regulation of protein kinase $B$ signaling negative regulation of transforming growth factor beta receptor signaling pathway negative regulation of vascular endothelial growth factor signaling pathway

cellular response to hypoxia

negative regulation of angiogenesis

negative regulation of calcium ion import

negative regulation of sprouting angiogenesis negative regulation of vascular associated smooth muscle cell migration

negative regulation of vascular smooth muscle cell proliferation

negative regulation of angiogenesis

negative regulation of $\mathrm{G} 1 / \mathrm{S}$ transition of mitotic cell cycle

negative regulation of sprouting angiogenesis

negative regulation of angiogenesis

negative regulation of cell migration involved in sprouting angiogenesis

negative regulation of ERK1 and ERK2 cascade

negative regulation of fibroblast growth factor receptor signaling pathway

negative regulation of $\mathrm{G} 0$ to $\mathrm{G} 1$ transition

negative regulation of vascular endothelial

growth factor signaling pathway

negative regulation of vascular smooth muscle cell proliferation
GO:0051898

PMID:26857067

GO:0030512

GO:1900747

PMID:26857067

$C L: 0002618$

GO:0071456

PMID:26857067

CL:0002618

GO:0016525

PMID:27302634

CL:0002591

GO:009028

PMID:24048733

$C L: 0002618$

GO:190367

PMID:27302634

CL:0002591

GO:1904753

PMID:23426265

CL:0002618 UBERON:0 000947

GO:1904706

PMID:26493107

PMID:2479236

,PMID:2649310

7

CL:0002546

GO:0016525 PMID:25203061 CL:0000071

GO:2000134 PMID:28890348 CL:0000359

GO:1903671

PMID:25251394

$\mathrm{CL}: 0002618$

GO:0016525

PMID:28566713

$\mathrm{CL}: 000007$

GO:009005

PMID:28566713

$\mathrm{CL}: 0000071$

GO:0070373

PM

PMID.21885851 CL:0002544

GO:0040037 ,PMID:2326362 ,CL:100156

6

GO:0070317 PMID:23263626 CL:1001568

GO:1900747 PMID:21885851 CL:0002544

GO:1904706 PMID:23263626 CL:0002591 endothelial cell of umbilical vein

endothelial cell of umbilical vein

endothelial cell of umbilical vein

smooth muscle cell of the pulmonary artery

endothelial cell of umbilical vein smooth muscle cell of the pulmonary artery

endothelial cell of umbilical vein

aorta

embryonic blood vessel endothelial progenitor cell,aorta

blood vessel endothelial cell

vascular associated smooth muscle cell

endothelial cell of umbilical vein

blood vessel endothelial cell

blood vessel endothelial cell

pulmonary artery endothelial cell

aortic endothelial

cell,pulmonary artery endothelial cell

pulmonary artery endothelial cell

aortic endothelial cell

smooth muscle cell of the pulmonary artery 


$\begin{array}{cc}\text { artery } & \text { hsa-miR-451a } \\ \text { artery } & \text { hsa-miR-4632-3p } \\ \text { artery } & \text { hsa-miR-483-5p } \\ \text { artery } & \text { hsa-miR-487b-3p } \\ \text { artery } & \text { hsa-miR-487b-3p } \\ \text { artery } & \text { hsa-miR-492 } \\ \text { artery } & \text { hsa-miR-495-3p } \\ \text { artery } & \text { hsa-miR-495-3p } \\ \text { artery } & \text { hsa-miR-503-5p } \\ \text { artery } & \text { hsa-miR-503-5p } \\ \text { artery } & \text { hsa-miR-503-5p } \\ \text { artery } & \text { hsa-miR-503-5p } \\ \text { artery } & \text { hsa-miR-503-5p } \\ \text { artery } & \text { hsa-miR-503-5p } \\ \text { artery } & \text { hsa-miR-503-5p } \\ \text { artery } & \text { hsa-miR-503-5p } \\ \text { artery } & \text { hsa-miR-505-3p } \\ \text { artery } & \text { hsa-miR-638 } \\ \text { artery } & \text { hsa-miR-638 } \\ & \\ & \end{array}$

$$
\begin{aligned}
& \text { positive regulation of vascular associated } \\
& \text { smooth muscle cell migration } \\
& \text { cellular response to platelet-derived growth }
\end{aligned}
$$
factor stimulus

negative regulation of cell migration involved in sprouting angiogenesis positive regulation of blood vessel endothelial

cell proliferation involved in sprouting angiogenesis

positive regulation of cell migration involved in sprouting angiogenesis

negative regulation of angiogenesis

negative regulation of endothelial cell apoptotic process

positive regulation of $\mathrm{G} 1 / \mathrm{S}$ transition of mitotic cell cycle

negative regulation of angiogenesis

negative regulation of cell-substrate adhesion negative regulation of cell migration involved in sprouting angiogenesis

negative regulation of endothelial cell migration

negative regulation of ERK1 and ERK2 cascade

negative regulation of fibroblast growth factor receptor signaling pathway

negative regulation of $\mathrm{G} 0$ to $\mathrm{G} 1$ transition

negative regulation of vascular smooth muscle cell proliferation

negative regulation of angiogenesis negative regulation of $\mathrm{G} 1 / \mathrm{S}$ transition of mitotic cell cycle

platelet-derived growth factor receptor signaling pathway

\section{GO:1904754 PMID:25006399 UBERON:0 \\ 002012}

GO:0036120 PMID:28701355 CL:0002591

GO:0090051 PMID:21893058 CL:0000071

GO:1903589 PMID:25660232 CL:0002618

GO:0090050 PMID:25660232 CL:0002618

GO:0016525 PMID:23802567 CL:0002618

GO:2000352 PMID:25466836 CL:0002618

GO:1900087 PMID:25466836 CL:0002618

GO:0016525 PMID:28566713 CL:0000071

GO:0010812 PMID:21220732 CL:0002543

GO:0090051 PMID:28566713 CL:0000071

GO:0010596 PMID:21220732 CL:0002543

GO:0070373 PMID:23263626 CL:1001568

GO:0040037 PMID:23263626 CL:1001568

GO:0070317 PMID:23263626 CL:1001568

GO:1904706 PMID:23263626 CL:0002591

GO:0016525 PMID:25449503 CL:0002618

GO:2000134 PMID:23554459 CL:0002539

GO:0048008 PMID:23554459 CL:0002539 pulmonary artery

smooth muscle cell of the

pulmonary artery

blood vessel endothelial cell

endothelial cell of umbilical vein

endothelial cell of umbilical vein

endothelial cell of umbilical vein

endothelial cell of umbilical vein

endothelial cell of umbilical vein

blood vessel endothelial cell

vein endothelial cell

blood vessel endothelial cell

vein endothelial cell

pulmonary artery endothelial cell

pulmonary artery endothelial cell

pulmonary artery endothelial cell

smooth muscle cell of the pulmonary artery

endothelial cell of umbilical vein

aortic smooth muscle cell

aortic smooth muscle cell 


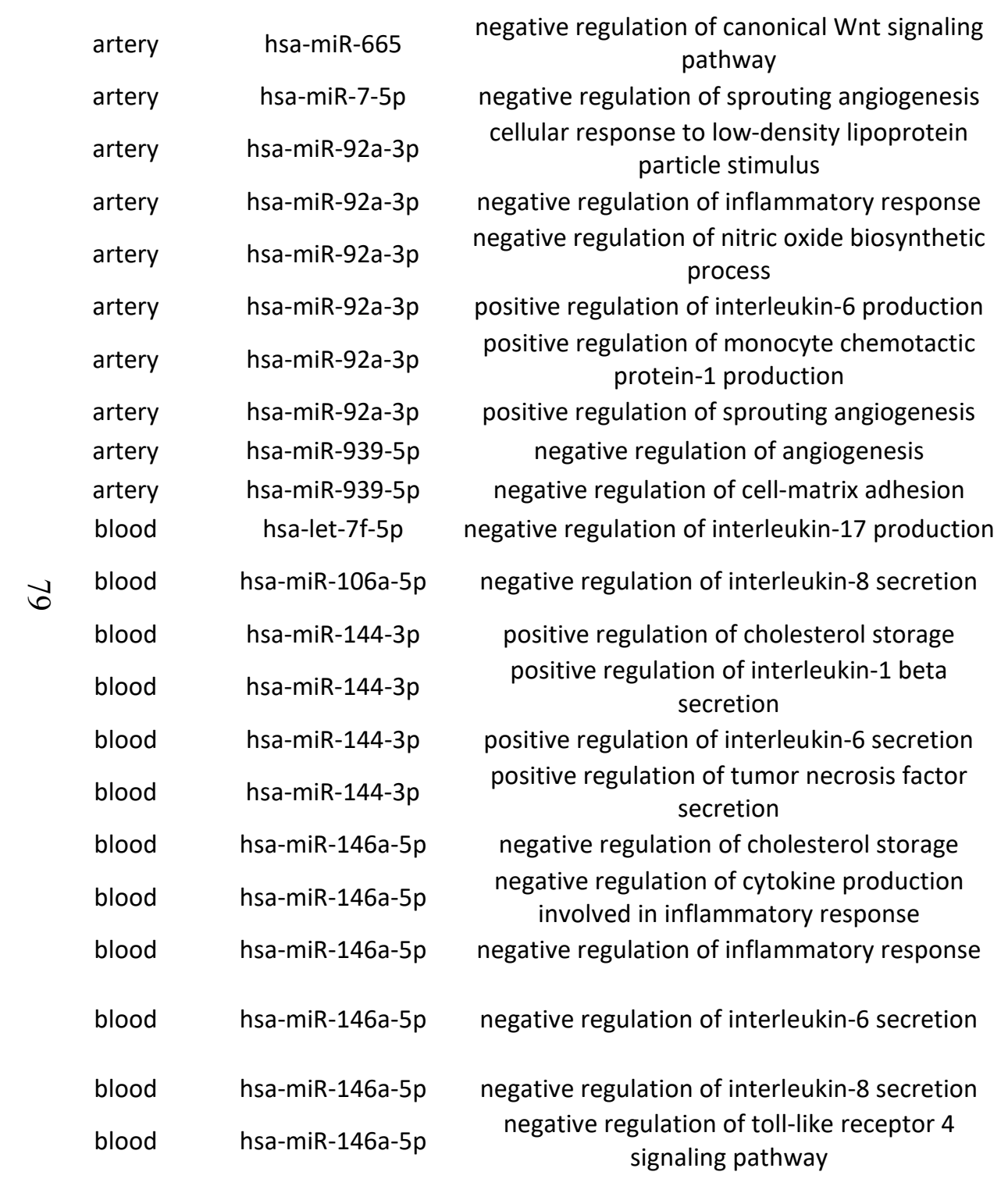

GO:0090090 PMID:29118903 CL:0002539

GO:1903671 PMID:27431648 CL:0002618

GO:0071404 PMID:24255059 CL:0002618

GO:0050728 PMID:22267480 CL:1000413

GO:0045019 PMID:21768538 CL:0000071

GO:0032755 PMID:24255059 CL:0002618

GO:0071639 PMID:24255059 CL:0002618

GO:1903672 PMID:26299712 CL:0002618

GO:0016525 PMID:28115160 CL:0002618

GO:0001953 PMID:28115160 CL:0002618

GO:0032700 PMID:21508257 CL:0000813

GO:2000483 PMID:26265888 CL:2000001

GO:0010886 PMID:24733347 CL:0000517

GO:0050718 PMID:24733347 CL:0000517

GO:2000778 PMID:24733347 CL:0000517

GO:1904469 PMID:24733347 CL:0000517

GO:0010887 PMID:21329689 CL:0000517

GO:1900016 PMID:29896267 CL:0000583

GO:0050728 PMID:21329689 CL:0000517

PMID:21329689 CL:0000517

GO:1900165 ,PMID:2989626 ,CL:000058

7

GO:2000483 PMID:21329689 CL:0000517

GO:0034144 PMID:21329689 CL:0000517 aortic smooth muscle cell

endothelial cell of umbilical vein

endothelial cell of umbilical vein

endothelial cell of artery

blood vessel endothelial cell

endothelial cell of umbilical vein

endothelial cell of umbilical vein

endothelial cell of umbilical vein

endothelial cell of umbilical vein

endothelial cell of umbilical vein

memory T cell

peripheral blood mononuclear cell

macrophage derived foam cell

macrophage derived foam cell

macrophage derived foam cell

macrophage derived foam cell

macrophage derived foam cell

alveolar macrophage

macrophage derived foam cell

macrophage derived foam

cell,alveolar macrophage

macrophage derived foam cell

macrophage derived foam cell 


\begin{tabular}{cc} 
blood & hsa-miR-155-5p \\
blood & hsa-miR-155-5p \\
blood & hsa-miR-155-5p \\
blood & hsa-miR-155-5p \\
blood & hsa-miR-155-5p \\
blood & hsa-miR-181a-5p \\
blood & hsa-miR-181b-5p \\
blood & hsa-miR-181b-5p \\
blood & hsa-miR-181b-5p \\
blood & hsa-miR-181b-5p \\
blood & hsa-miR-181b-5p \\
blood & hsa-miR-182-5p \\
blood & hsa-miR-182-5p \\
blood & hsa-miR-182-5p \\
blood & hsa-miR-182-5p \\
blood & hsa-miR-183-5p \\
blood & hsa-miR-19a-3p \\
\hline blood & hsa-miR-19b-3p \\
blood & hsa-miR-20a-5p \\
blood & hsa-miR-20a-5p \\
blood & hsa-miR-20a-5p \\
blood & hsa-miR-26b-5p \\
\hline
\end{tabular}

cellular response to low-density lipoprotein particle stimulus cholesterol homeostasis

negative regulation of inflammatory response negative regulation of NF-kappaB transcription factor activity

negative regulation of protein localization to nucleus

negative regulation of tumor necrosis factor production

negative regulation of defense response to bacterium

negative regulation of innate immune response negative regulation of phagocytosis

negative regulation of signal transduction positive regulation of inflammatory response cholesterol homeostasis

positive regulation of cytokine secretion positive regulation of lipoprotein lipase activity positive regulation of NIK/NF-kappaB signaling transforming growth factor beta receptor signaling pathway positive regulation of $B$ cell receptor signaling pathway

\section{cholesterol homeostasis}

negative regulation of inflammatory response negative regulation of phosphatidylinositol 3kinase signaling

negative regulation of protein kinase $B$ signaling defense response to virus
GO:0071404 PMID:21030878 CL:0000517

GO:0042632 PMID:21030878 CL:0000517

GO:0050728 PMID:21030878 CL:0000517

GO:0032088 PMID:21030878 CL:0000517

GO:1900181 PMID:21030878 CL:0000517

GO:0032720 PMID:23516523 CL:0000235

GO:1900425 PMID:25505240 CL:0000235

GO:0045824 PMID:25505240 CL:0000235

GO:0050765 PMID:25505240 CL:0000235

GO:0009968 PMID:25505240 CL:0000235

GO:0050729 PMID:25505240 CL:0000235

GO:0042632 PMID:28855441 CL:0000235

GO:0050715 PMID:28855441 CL:0000235

GO:0051006 PMID:28855441 CL:0000235

GO:1901224 PMID:28855441 CL:0000235

GO:0007179 PMID:24586048 CL:0000623

GO:0050861 PMID:26017478 CL:2000001

PMID:25084135 CL:0000517

GO:0042632 ,PMID:2576559 ,CL:000051 6 7

GO:0050728 PMID:28972028 CL:0000492

GO:0014067 PMID:28972028 CL:0000492

GO:0051898 PMID:28972028 CL:0000492

GO:0051607 PMID:26222045 CL:2000001 macrophage derived foam cell

macrophage derived foam cell macrophage derived foam cell

macrophage derived foam cell

macrophage derived foam cell

macrophage

macrophage

macrophage

macrophage

macrophage

macrophage

macrophage

macrophage

macrophage

macrophage

natural killer cell

peripheral blood mononuclear cell

macrophage derived foam

cell, macrophage derived foam cell

CD4-positive helper T cell

CD4-positive helper T cell

CD4-positive helper T cell peripheral blood mononuclear cell 


$\begin{array}{cc}\text { blood } & \text { hsa-miR-26b-5p } \\ \text { blood } & \text { hsa-miR-27a-5p } \\ \text { blood } & \text { hsa-miR-302a-3p } \\ \text { blood } & \text { hsa-miR-302a-3p } \\ \text { blood } & \text { hsa-miR-33b-5p } \\ \text { blood } & \text { hsa-miR-361-5p } \\ \text { blood } & \text { hsa-miR-488-3p } \\ \text { blood } & \text { hsa-miR-488-3p } \\ \text { blood } & \text { hsa-miR-590-3p } \\ \text { blood } & \text { hsa-miR-590-3p } \\ \text { blood } & \text { hsa-miR-758-3p } \\ \text { blood } & \text { hsa-miR-920 } \\ \text { blood } & \text { hsa-miR-920 } \\ \text { brain } & \text { hsa-miR-195-5p } \\ \text { heart } & \text { hsa-let-7b-5p } \\ \text { heart } & \text { hsa-miR-1-3p } \\ \text { heart } & \text { hsa-miR-1-3p } \\ \text { heart } & \text { hsa-miR-1-3p } \\ \text { heart } & \text { hsa-miR-1-3p } \\ \text { heart } & \text { hsa-miR-155-5p } \\ \text { heart } & \text { hsa-miR-155-5p }\end{array}$

negative regulation of defense response to virus

cellular response to transforming growth factor beta stimulus

cellular response to low-density lipoprotein particle stimulus

cholesterol homeostasis

cholesterol homeostasis

regulation of inflammatory response

negative regulation of inflammatory response negative regulation of tumor necrosis factor biosynthetic process

cholesterol homeostasis

negative regulation of inflammatory response cellular response to low-density lipoprotein particle stimulus

negative regulation of inflammatory response negative regulation of tumor necrosis factor biosynthetic process

response to ischemia

\section{positive regulation of angiogenesis}

negative regulation of cardiac muscle hypertrophy

positive regulation of protein phosphorylation

positive regulation of sprouting angiogenesis

regulation of release of sequestered calcium ion

into cytosol by sarcoplasmic reticulum

negative regulation of cell migration involved in sprouting angiogenesis

negative regulation of hydrogen peroxideinduced cell death
GO:0050687 PMID:26222045 CL:2000001

GO:0071560 PMID:28791023 CL:0000623

GO:0071404 PMID:25524771 CL:0000235

GO:0042632 PMID:25524771 CL:0000235

GO:0042632 PMID:24931346 CL:0000581

GO:0050727 PMID:28444107 CL:0000517

GO:0050728 PMID:28915828 CL:0000235

GO:0042536 PMID:28915828 CL:0000235

GO:0042632 PMID:25149060 CL:0000235

GO:0050728 PMID:25149060 CL:0000235

GO:0071404 PMID:21885853 CL:0000235

GO:0050728 PMID:28915828 CL:0000235

GO:0042536 PMID:28915828 CL:0000235

G0:0002931 PMID.30497184 UBERON:0

000955

GO:0045766 PMID:26296645 UBERON:0

002349

GO:0010614 PMID:19933931 UBERON:0 006566

GO:0001934 PMID:19131648 CL:0000746

GO:1903672 PMID:23625462 CL:0000513

GO:0010880 PMID:19131648 CL:0000746

GO:0090051 PMID:28408180 UBERON:0 000948

GO:1903206 PMID:20550618 CL:0010021 peripheral blood mononuclear cell

natural killer cell

macrophage

macrophage

peritoneal macrophage

macrophage derived foam cell

macrophage

macrophage

macrophage

macrophage

macrophage

macrophage

macrophage

brain

myocardium

left ventricle myocardium

cardiac muscle cell

cardiac muscle myoblast

cardiac muscle cell

heart

cardiac myoblast 


$\begin{array}{cc}\text { heart } & \text { hsa-miR-21-5p } \\ \text { heart } & \text { hsa-miR-223-3p } \\ \text { heart } & \text { hsa-miR-223-3p } \\ \text { kidney } & \text { hsa-miR-590-5p } \\ \text { liver } & \text { hsa-miR-144-3p } \\ \text { liver } & \text { hsa-miR-148a-3p } \\ \text { liver } & \text { hsa-miR-148a-3p } \\ \text { liver } & \text { hsa-miR-185-5p } \\ \text { liver } & \text { hsa-miR-199a-5p } \\ \text { liver } & \text { hsa-miR-199a-5p } \\ \text { liver } & \text { hsa-miR-21-5p } \\ \text { liver } & \text { hsa-miR-27a-3p } \\ \text { liver } & \text { hsa-miR-27b-3p } \\ \text { liver } & \text { hsa-miR-27b-3p } \\ \text { liver } & \text { hsa-miR-30c-5p } \\ \text { liver } & \text { hsa-miR-548p } \\ \text { muscle_skelet } & \text { hsa-miR-15b-5p } \\ \text { muscle_skelet } & \text { hsa-miR-16-5p } \\ \text { nerve } & \text { hsa-miR-103a-3p } \\ \text { nerve } & \text { hsa-miR-103a-3p }\end{array}$

regulation of calcium ion transmembrane transport via high voltage-gated calcium channel

positive regulation of glucose import

positive regulation of protein localization to plasma membrane

negative regulation of epithelial to mesenchymal transition

cholesterol homeostasis

cholesterol homeostasis

negative regulation of low-density lipoprotein particle clearance

negative regulation of low-density lipoprotein particle clearance

negative regulation of low-density lipoprotein particle clearance

negative regulation of receptor internalization cellular response to virus

negative regulation of low-density lipoprotein particle clearance cholesterol homeostasis

negative regulation of low-density lipoprotein particle clearance

negative regulation of fatty acid biosynthetic process

negative regulation of fatty acid biosynthetic process

positive regulation of translation

positive regulation of translation

negative regulation of cyclin-dependent protein serine/threonine kinase activity

negative regulation of peptidyl-threonine phosphorylation
GO:1902514 PMID:25107449 CL:0000746

GO:0046326 PMID:20080987 CL:0000746

GO:1903078 PMID:20080987 CL:2000046

GO:0010719 PMID:26459119 CL:1000497

GO:0042632 PMID:23519695 CL:0000182

GO:0042632 PMID:26437365 CL:0000182

GO:0010989 PMID:26437365 CL:0000182

GO:0010989 PMID:26523989 CL:0000182

GO:0010989 PMID:26163491 CL:0000182

GO:0002091 PMID:26163491 CL:0000182

GO:0098586 PMID:27571873 CL:0000182

GO:0010989 PMID:26318398 CL:0000182

GO:0042632 PMID:26520906 CL:0000182

GO:0010989 PMID:26520906 CL:0000182

GO:0045717 PMID:23749231 UBERON:0

002107

GO:0045717 PMID:28336556 CL:0000182

GO:0045727 PMID:25403480 CL:0000737

GO:0045727 PMID:25403480 CL:0000737

GO:0045736 PMID:27343180 CL:0000540

GO:0010801 PMID:27343180 CL:0000540 cardiac muscle cell

cardiac muscle cell

ventricular cardiac muscle cell

kidney cell
hepatocyte
hepatocyte
hepatocyte
hepatocyte
hepatocyte
hepatocyte
hepatocyte
hepatocyte
hepatocyte
hepatocyte
liver
neuron
hepatocyte
riated muscle cell
riated muscle cell




\begin{tabular}{|c|c|}
\hline nerve & hsa-miR-106b-5p \\
\hline nerve & hsa-miR-106b-5p \\
\hline nerve & $\begin{array}{c}\text { hsa-miR-125b-1- } \\
3 p\end{array}$ \\
\hline nerve & $\begin{array}{c}\text { hsa-miR-125b-1- } \\
3 p\end{array}$ \\
\hline nerve & hsa-miR-132-3p \\
\hline nerve & hsa-miR-132-3p \\
\hline nerve & hsa-miR-132-3p \\
\hline nerve & hsa-miR-140-5p \\
\hline nerve & hsa-miR-146a-5p \\
\hline nerve & hsa-miR-146a-5p \\
\hline nerve & hsa-miR-15a-5p \\
\hline nerve & hsa-miR-15a-5p \\
\hline nerve & hsa-miR-212-3p \\
\hline nerve & hsa-miR-212-3p \\
\hline nerve & hsa-miR-212-3p \\
\hline nerve & hsa-miR-218-5p \\
\hline nerve & hsa-miR-29b-3p \\
\hline nerve & hsa-miR-98-5p \\
\hline skir & hsa-miR-181b-5p \\
\hline
\end{tabular}

cellular response to amyloid-beta
negative regulation of peptidyl-tyrosine
phosphorylation
positive regulation of protein phosphorylation
positive regulation of tau-protein kinase activity
negative regulation of nitric-oxide synthase
activity
negative regulation of nitric oxide biosynthetic
process
negative regulation of peptidyl-serine
phosphorylation
cellular response to amyloid-beta
negative regulation of protein kinase B signaling
positive regulation of apoptotic process
negative regulation of cyclin-dependent protein
serine/threonine kinase activity
negative regulation of peptidyl-threonine
phosphorylation
negative regulation of nitric-oxide synthase
activity
negative regulation of nitric oxide biosynthetic
process
negative regulation of peptidyl-serine
phosphorylation
negative regulation of toll-like receptor 4
signaling pathway
process
negative regulation of collagen biosynthetic
negative regulation of collagen biosynthetic
process

$\begin{array}{llll}\text { GO:1904646 } & \text { PMID:27520374 } & \text { CL:0000540 } & \text { neuron } \\ \text { GO:0050732 } & \text { PMID:27520374 } & \text { CL:0000540 } & \text { neuron } \\ \text { GO:0001934 } & \text { PMID:28947385 } & \text { CL:0000540 } & \text { neuron } \\ \text { GO:1902949 } & \text { PMID:28947385 } & \text { CL:0000540 } & \text { neuron } \\ \text { GO:0051001 } & \text { PMID:28089352 } & \text { CL:0000540 } & \text { neuron } \\ \text { GO:0045019 } & \text { PMID:28089352 } & \text { CL:0000540 } & \text { neuron } \\ \text { GO:0033137 } & \text { PMID:28089352 } & \text { CL:0000540 } & \text { neuron } \\ \text { GO:1904646 } & \text { PMID:29253717 } & \text { CL:0000540 } & \text { neuron } \\ \text { GO:0051898 } & \text { PMID:27241555 } & \text { CL:0000540 } & \text { neuron } \\ \text { GO:0043065 } & \text { PMID:27241555 } & \text { CL:0000540 } & \text { neuron } \\ \text { GO:0045736 } & \text { PMID:27343180 } & \text { CL:0000540 } & \text { neuron } \\ \text { GO:0010801 } & \text { PMID:27343180 } & \text { CL:0000540 } & \text { neuron } \\ \text { GO:0051001 } & \text { PMID:28089352 } & \text { CL:0000540 } & \text { neuron } \\ \text { GO:0045019 } & \text { PMID:28089352 } & \text { CL:0000540 } & \text { neuron } \\ \text { GO:0033137 } & \text { PMID:28089352 } & \text { CL:0000540 } & \text { neuron } \\ \text { GO:0032966 } & \text { PMID:19913496 } & \text { CL:0000122 } & \text { stellate neuron } \\ \text { GO:0032966 } & \text { PMID:19913496 } & \text { CL:0000122 } & \text { stellate neuron } \\ \text { GO:1904646 } & \text { PMID:27541017 } & \text { CL:0000540 } & \text { neuron } \\ \text { GO:0034144 } & \text { PMID:27641447 } & \text { CL:0000312 } & \text { keratinocyte }\end{array}$




\begin{tabular}{rcccccc} 
skin & hsa-miR-200b-3p & $\begin{array}{c}\text { negative regulation of blood vessel endothelial } \\
\text { cell migration }\end{array}$ & $\begin{array}{c}\text { GO:0043537 } \\
\text { PMID:22499991 }\end{array}$ & $\begin{array}{c}\text { UBERON:0 } \\
002067\end{array}$ & dermis \\
skin & hsa-miR-203a-3p & $\begin{array}{c}\text { negative regulation of cytokine production } \\
\text { involved in inflammatory response }\end{array}$ & GO:1900016 & PMID:23608026 & CL:0000312 & keratinocyte \\
skin & hsa-miR-203a-3p & negative regulation of interleukin-8 secretion & GO:2000483 & PMID:23608026 & CL:0000312 & keratinocyte \\
\hline
\end{tabular}




\title{
CURRICULUM VITA
}

\author{
Mohammed Sayed \\ Department of Computer Science and Engineering \\ University of Louisville \\ Louisville, KY, 40292 \\ Email: mohammed.sayed@louisville.edu
}

\section{Education}

- Ph.D., Computer Science and Engineering (Expected: May 2021)

University of Louisville, Louisville, KY

Advisors: Dr. Juw Won Park

- $\quad$ MSc, Biomedical Image Processing, 2010 - 2015

Alexandria University, Alexandria, Egypt

- B.Sc., Computer Science and Engineering, 2004-2009

Minia Universit, Minia, Egypt

\section{Experience}

- Graduate teaching assistant, 08/2017 - 04/2021

Computer Science and Engineering department

University of Louisville, Louisville, KY

- Bioinformatics scientist intern, 06/2019-08/2019

National Marrow Donor Program

Minneapolis, MN 


\section{Awards}

- Grosscurth Fellowship, Speed School of Engineering, University of Louisville, 2015 - 2016

\section{Publications}

- Sayed M, Park JW. 2020. miRinGO: Prediction of biological processes indirectly targeted by human microRNAs. bioRxiv doi: $10.1101 / 2020.07 .24 .220335$

- Alugubelly, N., Mohammad, A. N., Edelmann, M. J., Nanduri, B., Sayed, M., Park, J. W., \& Carr, R. L. (2019). Proteomic and transcriptional profiling of rat amygdala following social play. Behavioural brain research, 376, 112210.

- Teng Y, Ren Y, Sayed M, Hu X, Lei C, Kumar A, Hutchins E, Mu J, Deng Z, Luo C, Sundaram K. Plant-Derived Exosomal MicroRNAs Shape the Gut Microbiota. Cell host \& microbe. 2018 Nov 14; 24(5):637-52.

- Sayed, Mohammed, Jae Yeon Hwang, and Juw Won Park. Sequence homology in circular RNA detection. Proceedings of the 2018 Conference on Research in Adaptive and Convergent Systems. ACM, 2018.

- Abdelfadeel, M. A., ElShehaby, S., \& Abougabal, M. S. (2014, December). Automatic segmentation of left ventricle in cardiac MRI using maximally stable extremal regions. In 2014 Cairo International Biomedical Engineering Conference (CIBEC) (pp. 145-148). IEEE. 